OAK RIDGE NATIONAL LABORATORY

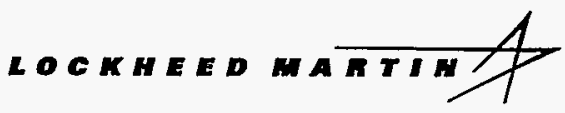

MANAGED AND OPERATED BY

LOCKHEED MARTIN ENERGY RESEARCH CORPORATION FOR THE UNTED STATES

DEPARTMENT OF ENERGY
Supplement to the "Determination Analysis" (ORNL-6847) and Analysis of the NEMA Efficiency Standard for Distribution Transformers
P. R. Barnes
S. Das
B. W. McConnell
J. W. Van Dyke

\section{RECEIVED}

SEP 291997

QSTI
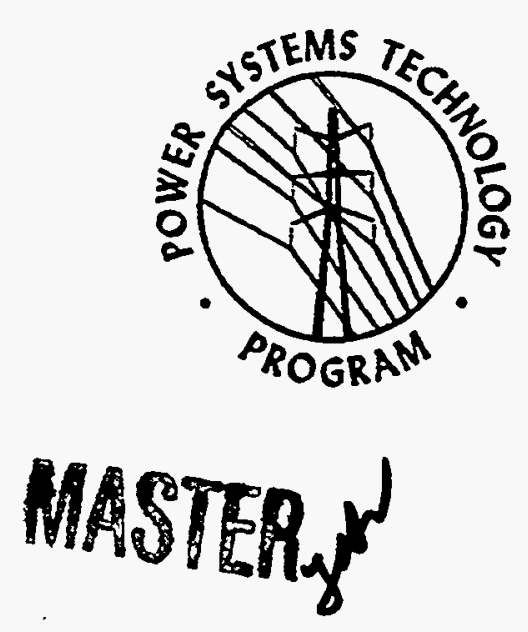

Digribution of THIS DOCUMENT is UNEMATED 
This report has been reproduced directly from the best available copy.

-

Available to DOE and DOE contractors from the Office of Scientific and Technical Information, P. O. Box 62, Oak Ridge, TN 37831; prices available from (423) 576-8401, FTS 626-8401.

Available to the public from the National Technical Information Service, U.S. Department of Commerce, 5285 Port Royal Road, Springfield, VA 22161.

This report was prepared as an account of work sponsored by an agency of the United States Government. Neither the United States Government nor any agency thereof, nor any of their employees, makes any warranty, express or implied, or assumes any legal liability or responsibility for the accuracy, completeness, or usefulness of any information, apparatus, product, or process disclosed, or represents that its use would not infringe privately owned rights. Reference herein to any specific commercial product, process, or service by trade name, trademark, manufacturer, or otherwise, does not necessarily constitute or imply its endorsement, recommendation, or favoring by the United States Government or any agency thereof. The views and opinions of authors expressed herein do not necessarily state or reflect those of the United States Government of any agency thereof. 


\section{DISCLAIMER}

Portions of this document may be illegible in electronic image products. Images are produced from the best available original document. 


\title{
SUPPLEMENT TO THE "DETERMINATION ANALYSIS" (ORNL-6847) AND ANALYSIS OF THE NEMA EFFICIENCY STANDARD FOR DISTRIBUTION TRANSFORMERS
}

\author{
P. R. Barnes \\ S. Das
}

B. W. McConnell

J. W. Van Dyke

September 1997

\author{
Prepared by the \\ POWER SYSTEMS TECHNOLOGY PROGRAM \\ OAK RIDGE NATIONAL LABORATORY \\ Oak Ridge, Tennessee 37831 \\ managed by \\ LOCKHEED MARTIN ENERGY RESEARCH CORP. \\ for the \\ U.S. DEPARTMENT OF ENERGY \\ under contract DE-AC05-96OR22464
}




\section{CONTENTS}

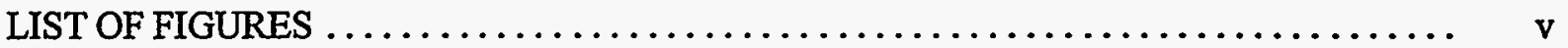

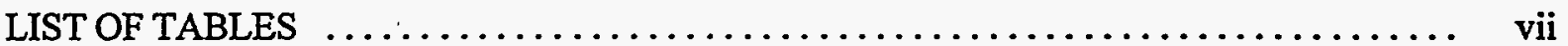

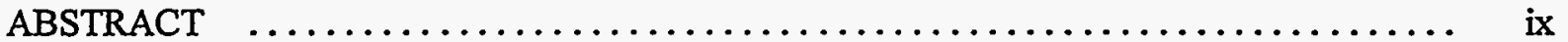

ACRONYMS AND ABBREVIATIONS $\ldots \ldots \ldots \ldots \ldots \ldots \ldots \ldots \ldots \ldots \ldots \ldots \ldots, \quad x i$

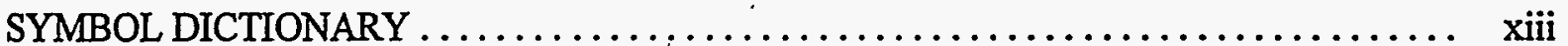

ACKNOWLEDGMENTS $\ldots \ldots \ldots \ldots \ldots \ldots \ldots \ldots \ldots \ldots \ldots \ldots \ldots \ldots, \ldots \ldots \ldots, \quad$ xv

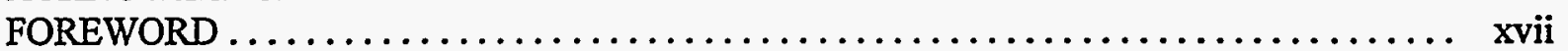

1. INTRODUCTION $\ldots \ldots \ldots \ldots \ldots \ldots \ldots \ldots \ldots \ldots \ldots \ldots \ldots \ldots \ldots \ldots \ldots \ldots \ldots \ldots \ldots, 1-1$

1.1 BACKGROUND $\ldots \ldots \ldots \ldots \ldots \ldots \ldots \ldots \ldots \ldots \ldots \ldots \ldots \ldots \ldots, 1-1$

1.2 UPDATED ANALYSIS $\ldots \ldots \ldots \ldots \ldots \ldots \ldots \ldots \ldots \ldots \ldots \ldots \ldots \ldots \ldots \ldots \ldots, 1-2$

1.3 DEFINITION OF DISTRIBUTION TRANSFORMERS $\ldots \ldots \ldots \ldots \ldots \ldots \ldots \ldots \ldots 1-2$

2. TYPICAL LOADING PRACTICE $\ldots \ldots \ldots \ldots \ldots \ldots \ldots \ldots \ldots \ldots \ldots \ldots \ldots \ldots \ldots \ldots, 2-1$

2.1 INTRODUCTION $\ldots \ldots \ldots \ldots \ldots \ldots \ldots \ldots \ldots \ldots \ldots \ldots \ldots \ldots \ldots \ldots \ldots \ldots \ldots \ldots, 2-1$

2.2 UTILITY-OWNED LIQUID-IMMERSED TRANSFORMERS $\ldots \ldots \ldots \ldots \ldots \ldots, 2-1$

2.2 .1 Average Loads $\ldots \ldots \ldots \ldots \ldots \ldots \ldots \ldots \ldots \ldots \ldots \ldots \ldots \ldots \ldots \ldots, 2-1$

2.2.2 Effective Load $\ldots \ldots \ldots \ldots \ldots \ldots \ldots \ldots \ldots \ldots \ldots \ldots \ldots \ldots \ldots \ldots, \quad 2-2$

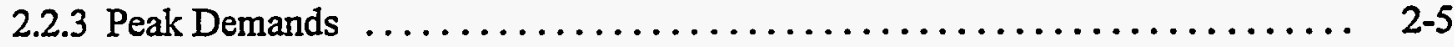

2.2.4 Average Loading by Nameplate Capacity $\ldots \ldots \ldots \ldots \ldots \ldots \ldots \ldots \ldots, \quad 2-8$

2.3 DRY-TYPE LOW-VOLTAGE TRANSFORMERS $\ldots \ldots \ldots \ldots \ldots \ldots \ldots \ldots \ldots, 2-8$

2.4 DRY-TYPE MEDIUM-VOLTAGE TRANSFORMERS $\ldots \ldots \ldots \ldots \ldots \ldots \ldots \ldots, 2-10$

2.5 NON-UTILITY LIQUID-IMMERSED TRANSFORMERS . . . . . . . . . . . . . $2-11$

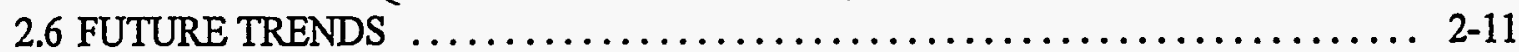

2.7 SUMMARY $\ldots \ldots \ldots \ldots \ldots \ldots \ldots \ldots \ldots \ldots \ldots \ldots \ldots \ldots \ldots \ldots \ldots \ldots \ldots \ldots \ldots \ldots \ldots, 11$

3. ENERGY ANALYSIS MODEL $\ldots \ldots \ldots \ldots \ldots \ldots \ldots \ldots \ldots \ldots \ldots \ldots \ldots \ldots \ldots, 3-1$

3.1 INTRODUCTION $\ldots \ldots \ldots \ldots \ldots \ldots \ldots \ldots \ldots \ldots \ldots \ldots \ldots \ldots \ldots \ldots \ldots \ldots, 3-1$

3.2 ANNUAL ENERGY LOSSES $\ldots \ldots \ldots \ldots \ldots \ldots \ldots \ldots \ldots \ldots \ldots \ldots \ldots \ldots, 3-1$

3.3 CONSERVATION CASE EFFICIENCY $\ldots \ldots \ldots \ldots \ldots \ldots \ldots \ldots \ldots \ldots, 3-2$

3.4 ENERGY SAVINGS $\ldots \ldots \ldots \ldots \ldots \ldots \ldots \ldots \ldots \ldots \ldots \ldots \ldots \ldots \ldots, 3-3$

3.5 LOAD SPECIFIED BY A STANDARD $\ldots \ldots \ldots \ldots \ldots \ldots \ldots \ldots \ldots \ldots \ldots, 3-4$

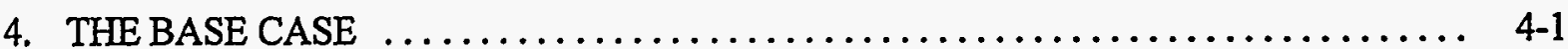

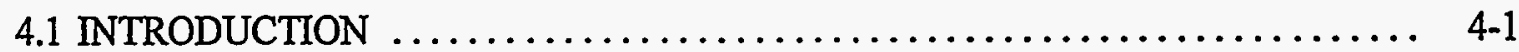

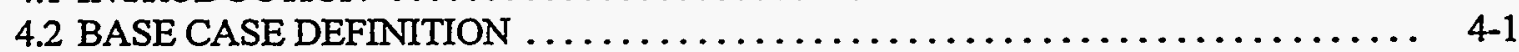

4.3 BASE CASE ASSUMPTIONS $\ldots \ldots \ldots \ldots \ldots \ldots \ldots \ldots \ldots \ldots \ldots \ldots \ldots \ldots, 4,1$

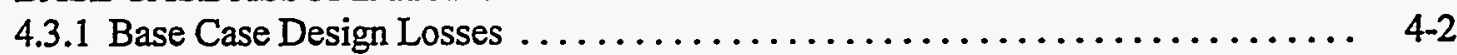

4.3.2 Base Case Loads $\ldots \ldots \ldots \ldots \ldots \ldots \ldots \ldots \ldots \ldots \ldots \ldots \ldots \ldots \ldots \ldots \ldots \ldots, 4,2$

4.3.3 Market Trends and Forecasts $\ldots \ldots \ldots \ldots \ldots \ldots \ldots \ldots \ldots \ldots \ldots \ldots \ldots \ldots \ldots \ldots \ldots, \quad 4-6$

4.4 BASE CASE ENERGY ANALYSIS $\ldots \ldots \ldots \ldots \ldots \ldots \ldots \ldots \ldots \ldots \ldots \ldots, 4-12$ 
5. THE NEMA ENERGY CONSERVATION STANDARD $\ldots \ldots \ldots \ldots \ldots \ldots \ldots \ldots . . \ldots, 5-1$

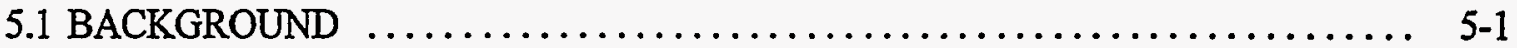

5.2 THE POTENTIAL ENERGY SAVINGS. $\ldots \ldots \ldots \ldots \ldots \ldots \ldots \ldots \ldots \ldots \ldots, \quad 5-2$

5.3 LOAD SENSITIVITY ANALYSIS $\ldots \ldots \ldots \ldots \ldots \ldots \ldots \ldots \ldots \ldots \ldots \ldots \ldots, \quad 5-8$

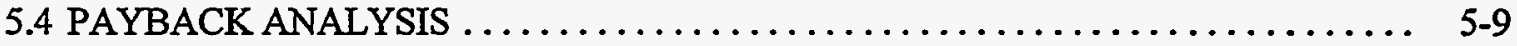

6. THE DETERMINATION CASES $\ldots \ldots \ldots \ldots \ldots \ldots \ldots \ldots \ldots \ldots \ldots \ldots \ldots \ldots \ldots \ldots, 6,1$

7. SUMMARY AND CONCLUSIONS $\ldots \ldots \ldots \ldots \ldots \ldots \ldots \ldots \ldots \ldots \ldots \ldots \ldots \ldots, 7-1$

7.1 EFFECTIVE LOADS $\ldots \ldots \ldots \ldots \ldots \ldots \ldots \ldots \ldots \ldots \ldots \ldots \ldots \ldots \ldots \ldots \ldots \ldots \ldots \ldots, 7,1$

7.2 DISTRIBUTION TRANSFORMER MARKET $\ldots \ldots \ldots \ldots \ldots \ldots \ldots \ldots \ldots \ldots, 7-1$

7.3 ENERGY SAVINGS $\ldots \ldots \ldots \ldots \ldots \ldots \ldots \ldots \ldots \ldots \ldots \ldots \ldots \ldots \ldots \ldots \ldots \ldots \ldots \ldots, 7-2$

7.4 CONCLUSIONS $\ldots \ldots \ldots \ldots \ldots \ldots \ldots \ldots \ldots \ldots \ldots \ldots \ldots \ldots \ldots \ldots \ldots \ldots \ldots, 7-2$

8. REFERENCES $\ldots \ldots \ldots \ldots \ldots \ldots \ldots \ldots \ldots \ldots \ldots \ldots \ldots \ldots \ldots \ldots \ldots \ldots, 8,1$

APPENDICES

Appendix A: FERC Form 1 Summary $\ldots \ldots \ldots \ldots \ldots \ldots \ldots \ldots \ldots \ldots \ldots \ldots \ldots \ldots \ldots$, A-1

Appendix B: Derivation of Total Owning Cost $\ldots \ldots \ldots \ldots \ldots \ldots \ldots \ldots \ldots \ldots \ldots$, B-1

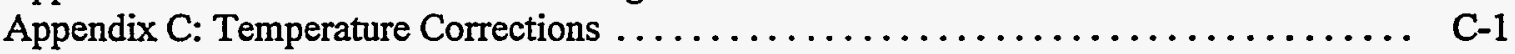

Appendix D: Calculation of No Load and Load Losses from a Specified Efficiency ...... D-1

Appendix E: The TP-1 Survey of Transformer Manufacturers $\ldots \ldots \ldots \ldots \ldots \ldots \ldots$ E-1 


\section{FIGURES}

2.1 Typical daily load profiles for a department store, a drugstore, and

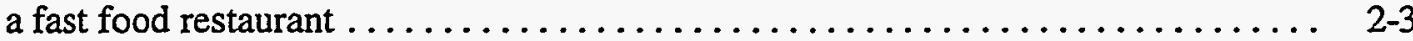

2.2 Per unit hourly load and maximum 30-minute demand for June 18, 1994

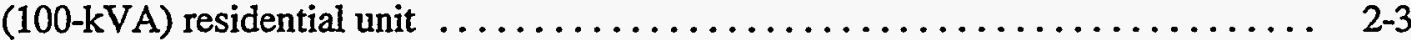

2.3 Average loads, peak loads, and load factors for a utility's three-phase

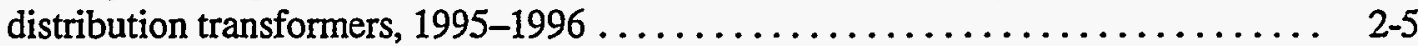

2.4 Peak load distribution for 25-kVA transformers, summer $1994 \ldots \ldots \ldots \ldots \ldots \ldots$. $2-6$

2.5 Relative number of units with per unit load greater than or equal to $x \ldots \ldots \ldots$

2.6 Average RMS load for single-phase transformers by size for three utilities . . . . . 2-9

$2.7 \quad$ Load profile for a dry-type three-phase $75-\mathrm{kVA}$ transformer $\ldots \ldots \ldots \ldots \ldots \ldots$

3.1 Efficiencies of 25-kVA distribution transformers purchased by 54 utilities $\ldots \ldots$ 3-3

3.2 Thirty-year cumulative differences in energy losses for designs that maximize transformer efficiency at five alternative loads, compared to energy losses if designs maximized efficiency at actual load ............ 3-5

4.1 Estimated 1995 market for liquid-immersed distribution transformers (MVA) . . . . 4-6

4.2 Estimated 1995 market for dry-type distribution transformers (kVA) . . . . . . . . 4 4-8

4.3 Estimated annual shipments of liquid-immersed transformers, $1995-2033 \ldots \ldots$. . . 4-12

4.4 Estimated annual shipments of dry-type transformers, $1995-2033 \ldots \ldots \ldots \ldots$. . .

4.5 Cumulative base case losses for new distribution transformer sales over 30 years, assuming 0.8 to $1.6 \%$ annual growth $\ldots \ldots \ldots \ldots \ldots \ldots \ldots \ldots$ 4-15

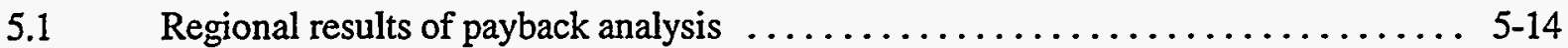




\section{TABLES}

2.1 Summary data for a utility's single-phase, pole-mounted

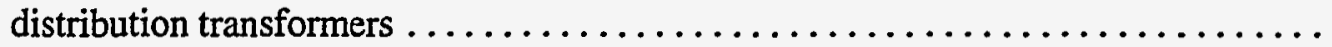

4.1 Base case design loss parameters: medium-voltage liquid-immersed

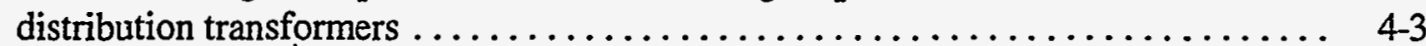

4.2 Base case ownership and loading parameters for medium-voltage liquid-immersed distribution transformers $\ldots \ldots \ldots \ldots \ldots \ldots \ldots \ldots \ldots .4 . \ldots \ldots$

4.3 Base case design loss parameters: dry-type distribution transformers $\ldots \ldots \ldots \ldots 4-5$

4.4 Estimated 1995 annual medium-voltage liquid-filled distribution transformer market by capacity $\ldots \ldots \ldots \ldots \ldots \ldots \ldots \ldots \ldots \ldots \ldots \ldots \ldots \ldots \ldots, 4$

4.5 Estimated 1995 annual dry-type distribution transformer market by capacity . . . . . 4-9

4.6 Annual shipments (in MVA) of distribution transformers in sizes of

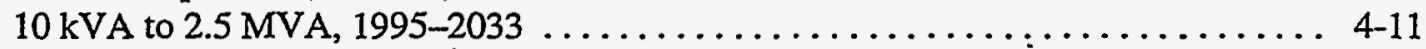

4.7 Historical and projected annual growth rates of distribution transformer shipments

4.8 Estimated losses by type of transformer for annual sales starting in 2004

(million of $\mathrm{kWh}$ )

5.1. TP-1 minimum efficiencies and transformer design losses assumed for liquid-immersed transformers $\ldots \ldots \ldots \ldots \ldots \ldots \ldots \ldots \ldots \ldots$

5.2 TP-1 minimum efficiencies and transformer design losses assumed for dry-type low-voltage transformers

5.3 TP-1 minimum efficiencies and transformer design losses assumed for dry-type medium-voltage transformers $\ldots \ldots \ldots \ldots \ldots \ldots \ldots \ldots \ldots \ldots \ldots$

5.4 Estimated annual rate of savings of electric energy per kilovolt-ampere and annual savings by transformer type in 1995 and 2004

5.5 Transformer energy savings for NEMA Standard TP-1 for major types of transformers

5.6 Manufacturer survey data for liquid-immersed medium-voltage distribution transformers

5.7 Manufacturer survey data for dry-type low-voltage distribution transformers 
5.8 Manufacturer survey data for dry-type medium-voltage three-phase

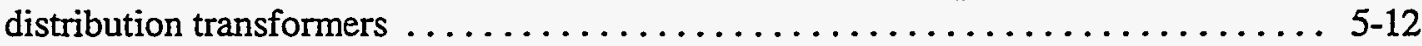

$5.9 \quad$ Simple payback by state for TP-1 standard $\ldots \ldots \ldots \ldots \ldots \ldots \ldots \ldots \ldots \ldots \ldots$

6.1 Summary of conservation cases analyzed in ORNL-6847 $\ldots \ldots \ldots \ldots \ldots \ldots \ldots$.1

6.2 Transformer efficiencies corresponding to losses for determination study cases ..... 6-3

6.3 Alternative conservation case savings: first year of policy and over a 30-year

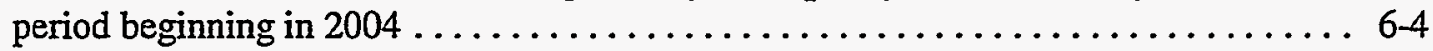

7.1 Current distribution transformer market $\ldots \ldots \ldots \ldots \ldots \ldots \ldots \ldots \ldots \ldots \ldots \ldots \ldots \ldots$

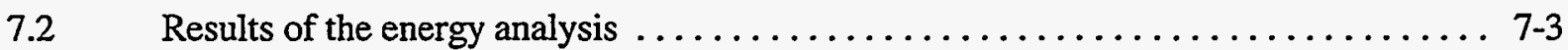




\begin{abstract}
This report contains additional information for use by the U.S. Department of Energy in making a determination on proposing energy conservation standards for distribution transformers as required by the Energy Policy Act of 1992. An earlier determination study by the Oak Ridge National Laboratory determined that cost-effective, technically feasible energy savings could be achieved by distribution transformer standards and that these savings are significant relative to other product conservation standards. This study was documented in a final report, Determination Analysis of Energy Conservation Standards for Distribution Transformers (ORNL-6847, July 1996). The energy conservation options analyzed in this study were estimated to save 5.2 to 13.7 quads from 2000 to 2030. The energy savings for the determination study cases have been revised downward for a number of reasons. The transformer market, both present and future, was overestimated in the previous study, particularly for dry-type transformers, which have the greatest energy-saving potential. Moreover, a revision downwards of the effective annual loads for utility-owned transformers also results in lower energy savings. The present study assesses four of the five conservation cases from the earlier determination study as well as the National Electrical Manufacturers Association energy efficiency standard NEMA TP 1-1996 using the updated data and a more accurate disaggregated analysis model. According to these new estimates, the savings ranged from 2.5 to 10.7 quads of primary energy for the 30 -year period 2004 to 2034 . For the TP-1 case, data were available to calculate the payback period required to recover the extra cost from the value of the energy saved. The average payback period based on the average national cost of electricity is 2.76 years.
\end{abstract}




\section{ACRONYMS AND ABBREVIATIONS}

$\begin{array}{ll}\text { DOC } & \text { U.S. Department of Commerce } \\ \text { EEI } & \text { Edison Electric Institute } \\ \text { EIA } & \text { Energy Information Administration } \\ \text { EPA } & \text { U.S. Environmental Protection Agency } \\ \text { FERC } & \text { Federal Energy Regulatory Commission } \\ \text { kWh } & \text { kilowatt-hour } \\ \text { MVA } & \text { megavolt-ampere } \\ \text { MWh } & \text { megawatt-hour } \\ \text { NEC } & \text { National Electrical Code } \\ \text { NEMA } & \text { National Electrical Manufacturers Association } \\ \text { ORNL } & \text { Oak Ridge National Laboratory } \\ \text { PU } & \text { per unit } \\ \text { RMS } & \text { root mean square } \\ \text { TOC } & \text { total owning cost }\end{array}$





\section{SYMBOL DICTIONARY}

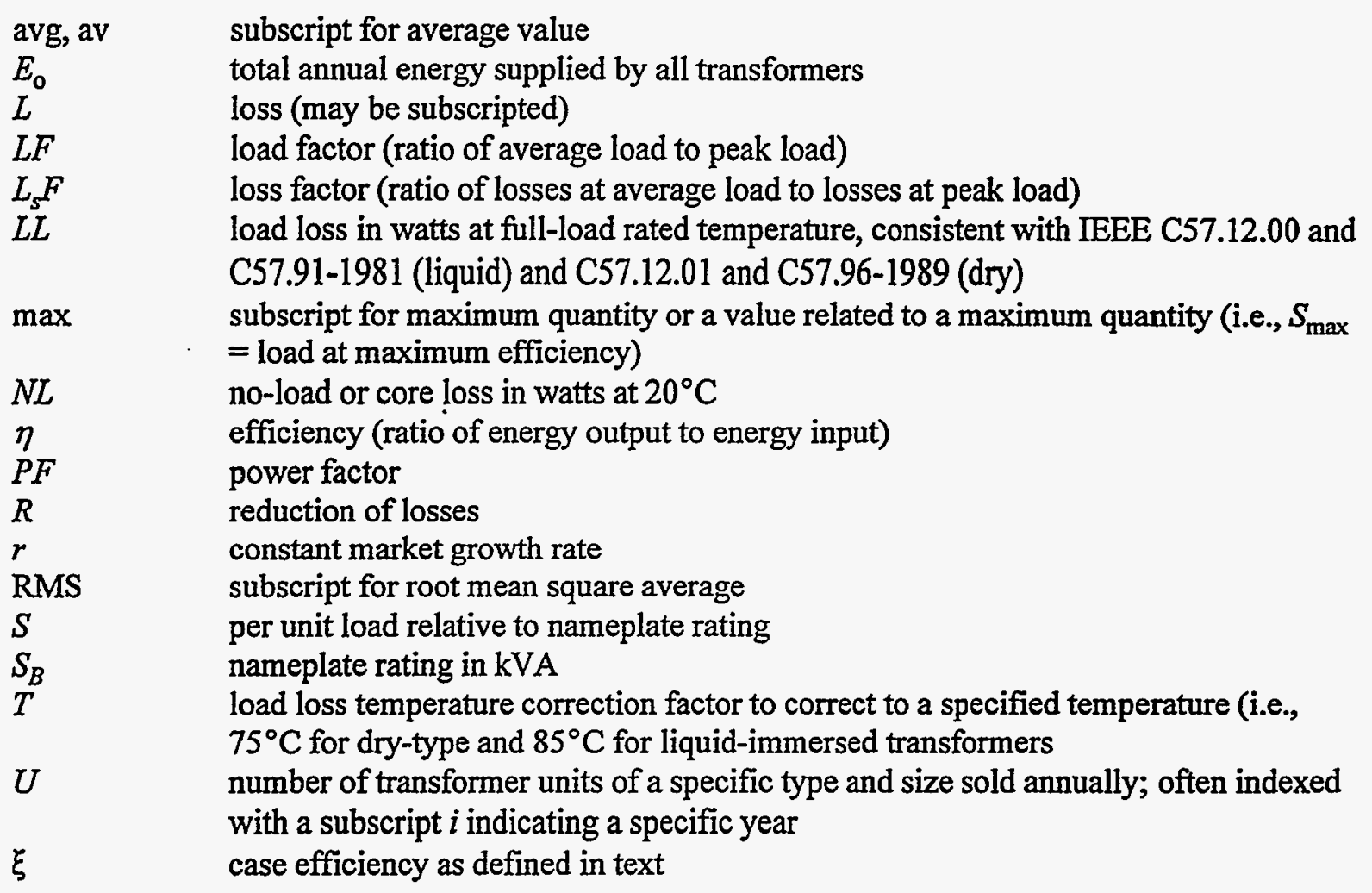





\section{ACKNOWLEDGMENTS}

The authors thank Kathi Epping and Ingrid Watson of the U.S. Department of Energy; Jim VanCoevering of Oak Ridge National Laboratory; and John Gauthier, Kyle Pitsor, and Lake Coulson of the National Electrical Manufacturers Association for their support and guidance. In addition, we thank Phil Hopkinson of the Square D Company; Donald Duckett of the General Electric Company; Wesley Patterson of Asea Brown Boveri, Inc.; Don Kline, a consultant for Southern Transformer; Carl Bush, Timothy Holdway, and Robert Smith of Federal Pacific Transformer Company; Gerald Hodge of Howard Industries; Alan Wilks of ERMCO; Ed Smith of Central Moloney, Inc.; and David Rolling of Cooper Industry for their assistance in providing technical data on distribution transformers.

The authors convey a special thanks to Andrew deLaski of the Consortium for Energy Efficiency, Margaret Suozzo of the American Council for an Energy Efficient Economy, and Randy James of ORNL for reviewing this document. The many comments and helpful suggestions provided by these individuals are gratefully acknowledged. 


\section{FOREWORD}

Subtitle C, Sect. 124, of the Energy Policy Act of 1992 (Pub. L. 102-486, Oct. 24, 1992) contains an amendment to Sect. 346 of the Energy Policy and Conservation Act (42 U.S.C. Sect. 6317). A portion of that amendment is provided below:

Sec. 346 (a) (1) The Secretary shall, within 30 months after the date of the enactment of the Energy. Policy Act of 1992, prescribe testing requirements for those high-intensity discharge lamps and distribution transformers for which the Secretary makes a determination that energy conservation standards would be technologically feasible and economically justified, and would result in significant energy savings.

(2) The Secretary shall, within 18 months after the date on which testing requirements are prescribed by the Secretary pursuant to paragraph (1), prescribe, by rule, energy conservation standards for those high-intensity discharge lamps and distribution transformers for which the Secretary prescribed testing requirements under paragraph (1).

This report and an earlier report, ORNL-6847, contain information to assist the U.S. Department of Energy in making a determination on the feasibility and significance of energy conservation for distribution transformers as required by par. (a)(1) above. 


\section{INTRODUCTION}

\subsection{BACKGROUND}

Distribution transformers are used to transform the voltage of an electric utility power distribution line $(4-35 \mathrm{kV})$ to a lower secondary voltage $(120-480 \mathrm{~V})$ suitable for customer equipment. Over one million new distribution transformers are purchased annually. Utility distribution transformers account for an estimated 61 billion kilowatt-hours ( $\mathrm{kWh}$ ) of the annual energy lost in the generation and delivery of electricity. Additional transformer losses in non-utility applications are estimated to be 79 billion $\mathrm{kWh}$. Distribution transformers are very reliable and efficient devices, with no moving parts and average life spans of over 30 years. Because of the large number of units and the long periods of operation, even small changes in efficiencies can add up to large energy savings. Of the potential savings, about two-thirds could be realized through the use of more energy-efficient, cost-effective dry-type transformers by industrial and commercial customers; the remaining one-third could be achieved through the use of more energy-efficient distribution transformers by utilities.

Market forces do not necessarily encourage the use of energy-efficient transformers. Most dry-type transformers are installed inside buildings or plants and are purchased by contractors. Contractors are drawn to low-price (low-efficiency) transformers because they do not pay the energy costs associated with transformer losses. By contrast, utilities are concerned with operating costs, and about $85 \%$ are purchasing relatively efficient transformers. However, there are periods when some utilities with limited budgets will buy lower-cost, inefficient transformers. The extra cost of the fuel required by the higher losses from these inefficient transformers can often be passed on to ratepayers. Thus, the market structure and unique accounting procedures associated with distribution transformers result in a disincentive to use cost-effective, energy-efficient designs.

To determine if energy conservation standards for distribution transformers would save significant energy and be technically feasible and economically justified, the Energy Division of Oak Ridge National Laboratory (ORNL) conducted a determination study. This study - documented in the report Determination Analysis of Energy Conservation Standards for Distribution Transformers (Barnes et al. 1996) — found that cost-effective, technically feasible energy savings could be achieved by distribution transformer standards and that these savings are significant relative to other product conservation standards. The final report was reviewed by a special transformer review group consisting of manufacturers, utilities, commercial and industrial users, research laboratories, contractors, materials suppliers, and public interest groups. It was concluded that efficiency standards similar to those in the cases analyzed could save a significant amount of energy, on the order of 5 to 13 quads, ${ }^{1}$ during the period from 2000 to 2030 . While new information on the size of the transformer market and the anticipated market growth have reduced these estimated savings, the possible energy savings from more efficient transformers are still significant.

${ }^{1}$ A quad of energy equals 1 quadrillion $\left(10^{15}\right)$ Btu. 


\subsection{UPDATED ANALYSIS}

In 1996, the National Electrical Manufacturers Association (NEMA) developed and published an efficiency standard for distribution transformers, NEMA TP 1-1996, for its members (NEMA 1996). Since the NEMA standard was not available during the ORNL determination study, it was not analyzed. This standard is based on a short payback period to recover the additional cost of the more efficient transformers from the money saved by the reduced energy consumption.

The current report assesses NEMA TP-1 along with the options considered in the 1996 determination study with a more accurate analysis model and more accurate transformer market and loading data. The report presents a national energy savings analysis and a payback analysis. The payback analysis is limited to the NEMA standard, since much of the data in the determination study is not appropriate for a payback analysis. The assessments include a sensitivity study on the impacts of various levels of voluntary adherence to the NEMA TP-1 standard.

\subsection{DEFINITION OF DISTRIBUTION TRANSFORMERS}

Distribution transformers are defined by ANSI and IEEE standards (IEEE 1994). A distribution transformer is defined by paragraph 2.3.1.1 of ANSI/IEEE C57.12.80-1978 as a transformer for transferring electrical energy from a primary distribution circuit to a secondary distribution circuit or to a consumer's service circuit. A note at the bottom of this definition indicates that the rated capacity of distribution transformers ranges from about 5 to $500 \mathrm{kVA}$. However, ANSI C57.12.221989 provides a revised rating for pad-mounted distribution transformers. According to the C57.12.22 rating, pad-mounted distribution transformers are rated $2500 \mathrm{kVA}$ and smaller, with high voltages of $34.5 \mathrm{kV}$ and below and low voltages of $480 \mathrm{~V}$ and below. Low-voltage transformers with an insulation voltage class of $1.2 \mathrm{kV}(120$ to $480 \mathrm{~V}$ in the United States) are also listed as distribution transformers in IEEE Standard C57.12.00-1993. For dry-type transformers, IEEE C57.12.01-1989 defines preferred distribution transformers ratings, with single-phase transformers rated as low as $1 \mathrm{kVA}$.

For the purposes of this study, distribution transformers are taken to be any transformer in the distribution power circuit with a primary voltage of 480 to $34.5 \mathrm{kV}$ and a secondary voltage of 120 to $480 \mathrm{~V}$. The rated capacities include 10 to $833 \mathrm{kVA}$ for single-phase liquid-immersed units, 15 to 833 kVA for single-phase dry-type units, and 15 to $2500 \mathrm{kVA}$ for all three-phase units. These specifications are the same as those in NEMA standard TP-1. This range of transformers captures most of the distribution transformer market. 


\section{TYPICAL LOADING PRACTICE}

\subsection{INTRODUCTION}

To determine the energy savings achievable by any standard, an estimate of the typical effective transformer loads is required. Utility transformer loads for new installations are often difficult if not impossible to predict because of the lack of detailed load information. Specifications for transformersizes are frequently based on the size of service entrances, known possible loads, and square footage of the buildings to be served. There can be wide variations, however, in both residential and commercial loads. For residential loads, individual lifestyles can result in different loads for identical homes, and loads for similar commercial customers similarly vary because of differences in operational schedules, lighting levels, and so on. Thus, there is considerable variation in the average loads of utility transformers of the same size and type. For dry-type transformers, the requirements for safety and reliability are the drivers for typical loading of these units. Using the limited data available, this chapter summarizes typical loading practices.

\subsection{UTILITY-OWNED LIQUID-IMMERSED TRANSFORMERS}

\subsubsection{Average Loads}

The annual average per unit (PU) load for all of the distribution transformers in a utility's distribution system can be estimated by dividing the annual sales in megawatt-hours (MWh) by the megavolt-amperage (MVA) of installed capacity times 8760 hours and the average power factor:

PU load $=$ sales $(M W h) /(8760 \times$ installed MVA $\times$ power factor $)$.

Except for the average power factor, this information is available in the Federal Energy Regulatory Commission (FERC) Form 1 database. The average power factor used for this calculation is the one measured at the distribution transformer, which is normally different from the power factors at substations or in the transmission system. For distribution transformer analysis, Nickel and Braunstein (1981) used 0.9 for the power factor, a figure that was based on an industry survey.

The analysis of the 1992 FERC Form 1 data is shown in Appendix A. If only residential and commercial sales are considered along with a power factor of 1.0, the FERC Form 1 data imply a per unit average load of 0.143 . For an average power factor of 0.9 , the per unit average load increases to 0.16 , as shown in Table A.1.This calculation is misleading, however, because not all of the capacity in the inventory is installed and the industrial sales through utility distribution transformers are not included. The in-service capacity can be determined by subtracting the idle and in-stock capacity listed in the FERC Form 1 database. The in-service capacity is shown in Table A.2, along with the total sales to residential, commercial, and other customers. The "other" category includes sales associated with streetlights, railroads, interdepartmental uses, and government authorities. While most of the electricity sold is metered on the secondary side of utility distribution transformers, a large fraction of sales to industry and large government installations is metered at the primary distribution voltage level, and the distribution transformers associated with these sales are not included in the inventory of utility transformers. In an effort to include these sales, ORNL conducted 
a telephone survey of selected utilities. This survey indicated that 77 to $97 \%$ of total retail sales are metered at low voltages (below $600 \mathrm{~V}$ ), with an average value near $85 \%$. Assuming that $85 \%$ of total sales pass through distribution transformers, the estimate of per unit average load increases to 0.24 , as shown in Table A.2. By contrast, if only $75 \%$ of total retail sales pass through utility-owned distribution transformers, then the per unit average load is estimated to be 0.21 .

\subsubsection{Effective Load}

The per unit effective loads used in development of B factors (cost of load losses) in total owning cost (TOC) evaluations are not simple averages but are instead the discounted values of the square of the projected load growth adjusted for capital recovery. (See Appendix B for derivation of TOC.) Thus, this form of per unit effective load represents the economic contribution of load growth to the cost of load losses and is not the correct loading to use in evaluating the effects of efficiency standards. To evaluate the impact of an efficiency standard, the root mean square (RMS) per unit average of the load for each transformer size and type included in the standard is required. ${ }^{1}$ Unfortunately, this quantity is not readily available and must generally be estimated using simple averages. Clearly, the long-term economic impacts and benefits of any efficiency standard must adjust the projected savings for present value and capital recovery, but for standards evaluations, this calculation is conducted later in the analysis.

As indicated above, the average per unit load from FERC Form 1 analysis can provide some indication of overall system average per unit load on transformers. However, FERC Form 1 analysis does not provide any information on the average per unit load for specific transformer sizes and types. If typical load profiles are available, the calculation of either the per unit average or the per unit RMS is a relatively easy task. Unfortunately, typical load profiles are not generally available at the transformer level, and an alternative approach must be used to arrive at the desired per unit average or RMS load. Examples of three normalized load profiles for commercial applications and of typical residential load and demand profiles for a 100-kVA single-phase transformer are shown in Figs. 2.1 and 2.2. The commercial load profiles are relative to the daily peak and provide minimal information for use in determining how a transformer serving the load might be loaded relative to its nameplate. The large residential unit $(100 \mathrm{kVA})$ provides a great deal of information but is not very useful relative to annual data. Simple calculations can be performed to obtain for this particular day the 100-kVA transformer's load factor (0.47), capacity factor or average per unit load (0.69), per unit peak load (1.47), per unit RMS load (0.78), and loss factor (0.22). Because this particular day is well within the utility's peak load week, it is not representative of annual load behavior.

\footnotetext{
${ }^{1}$ The root mean square (RMS) load is the square root of the average of the load squared $\left(\mathrm{load}^{2}\right)$ for transformers by type and size. RMS load is a crucial assumption in determining base case losses. Transformer loads are known to vary widely, and typical use patterns vary based on specific utility practices and the type of load that the transformer serves. For instance, the load on a 25-kVA transformer used to serve a residential load would tend to differ from one that served an irrigation load. Also, because of differences in air conditioning and heating loads, a transformer serving a residential load in Vermont would tend to differ from one serving a residential load in Alabama.
} 
DRAFT 2

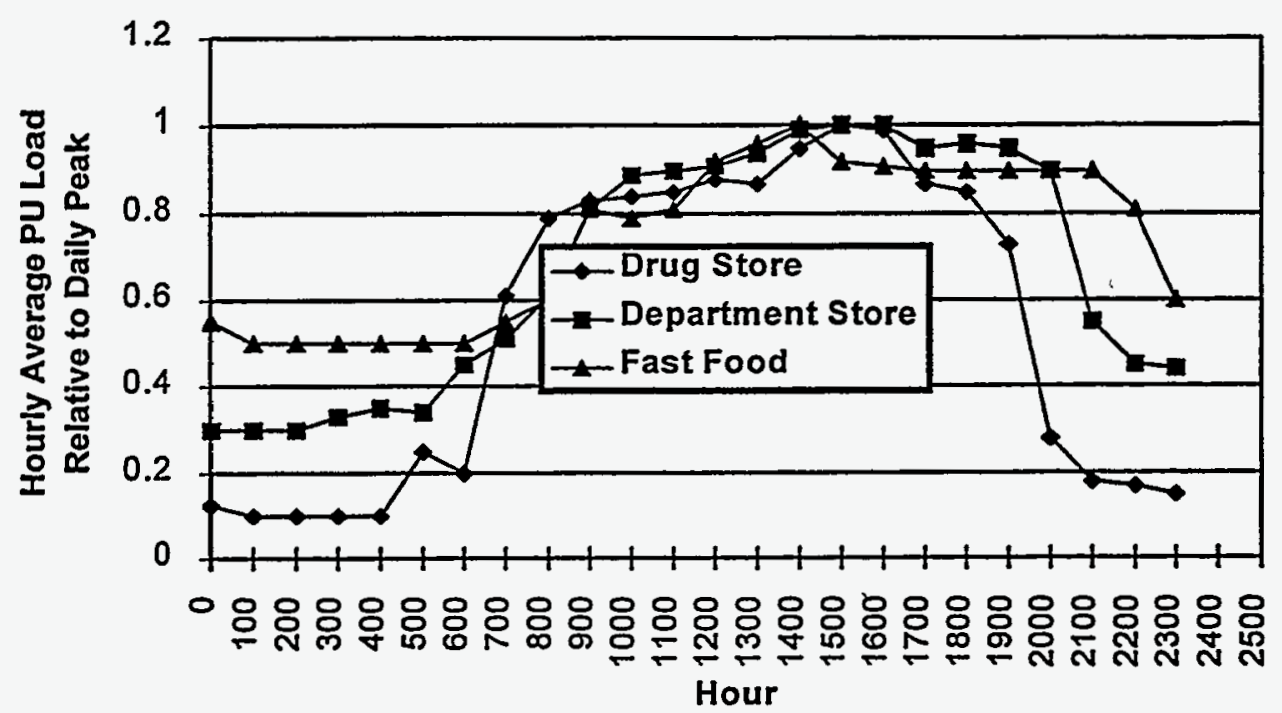

Fig. 2.1. Typical daily load profiles for a department store, a drugstore, and a fast food restaurant.

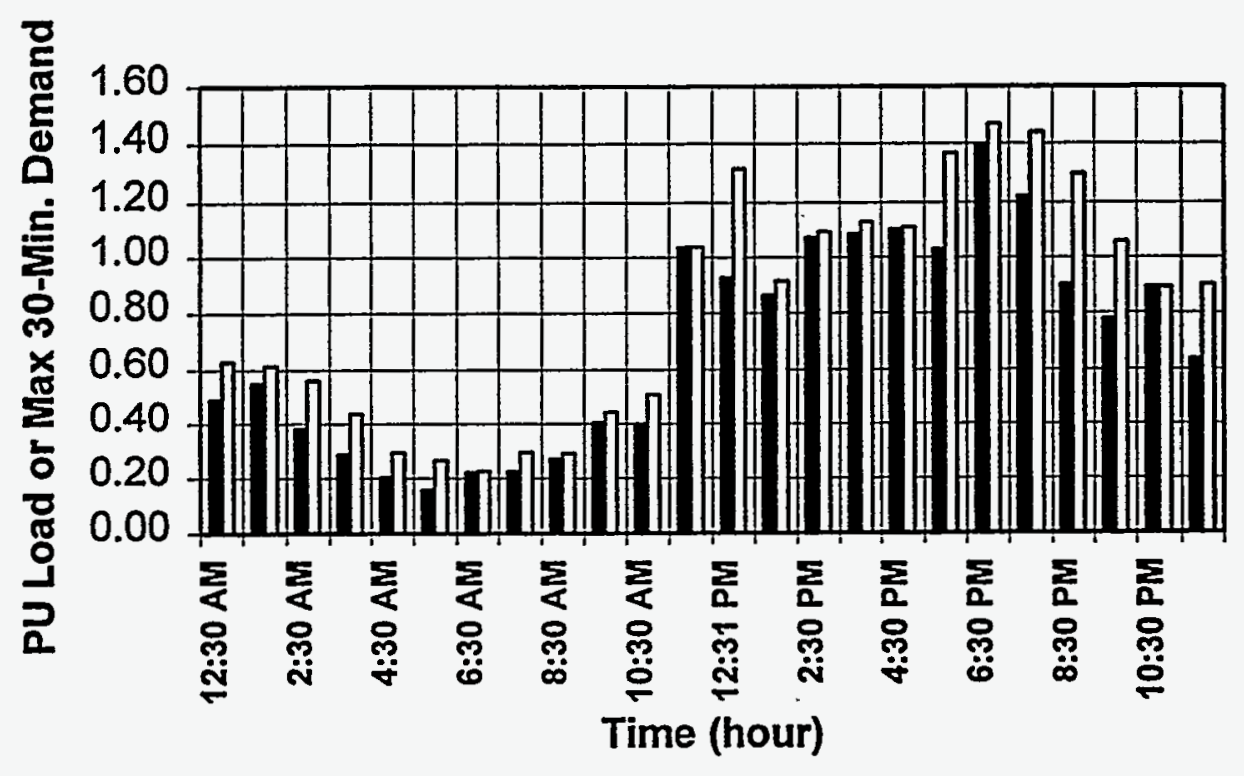

Fig. 2.2. Per unit hourly load and maximum 30-minute demand for June 18, 1994 (100-kVA) residential unit. 
If annual average peak load (which could be obtained from demand metering or estimated from kilowatt-hour data) and annual loss factor $\left(L_{s} F\right)$ data are available, then the per unit RMS load, $S_{\mathrm{RMS}}{ }^{2}$, is available through the calculation

$$
S_{\mathrm{RMS}}{ }^{2}=L_{s} F \times \text { peak }^{2} .
$$

In general, loss factor data are not available, and various methods have been developed to relate loss factor to load factor. Two classic references in this area are Gangel and Propst (1965) and Westinghouse Electric (1959). Note that these data are more than 30 years old; hence, for residential load, the changing mix and characteristics of appliances and lifestyles warrants additional work in the determination of $a$ and $b$. Despite the fact that load and loss factors are not directly related, arguments can be given to establish that the loss factor is less than the load factor but greater than the square of the load factor. Hence, the expression $L_{s} F=\left(a \times L F^{2}\right)+(b \times L F)$, where $a+b=1$, has a legitimate mathematical but not physical basis. Generally accepted values of $a=0.85$ and $b=0.15$ are used for residential loads, but, if available, $a$ and $b$ values should be determined from specific utility data. While the methodology will enable estimation of $L_{s} F$ from $L F$ for commercial and industrial loads, no specific values for $a$ and $b$ for nonresidential loads are found in the literature. A general equation that is sometimes used for relating $L_{s} F$ and $L F$ is $L_{s} F=L F^{1.732}$, but the basis for this expression is unknown.

As the previous discussion makes clear, determining a representative per unit RMS or average load for each transformer size and type may not be easy. In earlier years utilities did considerable research on load characteristics and methods of predicting overall system and component loads. In most cases, given appropriate data, these methodologies are still valid. However, there are now several confounding issues such as changes in appliance characteristics and personal lifestyles. The expected load on a transformer is dependent upon the number and type of customers served, since the $\mathrm{kW}$ peak demand is related to the single customer $\mathrm{kWh}$, the associated diversity or coincidence factors, and the peak responsibility factor (Nickel and Braunstein 1981). Utility personnel have indicated a strong trend toward simplifying the $\mathrm{kWh} / \mathrm{kW}$ function, with many now using only a simple linear regression. Generally, diversity of load provides assurance that transformer peak loads will not exceed the sum of the individual loads. Diversity factors are very specific to the utility, the load, and the weather, but there are generic formulations that can be used with appropriate caution. The impact of weather (long, intense hot or cold periods) tends to reduce load diversity because most electric load is very dependent upon heating and/or cooling degree days. Since the allowed transformer peak loading is related to ambient temperature, regular long, hot periods may require adjustments to the transformer's loading pattern and size, as discussed in the IEEE loading guides (IEEE 1989, 1995).

There is no simple relationship between per unit RMS and simple averages. However, the ratio of average load to RMS load taken from typical load profiles suggests that at least a 1.10 multiplier would be prudent. Those transformers with low load factors and relatively high peaks will exhibit the greatest difference between RMS and average loads. Intuition and expected loading patterns would perhaps suggest that smaller units would experience the greatest peaks and lowest load factors and thus have the greatest difference between RMS and average. Unfortunately, the utility data obtained during our survey may not support this conclusion. These findings are presented following the discussion of utility data and peak demands. 


\subsubsection{Peak Demands}

Many utilities have transformer management programs that monitor the peak demand on their transformers by demand meters or estimates from kilowatt-hour data. ORNL collected and analyzed data from selected utilities. Typical results are given in Figs. 2.3-2.5, which show relative loading, and in Table 2.1, which shows the analysis of single-phase, pole-mounted units. Of special note in Figs. 2.4 and 2.5 are the relative number of transformers with peak loads exceeding the nameplate rating. These data alone support a relative per unit load of 0.25 to 0.35 . Fig. 2.5 provides some insight into the relative loading of small and large units. Clearly, the smaller unit has a greater proportion of the population, with peak load exceeding the nameplate rating, while the average load of the larger unit would appear to be greater. This trend is the expected classical loading pattern, but other transformer sizes do not support this conclusion, as is seen in Fig. 2.3. Figs. 2.4 and 2.5 present only the estimated peak load or demand. Average load, load factor, kilowatt-hours, loss factor, and power factor are not given. Nevertheless, the data imply a relatively low average load, since only a small fraction of transformers have peak loads above nameplate. Data provided from the same utility for 1988-94 consistently support this conclusion.

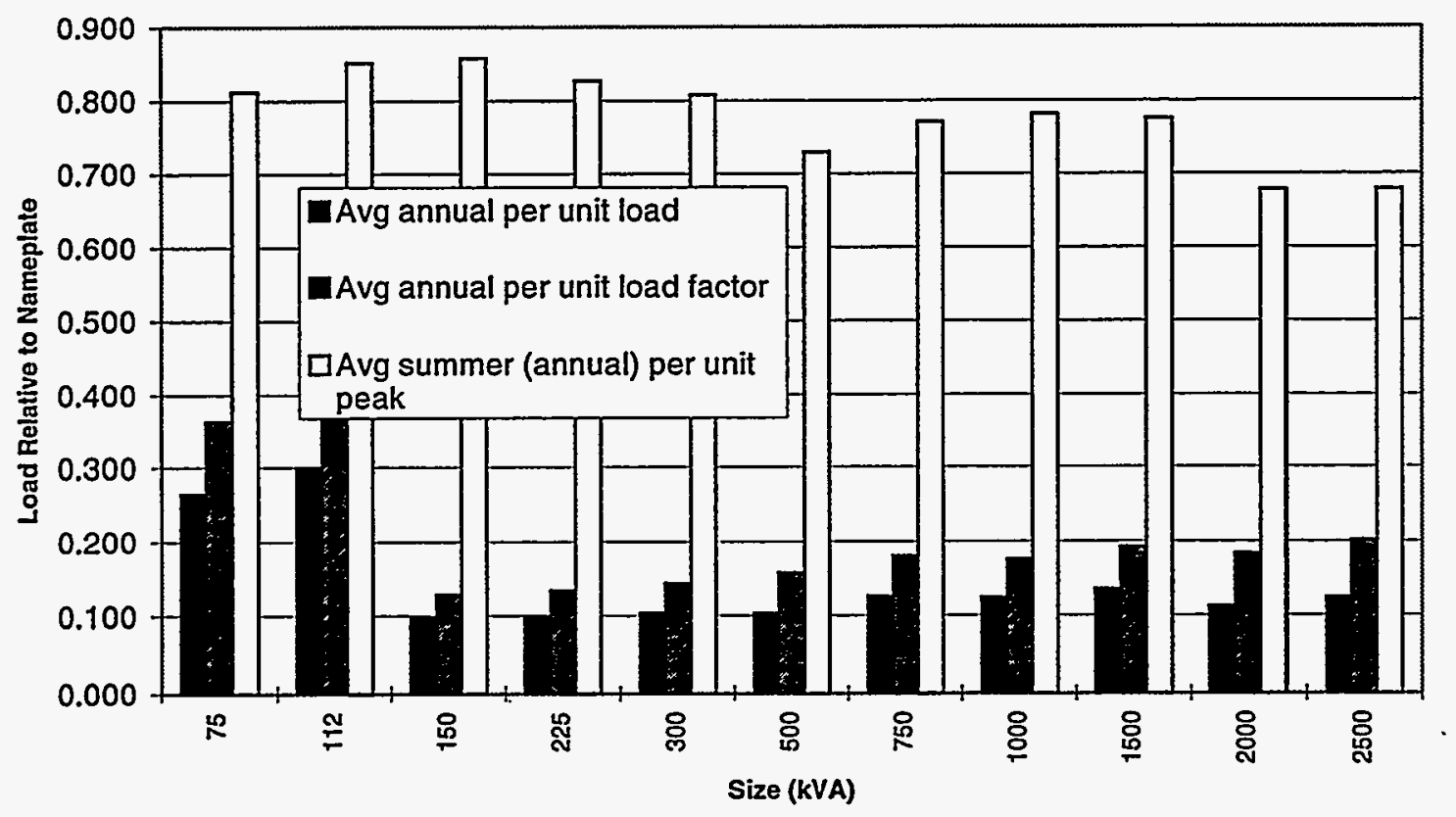

Fig. 2.3. Average loads, peak loads, and load factors for a utility's three-phase distribution transformers, 1995-1996. 


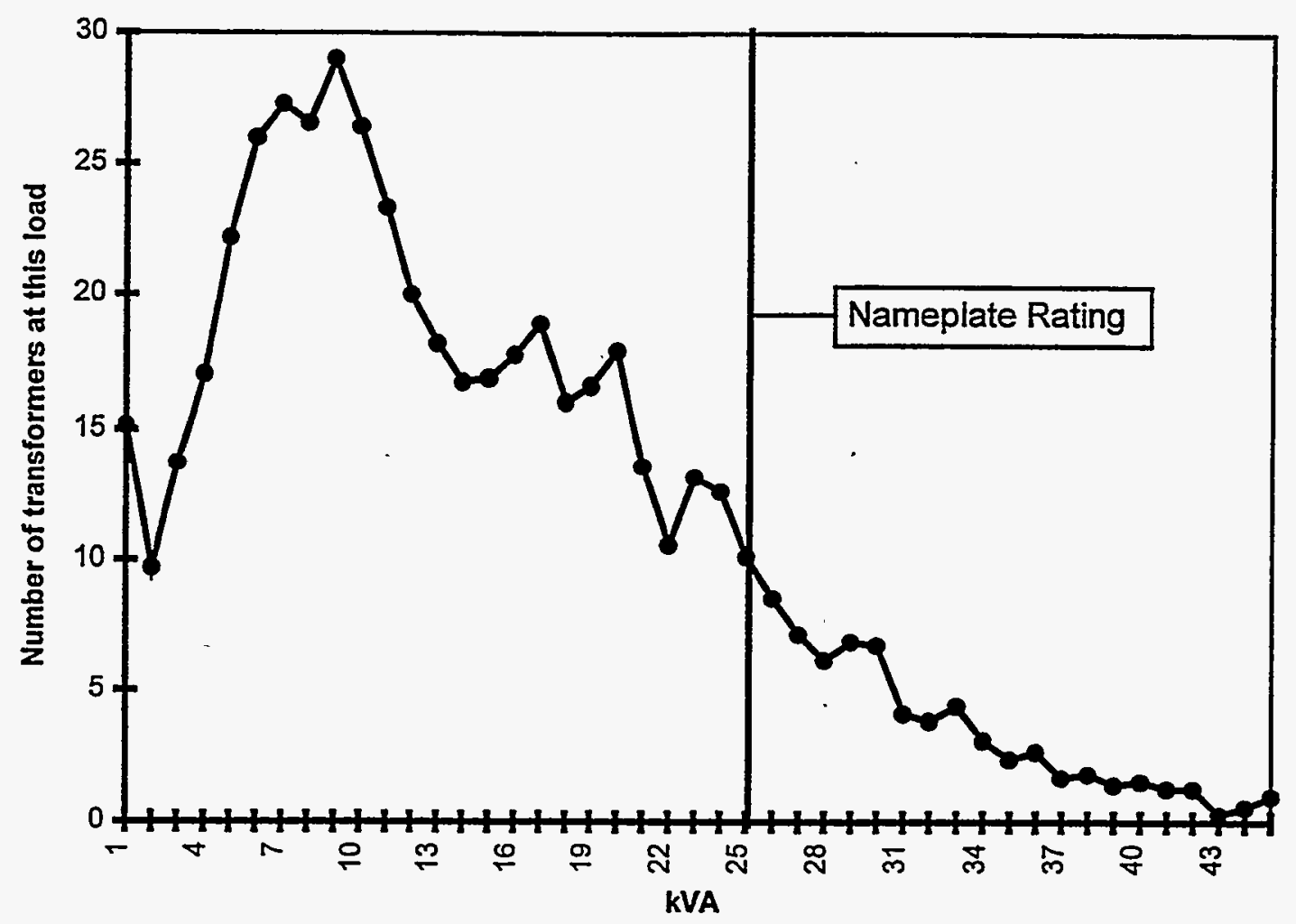

Fig. 2.4. Peak load distribution for 25-kVA transformers, summer 1994.

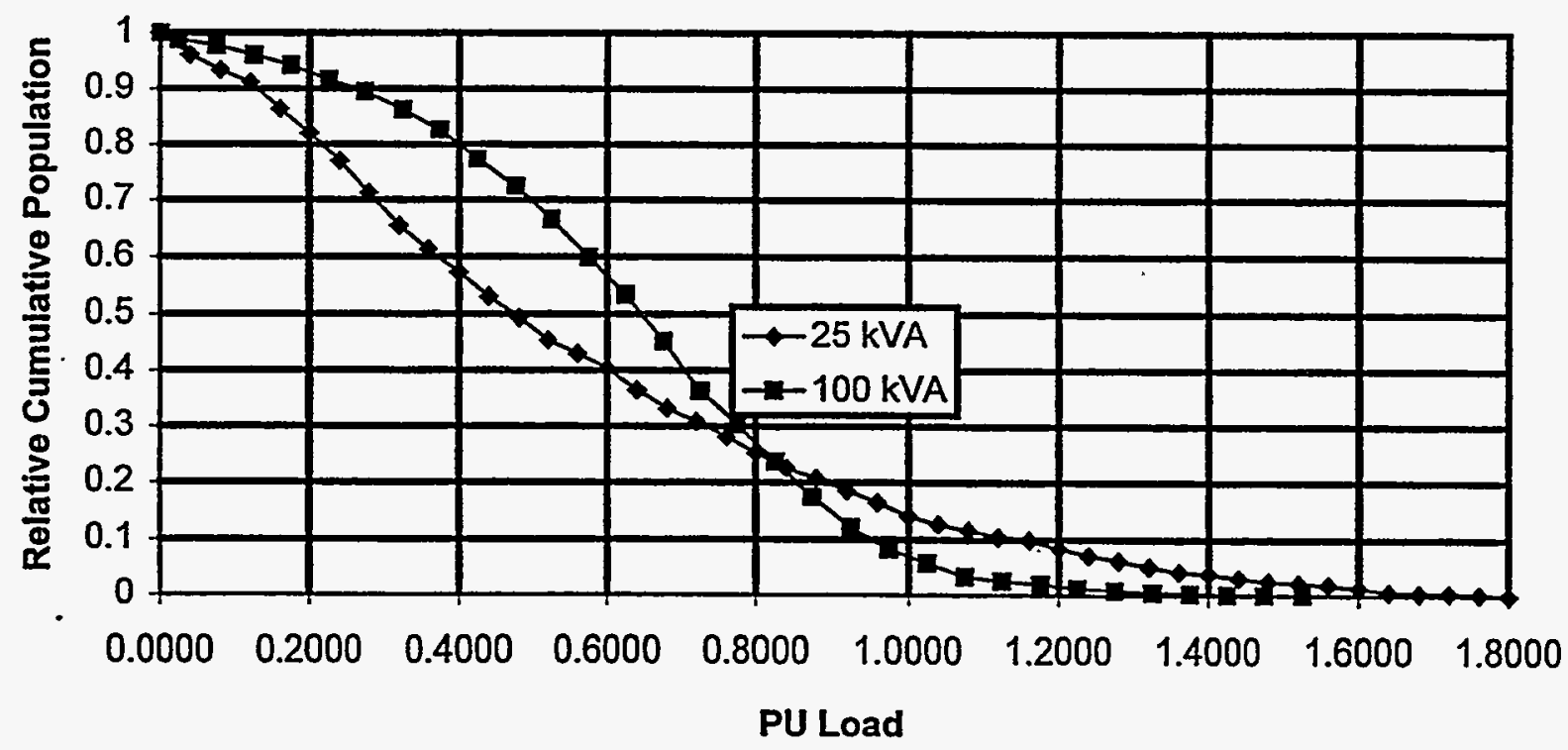

Fig. 2.5. Relative number of units with per unit load greater than or equal to $x$. 
Table 2.1. Summary data for a utility's single-phase, pole-mounted distribution transformers

\begin{tabular}{|c|c|c|c|c|c|c|c|c|c|}
\hline $\begin{array}{c}\text { Size } \\
\text { (kVA) }\end{array}$ & $\begin{array}{c}\text { Summer } \\
\text { (annual) } \\
\text { peak } \\
(\mathrm{kW})\end{array}$ & $\begin{array}{c}\text { Summer } \\
\text { (annual) } \\
\text { PU peak } \\
(\mathrm{kW})\end{array}$ & $\begin{array}{l}\text { Total } \\
\text { MWh }\end{array}$ & $\begin{array}{c}\text { No. of } \\
\text { installed } \\
\text { transformers }\end{array}$ & $\begin{array}{c}\mathbf{k W h} / \\
\text { transformer }\end{array}$ & $\begin{array}{l}\text { Annual PU } \\
\text { avg load } \\
\text { (kVA) }\end{array}$ & $\begin{array}{l}\text { Annual PU } \\
\text { load factor }\end{array}$ & $\begin{array}{l}\text { Calculated } \\
\text { loss factor }\end{array}$ & $\begin{array}{l}\text { Annual PU } \\
\text { RMS load }\end{array}$ \\
\hline 10 & 6.6 & 0.73 & $1,259,756$ & 59,793 & 21,069 & 0.267 & 0.405 & 0.200 & 0.295 \\
\hline 15 & 10.2 & 0.76 & $3,679,621$ & 106,476 & 34,558 & 0.292 & 0.430 & 0.221 & 0.320 \\
\hline 25 & 17.4 & 0.77 & $7,217,228$ & 118,584 & 60,862 & 0.309 & 0.444 & 0.234 & 0.337 \\
\hline 37 & 27.4 & 0.82 & $7,403,986$ & 77,076 & 96,061 & 0.329 & 0.445 & 0.235 & 0.359 \\
\hline 50 & 35.8 & 0.80 & $6,140,474$ & 50,580 & 121,401 & 0.308 & 0.430 & 0.222 & 0.337 \\
\hline 75 & 48.6 & 0.72 & $4,105,873$ & 24,682 & 166,351 & 0.281 & 0.434 & 0.225 & 0.308 \\
\hline 100 & 60.5 & 0.67 & $1,868,048$ & 8,457 & 220,888 & 0.280 & 0.463 & 0.252 & 0.304 \\
\hline 167 & 91.6 & 0.61 & $1,423,559$ & 3,820 & 372,659 & 0.283 & 0.516 & 0.304 & 0.302 \\
\hline 250 & 140.9 & 0.63 & 373,670 & 592 & 631,199 & 0.320 & 0.568 & 0.360 & 0.338 \\
\hline 333 & 181.0 & 0.60 & 246,846 & 284 & 869,176 & 0.331 & 0.609 & 0.407 & 0.347 \\
\hline 500 & 254.5 & 0.57 & 277,229 & 231 & $1,200,126$ & 0.304 & 0.598 & 0.394 & 0.319 \\
\hline 667 & 443.7 & 0.74 & 14,995 & 9 & $1,666,111$ & 0.317 & 0.476 & 0.264 & 0.342 \\
\hline 833 & 441.2 & 0.59 & 111,564 & 51 & $2,187,529$ & 0.333 & 0.629 & 0.431 & 0.348 \\
\hline
\end{tabular}

Note: $\mathrm{PU}=$ per unit. 


\subsubsection{Average Loading by Nameplate Capacity}

Traditional wisdom would expect larger transformers, both liquid-immersed and dry-type, to be loaded more uniformly - i.e., to have a-lower per unit peak loading and a higher average load (EPRI 1983; Nickel and Braunstein 1981). This logic is justified by the desire to increase reliability, which tends to reduce the peak load of large transformers. However, the utility survey data available to ORNL researchers indicate both a relatively low peak load and a low average load. This result may be representative of the utilities surveyed (most have high air conditioning loads) or of the application (high motor loads with frequent starts). In either case, the desire to prevent voltage sag and lighting flicker may prevent increased average load with increased size. Per unit RMS loading by nameplate capacity for liquid-filled utility transformers is shown in Fig. 2.6. Because there was insufficient data to support estimates of the loadings of larger units, a value of 0.5 was assumed until better data are available. Non-utility applications are loaded to 0.35 for low-voltage or 0.5 for medium-voltage per unit RMS.

\subsection{DRY-TYPE LOW-VOLTAGE TRANSFORMERS}

Dry-type low-voltage transformers are used in power distribution networks of large commercial and industrial buildings to transform the building voltage (typically $480 \mathrm{~V}$ ) to a lower voltage of 120 , 240 , or $208 \mathrm{~V}$ (three-phase) for powering equipment and lights. The designs of building power networks are normally based on the National Electrical Code (NEC), which establishes the minimum standards for wiring design and installation practices to minimize fire and accident hazards. NEC rules are often enforced by being incorporated into local building codes. NEC requires that certain minimum loadings be assumed in designing branch circuits and feeders. In addition to the known or assumed minimum loading, engineering practice is to make provisions for future load growth by increasing feeder and panel capacities by $50 \%$ (Fink and Carroll 1969, ch. 17). Thus, the rated capacities of feeder distribution panels are very conservative, since not all circuits are fully loaded at the same time and since a $50 \%$ growth margin is included in the size specifications. In addition, because of the limited number of standard panel sizes (100 A, $200 \mathrm{~A}, 400 \mathrm{~A}$, etc.), a much larger capacity.than necessary would be selected, to accommodate a load that is closer to but larger than that of the next smaller panel size. This conservatism is also used in specifying the transformer that supplies the panel(s). Since additional loads can be added later, up to the panel rating, transformers are sized to adequately power the panel unless it can be established that additional loads will not be added over the life of the building. For example, a 200-A three-wire $120 / 240-\mathrm{V}$ panel would require a 50-kVA transformer; and a 200-A three-phase four-wire 120/208-V panel would require a 75-kVA transformer.

Because of load diversity, the fact that many actual loads at outlets are well below the maximum circuit ratings, and the conservatism for future load growth, most low-voltage dry distribution transformers have a peak load of only about 50-60\% of their rated capacity. An example of the load profile of a three-phase 75-kVA transformer in an office building is shown in Fig. 2.7. The peak load is about $44 \%$ of the rated capacity. The per unit average and RMS loads are 0.2 and 0.22 , respectively. Several years ago, a conservation program in the form of more efficient lighting reduced the peak load on this unit by about $25 \%$ (the exact reduction is uncertain); thus, the transformer was initially loaded to about $58 \%$. Prior to the conservation activities, the per unit average and RMS loads were about 0.26 and 0.29 . A per unit RMS load of 0.35 is a reasonable assumption. 


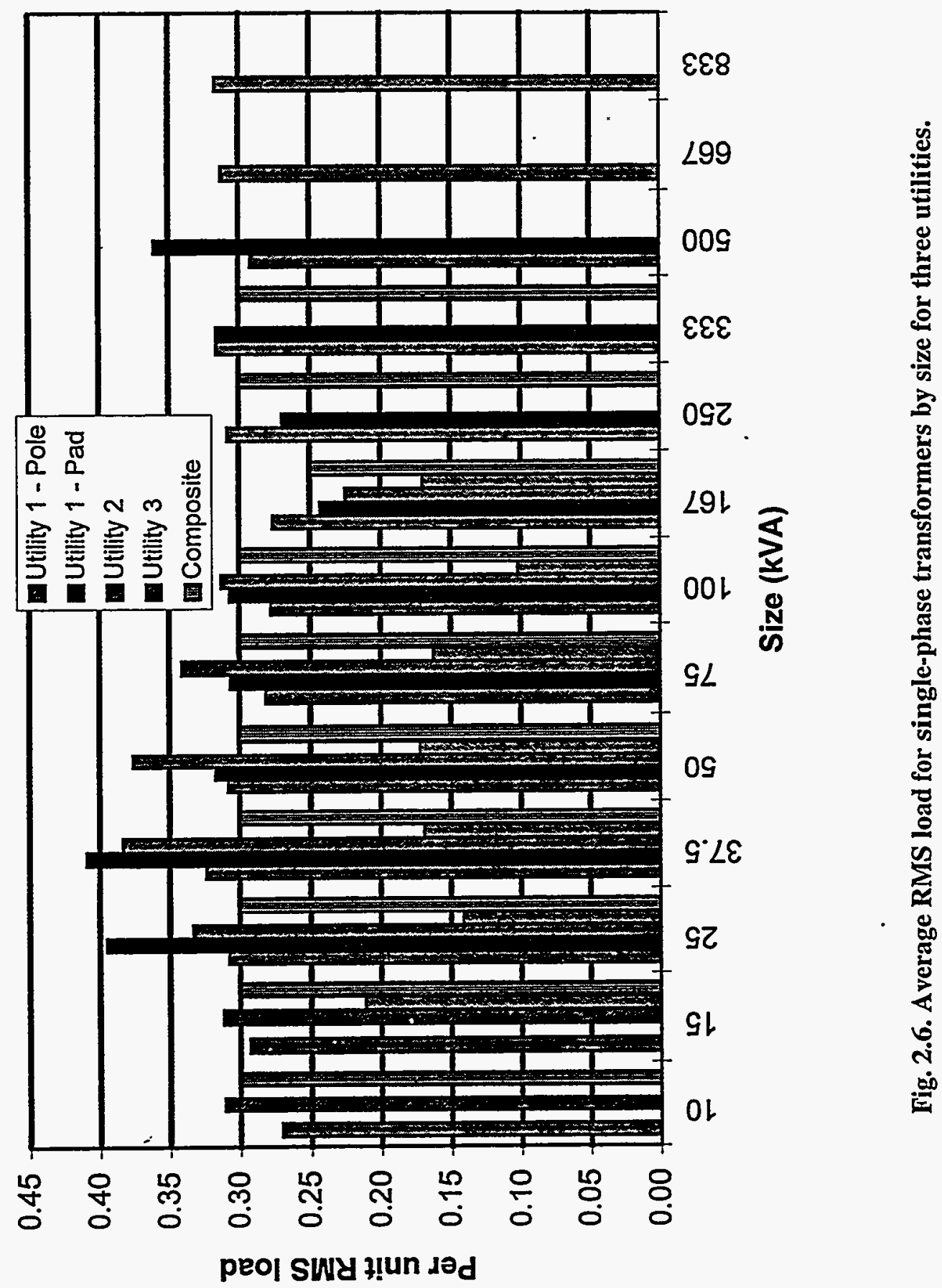




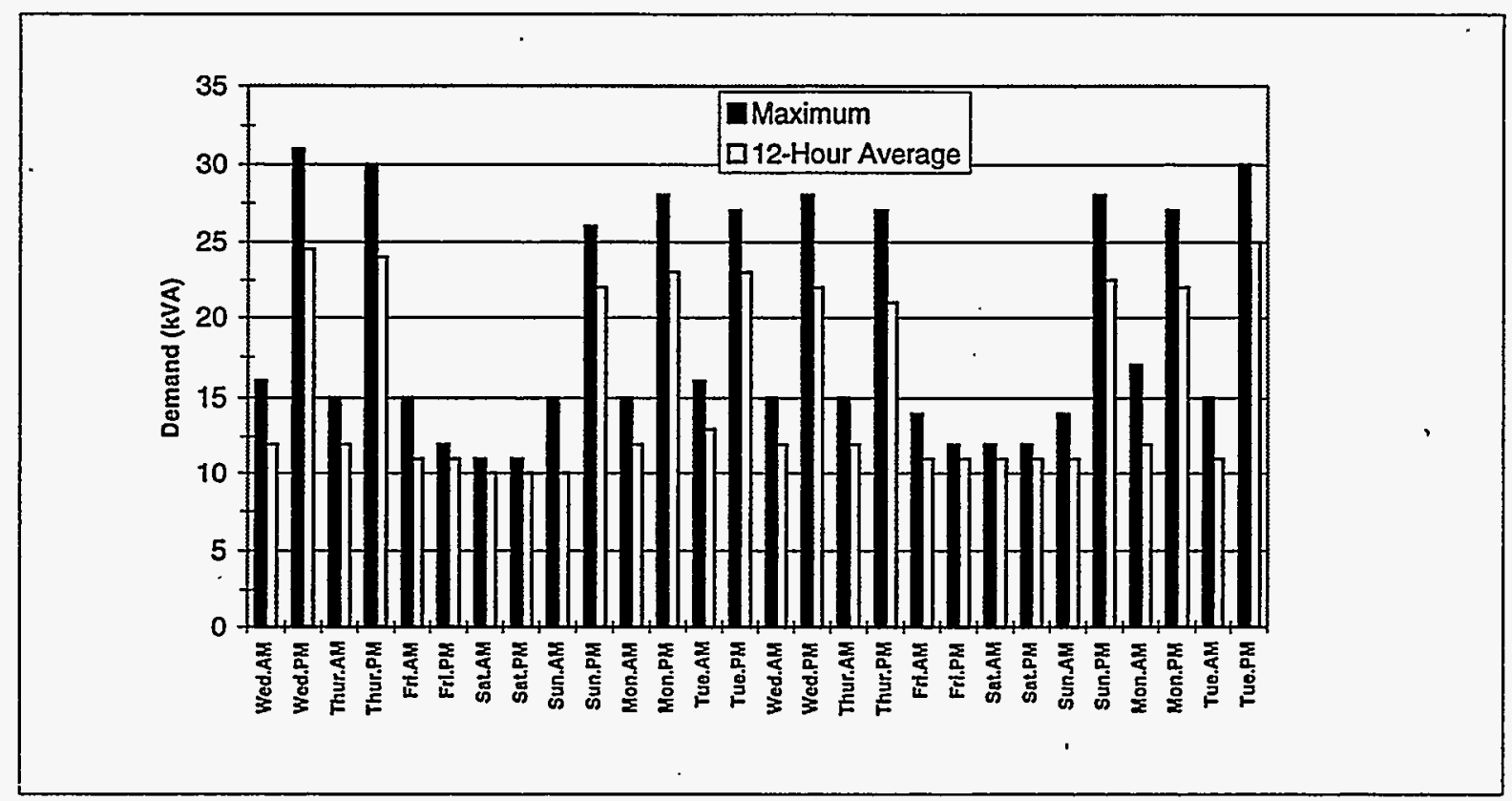

Fig. 2.7. Load profile for a dry-type three-phase 75-kVA transformer.

\subsection{DRY-TYPE MEDIUM-VOLTAGE TRANSFORMERS}

Relatively large three-phase dry-type medium-voltage transformers are typically used in unit substations to transform the utility primary distribution voltage to the building voltage for use in powering feeder circuits and large motors. Diversity in the loads among the various feeders results in a larger load factor and a higher average per unit load than the low-voltage transformers in the feeder circuits. The demand factor - the ratio of the maximum demand to the sum of the feeder peak demands - for various loads of "commercial power and general power" is typically $70 \%$ (Fink and Carroll 1969, ch. 16, p. 302). However, the average power is not affected by load diversity, and if the unit substation is sized on the basis of the demand factor, the per unit average and RMS power levels will increase by the inverse of the demand factor. Thus, if the low-voltage units in the branch circuits are loaded to $35 \%$, then the unit substation could reasonably have an effective load of $50 \%$.

Single-phase dry-type medium-voltage transformers are used in large industrial and commercial facilities where the building or plant voltage is in the medium-voltage class. They are also used to serve as unit substations in facilities where only single-phase power is required and in other special applications. The per unit effective load for unit substation applications will be similar to that of three-phase units. The smaller single- and three-phase units $(\leq 100 \mathrm{kV})$ that serve lighting panels, etc., can be expected to be lightly loaded in a way similar to low-voltage transformers. Fan motor loads used for continuous building ventilation and other applications result in these types of transformers' having relatively high effective loads. However, transformers associated with large motor loads are sized larger to reduce voltage sag and flicker caused by motor starting and inrush current, which can present major problems with cyclical loads. For medium-voltage applications in industrial or commercial applications, a load of 0.5 per unit is an acceptable value when voltage regulation issues are considered. 


\subsection{NON-UTILITY LIQUID-IMMERSED TRANSFORMERS}

Non-utility liquid-immersed transformers are used in large commercial and industrial applications. These transformers may be located outdoors or in a transformer vault along with switchgear and control equipment. Because the load profiles for large industrial customers are typically flatter than those for residential and commercial customers (Fink and Carroll 1969, ch. 16), the per unit average and effective transformer loads can be higher. An ORNL survey of transformer loading by local industrial users found that per unit average loads ranged from 0.19 to 0.73 , with the mean average being 0.47 . The mean per unit average load for large commercial users was 0.38 . RMS loads can be expected to be about $5 \%$ higher than the average loads, or about $40 \%$. Thus, commercial and industrial non-utility liquid-immersed transformers have a per unit RMS load of 0.4 to 0.5 .

\subsection{FUTURE TRENDS}

To cut inventory costs, some utilities are assessing their transformer requirements and are eliminating some of the sizes (Electrical World 1996). When a utility has fewer transformer sizes available, it must increase the range of loads for a given size, with the result that some units have higher loads. A survey of 37 utilities by Stone and Webster for Cooper Power Systems found that most utilities expect the average loads on distribution transformers to increase; none expected average loading to decrease (Austin 1994). A larger survey of 64 utilities by the Edison Electric Institute (EEI) found that nearly half of the respondents plan to load transformers initially at more than $100 \%$ (per unit peak) for new customers (Hall 1996).

\subsection{SUMMARY}

Under the NEMA standard TP 1-1996 (NEMA 1996), reference RMS load conditions for dry-type distribution transformers are $35 \%$ and $50 \%$ of nameplate loads for low-voltage and medium-voltage units, respectively. These reference loads are higher than the limited loading data examined in this study but appear to be consistent with engineering design practices. Smaller liquid-immersed distribution transformers that serve one or two residential customers or are used for outdoor lighting, pump houses, etc., have light annual per unit average loads ranging from a few percent to about $15 \%$. On the other hand, large transformers equal to or greater than $100 \mathrm{kVA}$ that serve commercial and industrial customers and large apartment buildings have higher average loads, typically ranging from 20 to $70 \%$ of nameplate loads, with mean values of about $35 \%$. Based on the data from three utilities used in this study, the TP-1 standard reference load condition of $50 \%$ of nameplate loads for medium-voltage liquid-immersed transformers is too high for typical utility distribution transformers. However, if utilities start loading their transformers higher, as indicated by recent surveys, then the RMS load may increase for new installations. 


\section{ENERGY ANALYSIS MODEL}

\subsection{INTRODUCTION}

A distribution transformer that is continuously energized and providing service to secondary load consumes energy 24 hours a day to magnetize the core and to overcome ohmic losses from eddy and conductor currents. Even when the transformer is not supplying power to a load, it is consuming energy because of losses in the core. The core losses are also called no-load losses. The transformer will normally experience varying load conditions with both diumal and seasonal variability. As discussed in Sect. 2, when the load increases from a no-load condition to a finite load, the losses increase proportionally with the square of the load current due to ohmic losses in the coils. Thus, over a period of varying loads, the coil losses are a function of the effective or RMS load current; these losses are also a function of the RMS load if the load voltage is assumed to be constant.

\subsection{ANNUAL ENERGY LOSSES}

The annual energy losses for a transformer can be determined by its loss parameters - namely, the no-load losses (NL), the full-load losses (LL), and the temperature correction factor (T). The annual losses in kilowatt-hours are given by

$$
L=8.76 \times\left(N L+L L \times T \times \mathrm{S}^{2}\right)
$$

where $N L$ and $L L$ are given in watts, $S$ is the per unit RMS load computed for an annual period, and $T$ is a temperature correction factor (see Appendix C). In general, $S$ is slightly larger than the average per unit load given by

$$
S_{\mathrm{av}}=E_{\mathrm{o}} /\left(S_{B} \times P F \times 8760\right) \text {, }
$$

where $E_{o}$ is the annual energy supplied to the load by the transformer in units of kilowatt-hours, $S_{B}$ is the nameplate rating of the transformer in kilovolt-amperes, and $P F$ is the power factor. The power factor, defined as the ratio of the real power to the apparent power, varies as the utility system load changes. During moderate- to high-load conditions, the power factor ranges from 0.80 to 0.95 , with an average value of 0.90 (Nickel and Braunstein 1981). For the analyses in this study, an effective value for $P F$ is assumed to be 0.90 .

Transformer efficiency varies with the load. The efficiency for the RMS load $S$ with a unity power factor is

$$
\eta=1000 \times S \times S_{B} \times\left(S \times S_{B}+N L+T \times L L \times S^{2}\right)^{-1}
$$

The annual energy consumption for each conservation case is calculated by adding the losses of the transformer capacity purchased during the year. A simplifying assumption is made that all transformers are placed into operation at the beginning of the year. For a conservation standards case where the transformer's losses are given in terms of an efficiency at a specified load, the losses are first determined by assuming that manufacturers will meet the standard with a design that minimizes 
both cost and materials. A design that maximizes the transformer efficiency at (or near) the load specified by the standard would permit the manufacturer to meet the standard at a minimum cost. ${ }^{3}$ This assumption is necessary because there are many designs that a manufacturer could choose to meet the standard. However, it is likely in a competitive market that the choice will be close to a minimum cost design. For a conservation standard efficiency $\eta_{\text {std }}$, specified load $S_{\text {std }}$, and a maximum efficiency $\eta_{\max }$ at a per unit load $S_{\max }$, the losses for a transformer designed to meet the standard are

$$
N L_{\mathrm{std}}=1000 \times S_{B} \times S_{\mathrm{std}} \times\left(1-\eta_{\mathrm{std}}\right) /\left[1+\left(S_{s t d} / S_{\max }\right)^{2}\right] \times \eta_{\mathrm{std}}
$$

and

$$
L L_{\mathrm{std}}=N L_{\mathrm{std}} /\left[T \times\left(S_{\max }\right)^{2}\right]
$$

This approach is described in more detail in Appendix D. In the ORNL energy analysis model, $S_{\max }$ is set equal to $S_{\text {std }}$.

Transformer losses are determined for each transformer in the conservation case as a function of size, type, and operating voltage. Once the individual transformer annual losses at the operating load are determined, they are multiplied by the projected sales for each transformer. The total annual case losses, $L_{\text {case }}$, is determined by summing the losses for all transformers in the conservation case.

\subsection{CONSERVATION CASE EFFICIENCY}

The case efficiency is defined as the ratio of the annual energy supplied to customers by the new transformers $E_{\mathrm{o}}$ to the total annual energy supplied to the transformers. The case efficiency can also be expressed as a function of $E_{\mathrm{o}}$ and the conservation case losses; i.e.,

$$
\xi=E_{\mathrm{o}} /\left(E_{\mathrm{o}}+L_{\text {case }}\right) \text {. }
$$

The total annual energy (in $\mathrm{kWh}$ ) supplied to customers by the new transformers, $E_{0}$, is determined by summing the energy supplied by all of the transformers in the conservation case and is equal to

$$
E_{\mathrm{o}}=\sum S_{B i} \times P F \times S_{\mathrm{avi}} \times 8760 \mathrm{hrs} \times U_{i}
$$

where $i$ is the $i$ th transformer in the case - for example, an evaluated 25-kVA medium-voltage liquid-filled transformer used for utility applications - and $U$ is the number of units sold annually. The energy consumed by the transformers in kilowatt-hours can be expressed in terms of the case efficiency:

$$
L_{\text {case }}=E_{0} \times(1-\xi) / \xi \text {. }
$$

${ }^{1}$ This is a simplifying assumption for the purposes of analysis. The minimum-cost design is affected by many factors, including core type and material costs, and actual designs will vary from manufacturer to manufacturer. 


\subsection{ENERGY SAVINGS}

The annual energy savings associated with a standard or conservation program is simply the energy losses for the base case, $L_{\text {base case }}$, minus the energy losses for the conservation case, $L_{\text {std }}$. The annual energy saving is given by

$$
E_{\text {savings }}=L_{\text {base case }}-L_{\text {std }} \text {. }
$$

Since transformers are generally efficient devices with efficiencies above $90 \%$, the reduction of the losses may provide a better measure for the effectiveness of a conservation case. The reduction of losses for a conservation case in percentage is given by

$$
R=100 \times E_{\text {savings }} / L_{\text {base case }} \text {. }
$$

For nonevaluated transformers the energy savings is straightforward, since the losses of the base case exceed the losses for the conservation case. For evaluated transformers the calculation is more complicated because many of the transformers being purchased have higher efficiencies than the minimum efficiency specified by the conservation case. Only those transformers with efficiencies lower than the standard would be affected. Figure 3.1 shows the range of efficiencies for $25-\mathrm{kVA}$ pole-mounted transformers taken from a survey of 54 utilities. To meet the NEMA standard, only about $6 \%$ of these utilities would have to purchase more efficient transformers. However, to meet

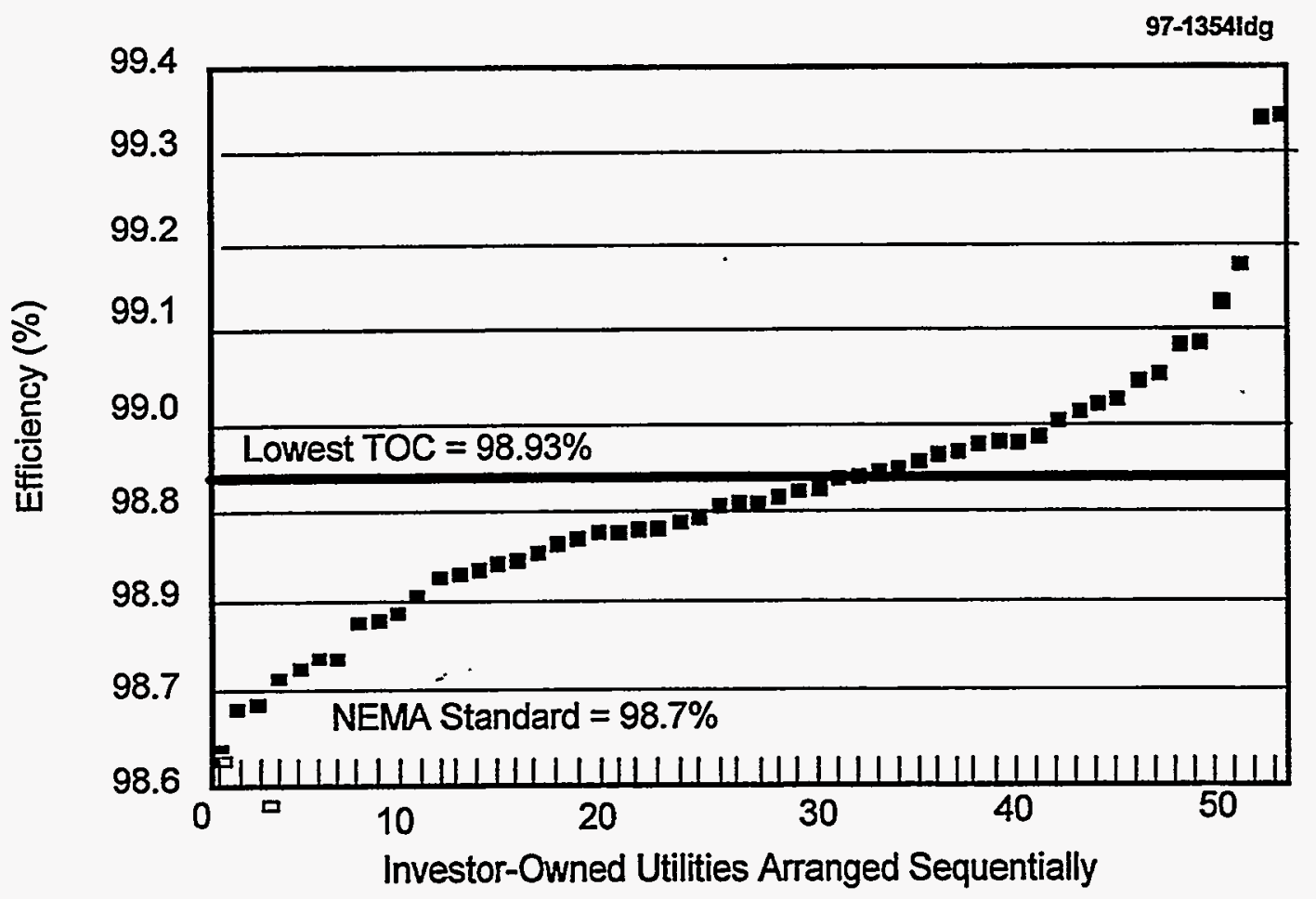

Fig. 3.1. Efficiencies of 25-kVA distribution transformers purchased by

54 utilities. Efficiencies are at 50\% effective load. A total owning cost (TOC) efficiency of $98.93 \%$ is based on $A=\$ 3.50$ and $B=\$ 0.75$. 
standards with higher minimum efficiencies, such as the TOC standard shown in Fig. 3.1, which is based on $A=\$ 3.50 /$ watt and $B=\$ 0.75 /$ watt, where $A$ is the equivalent first cost of no-load losses and $B$ is the equivalent first cost of full-load losses, many more utilities would be affected.

Calculations of the energy savings for evaluated transformers are based on a comparison of the losses defined by the efficiency standard to the average losses for transformers with efficiencies lower than the standard. The losses for transformers below the standard were determined from a survey of utilities for 11 types of liquid medium-voltage transformers, including 8 single-phase and 3 three-phase transformers. The average losses for these transformers were used to represent the losses of transformers of the same type and size. For transformers not included in the survey, the losses for a surveyed transformer of the same type that was closest in size were extrapolated according to the ratio of the unknown transformer to the known transformer's size to the 0.75 power. The fraction of transformers below the standard in the survey was used to estimate the total fraction of the evaluated capacity that would need to improve to meet the standard. The difference between the average for the losses of the transformers below the efficiency standard compared to the losses of transformers defined as just meeting the standard was used to determine the effect of the standard for this fraction of new transformer sales.

The energy savings over the conservation period of $n$ years is the sum of savings that are achieved during the first year for $n$ years plus the second year's savings for $n-1$ years, etc. The energy savings over the $n$-year period with a constant market growth rate $r$ are given by

$$
E_{\text {case }}=E_{\text {savings }}\left[(1+r)^{n+1}-(1+r)-n r\right] / r^{2} \text {. }
$$

For the case where the rate of growth is zero, the case savings reduces to

$$
E_{\text {case }}=E_{\text {savings }}[n(1+n) / 2] \text {. }
$$

\subsection{LOAD SPECIFIED BY A STANDARD}

The extent to which manufacturers would tend to design transformers for maximum efficiencies at the loads specified for meeting a standard (see Appendix D) could have an important impact on energy savings. In some cases losses could actually increase if actual operating loads are significantly below the specified load for meeting the standard's minimum efficiency. For instance, if the load specified for meeting the standard is $50 \%$ and the actual operating load for a transformer is $30 \%$, the standard could be met by increasing the transformer's efficiency at $50 \%$ while reducing its efficiency at $30 \%$. This would result from reducing full-load losses while increasing no-load losses. This condition of increased losses was observed for some sizes of evaluated liquid-immersed transformers during the analysis of the TP-1 standard conducted for Chapter 5.

This anomaly provides an important insight into setting standards. The TP-1 standard has been set for a $50 \%$ load for liquid-filled medium-voltage transformers. To the extent that transformers are designed to be at maximum efficiency at the load specified for meeting the standard, the ratio of the load to no-load losses will decrease if the load at which the efficiency is specified increases, and will increase if the load specified for the efficiency calculation decreases. If the actual loads at which transformers operate are less than the load specified for meeting the standard, the resulting transformer design will be less efficient under operating conditions than it would be if the specified 
load for meeting the standard was closer to the actual operating load. Therefore, for the same cost, a transformer designed to have its maximum efficiency at a 50\% load will tend to have a lower efficiency operating at a 30\% load than a transformer designed to have its maximum efficiency at a load between $30 \%$ and $50 \%$.

A sensitivity evaluation of this effect is presented in Fig. 3.2. As this figure indicates, setting an efficiency standard as close as possible to the actual operating load of the transformer can have a significant effect in reducing energy losses. This graph suggests that, given uncertainty about existing loads and future load trends, setting an efficiency standard near $40 \%$ could be a good strategy. Fortunately, it appears from recent surveys that many new transformers have been designed with a maximum efficiency of between 40 and $45 \%$.
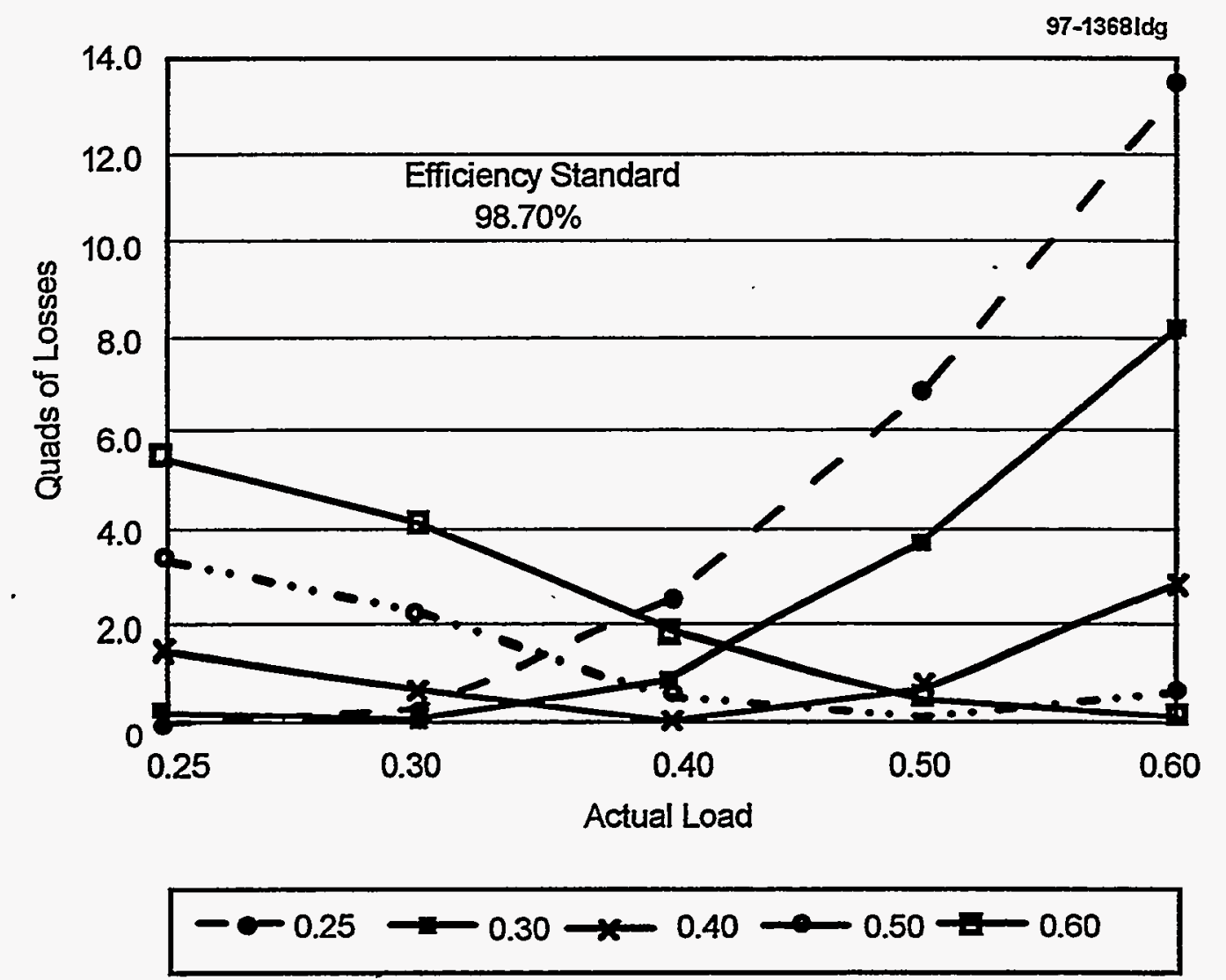

Fig. 3.2. Thirty-year cumulative differences in energy losses for designs that maximize transformer efficiency at five alternative loads, compared to energy losses if designs maximized efficiency at actual load. 


\section{THE BASE CASE}

\subsection{INTRODUCTION}

The base case is the business-as-usual case with no mandatory conservation standards to influence the energy efficiencies of future transformer purchases. The time period for analysis is the period during which the first transformers purchased under the new standard are expected to operate; for distribution transformers, a period of 30 years is the normal life expectancy. Thus, not only must the base case define the present transformer market and the energy consumption associated with annual sales of distribution transformers, but it must also make a projection of the market and transformer efficiencies over the analysis period. The simplest projection is a constant sales growth rate along with no changes in transformer efficiencies. Due to the uncertainties associated with long-term projections, there is a high probability that any projection scenario will ultimately be shown to be incorrect.

For distribution transformers, there are no indications at this time that the commercial and industrial applications will change in the future. Anticipated changes for utilities, however, could influence their application of distribution transformers. Utility restructuring and competition may result in an emphasis on shorter payback periods, which implies the use of transformers with a lower capital cost and higher losses. On the other hand, the U.S. Environmental Protection Agency's (EPA's) Energy Star program and other conservation programs that promote energy efficiency will encourage utilities to purchase more efficient transformers. Thus, the future trend for utility distribution transformers is unclear, and until more information is available, the simple projection scenario of no changes in transformer efficiencies and a low constant rate of growth appears to be appropriate.

\subsection{BASE CASE DEFINITION}

The base case is defined as the energy consumption of new transformers with existing energy efficiency characteristics. For the purposes of this report, the estimate of annual energy consumption is based on 1995, the year of the most recent sales data. This annual estimate has been adjusted upward by an expected growth in sales to 2004 , which is projected as the first year that energy conservation standards for transformers could be initiated. Cumulative energy consumption for the base case is defined for a 30-year period spanning 2004 through 2033. The rate of annual energy consumption has been assumed to be constant over this entire period except for changes resulting from projected increases in annual sales.

\subsection{BASE CASE ASSUMPTIONS}

Distribution transformer annual sales in nameplate capacity (MVA) and annual sales growth are parameters needed to conduct energy consumption or savings analysis for the base case and other conservation cases. Since transformer losses vary with size and type, the market characteristics associated with size and type are needed. These include the losses for evaluated and nonevaluated transformers, the number of evaluated transformers used for utility and commercial and industrial applications, and the total liquid-immersed transformer market associated with non-utility 
applications. The values and assumptions shown in Tables 4.1, 4.2, and 4.3 were developed from surveys of utilities and transformer manufacturers and follow-up discussions with the manufacturers.

Crucial base case assumptions utilized to calculate the energy losses include average transformer efficiencies by size and type of transformer and the annual sales of new transformers by size and type. Key assumptions discussed here include design losses, average transformer loading, and annual sales. These assumptions are made for each of $27^{\circ}$ liquid-immersed transformers and 46 dry-type transformers.

\subsubsection{Base Case Design Losses}

Table 4.1 shows the typical energy losses for evaluated and nonevaluated liquid medium-voltage transformers. Essentially all utility-owned transformers are of this type. Commercial and industrial applications for liquid medium-voltage transformers are mostly for the larger sizes (see Table 4.2). Table 4.2 breaks out liquid medium voltage transformers by ownership (utility vs non-utility) and by whether the transformers are evaluated. Evaluated transformers typically have higher efficiencies than nonevaluated ones. In the absence of a definitive source for this breakout, it has been based on information from discussions with and informal information provided by transformer manufacturers. The loss characteristics describing utility transformers are probably more reliable than those for nonutilities because of the additional information from utility surveys (Barnes et al. 1996).

The TP-1 Survey was considered as one source for these assumptions. This survey of NEMA and non-NEMA manufacturers during 1996, conducted by NEMA and ORNL, respectively, and reproduced in this report as Appendix E, was undertaken to determine how transformer manufacturers would design transformers to meet the NEMA TP-1 transformer efficiency standard. The survey also requested information on nonevaluated transformers and the additional costs associated with the purchase of a TP-1 transformer instead of a nonevaluated one. However, there were relatively few responses to the survey, and there were significant variations in losses and efficiencies within many of the transformer categories. Therefore, typical losses and characteristic efficiencies for these types of transformers were taken from data supplied by NEMA and by various transformer manufacturers, as indicated in the source notes in Tables 4.1 and 4.3.

\subsubsection{Base Case Loads}

Table 4.2 breaks out the liquid medium voltage transformers by ownership and presents the characteristic annual RMS load. Data on the total transformer capacity in use and the total energy served is reported by major utilities on FERC Form 1 . An initial assignment of RMS loads was based on a review of loads reported by several utilities (see Chapter 2). The loads for each type and size of transformer were then adjusted by a factor that made the aggregate of the individual loads weighted by sales consistent with the overall average load as calculated from the FERC 1 data (see Chapter 2).

In addition to the assumptions discussed above, the following assumptions, based on typical values from the literature, have been used:

- The average load is related to the RMS load approximately by $\dot{S}_{\mathrm{av}}=0.9 \times S$.

- The weighted average per unit load for all utility-owned transformers is 0.24 (see Chapter 2).

- The power factor is assumed to be equal to 0.9 (Nickel and Braunstein 1981). 
- The case time period is 30 years starting with year 2004 .

- Primary energy is based on $10,455 \mathrm{Btu} / \mathrm{kWh}$ primary energy conversion to net generation of electricity (EIA 1996b) and transmission and distribution system losses to the transformers of $5.89 \%$ (Barnes et al. 1994), for a total of $11,070 \mathrm{Btu} / \mathrm{kWh}$.

Crucial assumptions on future distribution transformer sales are discussed in Sect. 4.3.3.

Table 4.1. Base case design loss parameters: medium-voltage liquid-immersed distribution transformers

\begin{tabular}{|c|c|c|c|c|c|c|c|c|c|c|c|}
\hline \multirow{3}{*}{$\begin{array}{c}\text { Size } \\
(\mathrm{kVA})^{a}\end{array}$} & \multicolumn{5}{|c|}{ Single-phase" } & \multicolumn{6}{|c|}{ Three-phase } \\
\hline & \multicolumn{2}{|c|}{ Evaluated } & \multicolumn{2}{|c|}{ Nonevaluated } & \multirow{2}{*}{$\begin{array}{c}\% \\
\text { eval. }\end{array}$} & \multirow{2}{*}{$\begin{array}{c}\text { Size } \\
(\mathbf{k V A})^{a}\end{array}$} & \multicolumn{2}{|c|}{ Evaluated } & \multicolumn{2}{|c|}{ Nonevaluated } & \multirow{2}{*}{$\begin{array}{c}\% \\
\text { eval. }\end{array}$} \\
\hline & NL & $\mathbf{L L}$ & NL & $\mathbf{L L}$ & & & NL & $\mathbf{L L}$ & NL & $\mathbf{L L}$ & \\
\hline 10 & 31 & 193 & 44 & 237 & 85 & 15 & 63 & 204 & 94 & 356 & 85 \\
\hline 15 & 40 & 212 & 53 & 323 & 85 & 30 & 104 & 366 & 156 & 623 & 85 \\
\hline 25 & 58 & 312 & 90 & 460 & 85 & 45 & 141 & 489 & 224 & 868 & 85 \\
\hline 37.5 & 81 & 412 & 108 & 615 & 85 & 75 & 227 & 759 & 319 & 1,353 & 85 \\
\hline 50 & 101 & 540 & 153 & 670 & 85 & 112.5 & 268 & 1,117 & 443 & 1,853 & 85 \\
\hline 75 & 133 & 718 & 217 & 944 & 85 & 150 & 312 & 1,650 & 450 & 2,100 & 85 \\
\hline 100 & 166 & 873 & 271 & 1,201 & 85 & 225 & 396 & 1,998 & 647 & 3,172 & 85 \\
\hline 167 & 256 & 1,350 & 384 & 2,059 & 85 & 300 & 587 & 2,577 & 822 & 4,126 & 85 \\
\hline 250 & 361 & 1,888 & 543 & 2,950 & 85 & 500 & 721 & 4,021 & 1,178 & 5,738 & 85 \\
\hline 333 & 429 & 2,867 & 746 & 3,797 & 66 & 750 & 1,053 & 5,973 & 1,900 & 8,000 & 85 \\
\hline 500 & 608 & 4,050 & 1,062 & 5,060 & 62 & 1,000 & 1,337 & 6,486 & 1,946 & 11,306 & 68 \\
\hline 667 & 739 & 4,391 & 1,273 & 6,063 & 60 & 1,500 & 1,747 & 8,841 & 2,721 & 14,470 & 60 \\
\hline \multirow[t]{2}{*}{833} & 876 & 5,239 & 1,528 & 7,231 & 60 & 2,000 & 2,197 & 14,464 & 3,369 & 18,961 & 60 \\
\hline & & & & & & 2,500 & 2,619 & 15,023 & 4,041 & 21,985 & 60 \\
\hline
\end{tabular}

Sources: Barnes et al. 1994, 1996; NEMA letters to P. R. Barnes, September 15, 1995, and October 28, 1996; EEI utility survey (see Barnes 1994, Appendix A); and ORNLNEMA surveys of manufacturers in 1996.

Note: $\mathrm{NL}=$ no-load losses in watts; $\mathrm{LL}=$ full-load losses in watts.

${ }^{a}$ Nameplate capacity of the transformer in kilovolt-amperes. 


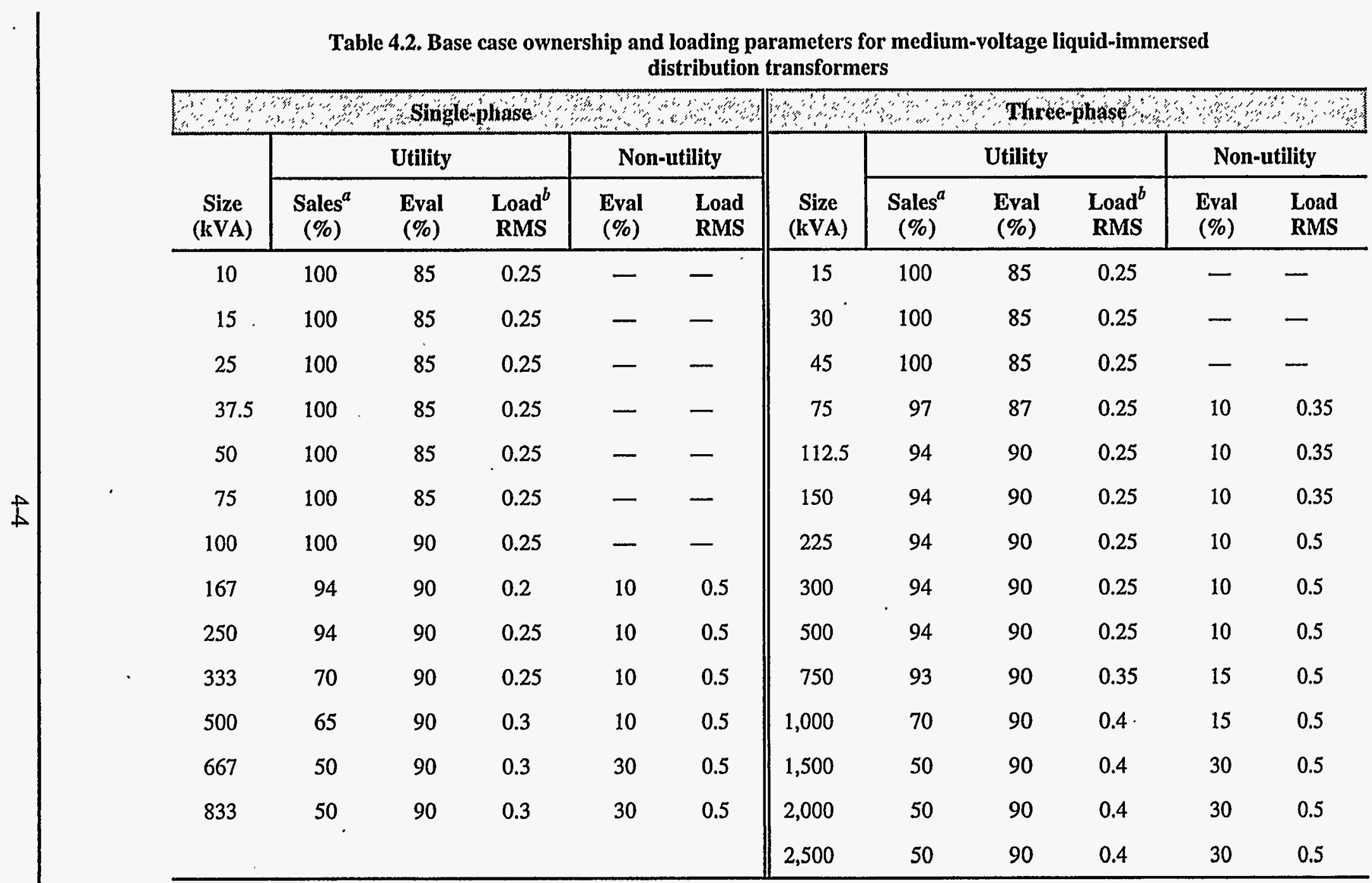

${ }^{a}$ Total utility sales are approximately $90 \%$ of the overall sales. For the percentage of sales, $100 \%$ is used to denote values greater than $99.9 \%$.

${ }^{b}$ The overall average per unit load weighted by capacity of sales for utility transformers is 0.24 . 
Table 4.3. Base case design loss parameters: dry-type distribution transformers

\begin{tabular}{|c|c|c|c|c|c|c|c|c|c|}
\hline \multirow{3}{*}{$\begin{array}{c}\text { Size } \\
(\mathbf{k V A})^{a}\end{array}$} & \multicolumn{4}{|c|}{ Singlephase } & \multicolumn{5}{|c|}{ Three-phase } \\
\hline & \multicolumn{2}{|c|}{ Low-voltage } & \multicolumn{2}{|c|}{ Medium-voltage } & \multirow{2}{*}{$\begin{array}{c}\text { Size } \\
(\mathrm{kVA})^{a}\end{array}$} & \multicolumn{2}{|c|}{ Low-voltage } & \multicolumn{2}{|c|}{ Medium-voltage } \\
\hline & NL & $\mathbf{L L}$ & NL & $\mathbf{L L}$ & & NL & LL & NL & $\mathbf{L L}$ \\
\hline 10 & - & - & 一 & - & 15 & 162 & 712 & 385 & 550 \\
\hline 15 & 110 & 670 & 275 & 590 & 30 & 256 & 1,274 & 550 & 1,050 \\
\hline 25 & 157 & 982 & 365 & 800 & 45 & 322 & 1,655 & 675 & 1,275 \\
\hline 37.5 & 222 & 1,410 & 475 & 1,200 & 75 & 462 & 2,542 & 920 & 2,100 \\
\hline 50 & 279 & 1,817 & 580 & 1,425 & 112.5 & 604 & 3,457 & $\cdot 1,040$ & 2,463 \\
\hline 75 & 348 & 2,327 & 735 & 1,800 & 150 & 661 & 4,690 & 1,316 & 3,183 \\
\hline 100 & 451 & 3,058 & 880 & 2,350 & 225 & 862 & 6,242 & 1,544 & 4,232 \\
\hline 167 & 683 & 4,487 & 1,260 & 3,500 & 300 & 1,087 & 7,397 & 1,888 & 5,028 \\
\hline 250 & 939 & 5,921 & 1,671 & 4,650 & 500 & 1,648 & 11,166 & 2,547 & 7,771 \\
\hline 333 & 1,256 & 7,190 & 2,092 & 5,650 & 750 & 2,189 & 14,830 & 3,216 & 10,047 \\
\hline 500 & - & - & 2,714 & 7,675 & 1,000 & 2,677 & 18,139 & 3,953 & 12,367 \\
\hline 667 & - & - & 3,203 & 9,506 & 1,500 & - & - & 4,627 & 16,039 \\
\hline \multirow[t]{2}{*}{833} & - & - & 3,708 & 11,198 & 2,000 & - & - & 5,589 & 20,042 \\
\hline & & & & & 2,500 & - & - & 6,574 & 24,318 \\
\hline
\end{tabular}

Sources: Barnes et al. 1994, 1996; NEMA letters to P. R. Barnes, September 15, 1995, and October 28, 1996; Barnes 1994; and ORNLNEMA surveys of manufacturers in 1996.

Note: $\mathrm{NL}=$ no-load losses in watts; $\mathrm{LL}=$ full-load losses in watts. All sizes are assumed to be nearly $100 \%$ nonevaluated.

Based on limited data, typical RMS loads range from 20 to $40 \%$ for low-voltage units and from 40 to $60 \%$ for medium-voltage units. The per unit loads of $35 \%$ and $50 \%$ for low-voltage and medium-voltage units, respectively, that are specified by NEMA TP 1-1996 (NEMA 1996) appear to be appropriate for the average RMS loads.

${ }^{a}$ Nameplate capacity of the transformer in kilovolt-amperes. 


\subsubsection{Market Trends and Forecasts}

The market information on distribution transformers is based mainly on the annual industry surveys by NEMA. Since the NEMA data do not reflect the entire industry (representing only $80 \%$ and $72 \%$ of the total dry-type and liquid-immersed markets, respectively), ORNL attempted to collect the data from non-NEMA manufacturers. The estimate for the current distribution transformer market is based on the average values for 1993 to 1995 for both NEMA and non-NEMA manufacturers. Data for the liquid-filled transformer market of non-NEMA manufacturers, which included four major manufacturers, were collected through a survey designed by ORNL. The total market for liquidimmersed transformers, estimated by major size categories and by single- and three-phase units is shown in Fig. 4.1. The current market for liquid-immersed distribution transformers is estimated to be $68,150 \mathrm{MVA}$, or 1.5 million units. Single-phase transformers of less than $100 \mathrm{kVA}$ hold the major market share, representing more than $50 \%$ of the total estimated liquid-immersed market, as shown in Fig 4.1. Single-phase transformers greater than $500 \mathrm{kVA}$ are generally specialty and custom-ordered transformers and are assumed to be $0.3 \%$ (21 MVA) of the total market for single-phase transformers larger than $100 \mathrm{kVA}$ (Smith 1996). The aggregate market data for the major size categories, further disaggregated into individual sizes based on the information obtained from several transformer manufacturers and a 1994 survey by NEMA, are shown in Table 4.4.

Compared to manufacturers of liquid-immersed transformers, non-NEMA manufacturers of dry-type transformers are numerous and smaller. However, only data from a large non-NEMA manufacturer were obtained from ORNL's survey. Therefore, the available market data on dry-type transformers (including data from NEMA manufacturers and a non-NEMA manufacturer) were increased by $20 \%$ to reflect the small and numerous non-NEMA manufacturers. The current total dry-type distribution transformer market is estimated to be $20,685 \mathrm{MVA}$, or 248,000 units; and it is disaggregated into seven major categories, as shown in Fig. 4.2. The three-phase low-voltage market is estimated to

ORNL 97-123411/mm

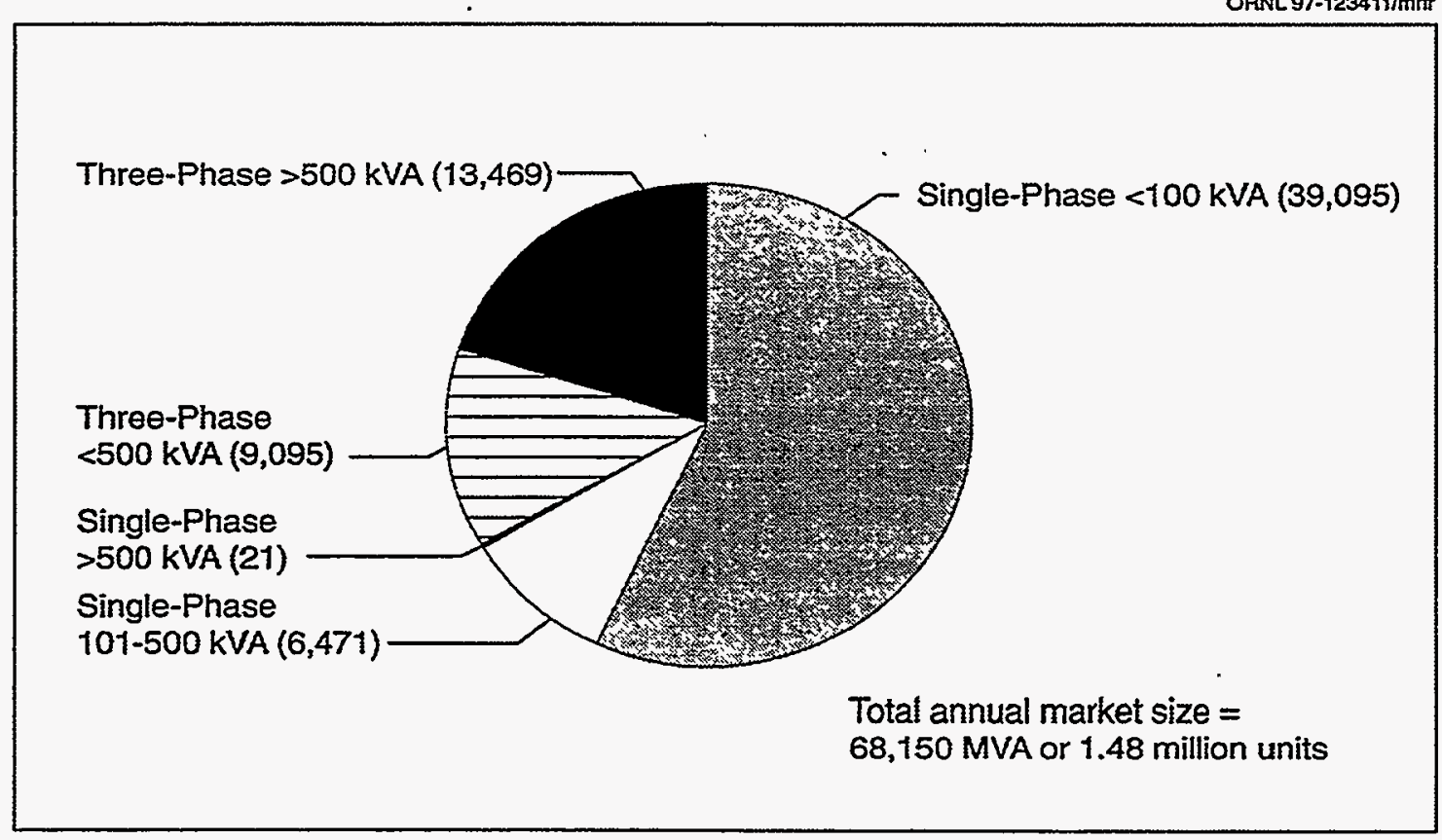

Fig. 4.1. Estimated 1995 market for liquid-immersed distribution transformers (MVA). 
Table 4.4. Estimated 1995 annual medium-voltage liquid-filled distribution transformer market by capacity

\begin{tabular}{|c|c|c|c|c|c|}
\hline$\cdots$ & ingle-pha & $\begin{array}{l}9 \\
y=0,0\end{array}$ & 4 & hree-phas & $\because$ \\
\hline $\begin{array}{c}\text { Size } \\
(\mathrm{kVA})\end{array}$ & $\begin{array}{l}\text { Sales in } \\
\text { MVA }\end{array}$ & $\begin{array}{l}\text { No. of } \\
\text { units }\end{array}$ & $\begin{array}{c}\text { Size } \\
\text { (kVA) }\end{array}$ & $\begin{array}{l}\text { Sales in } \\
\text { MVA }\end{array}$ & $\begin{array}{l}\text { No. of } \\
\text { units }\end{array}$ \\
\hline 10 & 2,341 & 234,098 & 15 & 45 & 3,032 \\
\hline 15 & 4,962 & 330,825 & 30 & 91 & 3,032 \\
\hline 25 & 11,474 & 458,965 & 45 & 182 & 4,042 \\
\hline 37.5 & 3,104 & 82,779 & 75 & 455 & 6,063 \\
\hline 50 & 10,556 & 211,116 & 112.5 & 273 & 2,425 \\
\hline 75 & 3,531 & 47,086 & 150 & 1,182 & 7,882 \\
\hline 100 & 3,126 & 31,263 & 225 & 910 & 4,042 \\
\hline 167 & 3,355 & 20,087 & 300 & 2,638 & 8,792 \\
\hline 250 & 809 & 3,237 & 500 & 3,320 & 6,639 \\
\hline 333 & 955 & 2,867 & 750 & 2,694 & 3,592 \\
\hline 500 & 1,352 & 2,704 & 1,000 & 2,155 & 2,155 \\
\hline 667 & 6 & 9 & 1,500 & 3,098 & 2,065 \\
\hline \multirow[t]{2}{*}{833} & 15 & 18 & 2,000 & 1,212 & 606 \\
\hline & & & 2,500 & 4,310 & 1,724 \\
\hline All sizes & 45,587 & $1,425,053$ & & 22,564 & 56,093 \\
\hline
\end{tabular}

capture about $55 \%$ of the total market. The single-phase medium voltage market is assumed to be small, about $1 \%$ of the total dry-type market; and this market is disaggregated into further size categories ( $<100 \mathrm{kVA}, 100-500 \mathrm{kVA}$, and $>500 \mathrm{kVA})$ based on the $30 \%, 65 \%$, and $5 \%$ distribution, respectively, among them (Nizinski 1996). The three-phase medium-voltage ( $>100 \mathrm{kVA}$ ) market is estimated to have the largest share (7820 MVA) of the total market among the different sizes considered here. It is assumed that $90 \%$ of this market, which is made up mainly of open-wound secondary unit substations and cast resin-type transformers, consists of sizes greater than $500 \mathrm{kVA}$, with an average size of $2000 \mathrm{kVA}$ (Hurst 1996). No data were available explicitly for the three-phase medium-voltage ( $<100 \mathrm{kVA})$ market; it is assumed to be $5 \%$ of the total low-voltage market for the same size category reported by NEMA (Hopkinson 1996). The market shares of specific sizes within a major category are based on the NEMA survey of dry-type manufacturers and follow-up discussions with manufacturers, and are shown in Table 4.5.

Single-phase dry-type transformers of less than $15 \mathrm{kVA}$ are not considered in the NEMA TP-1 standard (NEMA 1996). The market for single-phase 10-kVA dry-type transformers is small, not significantly different from that for 15-kVA transformers, shown in Table 4.5. However, about 1.4 


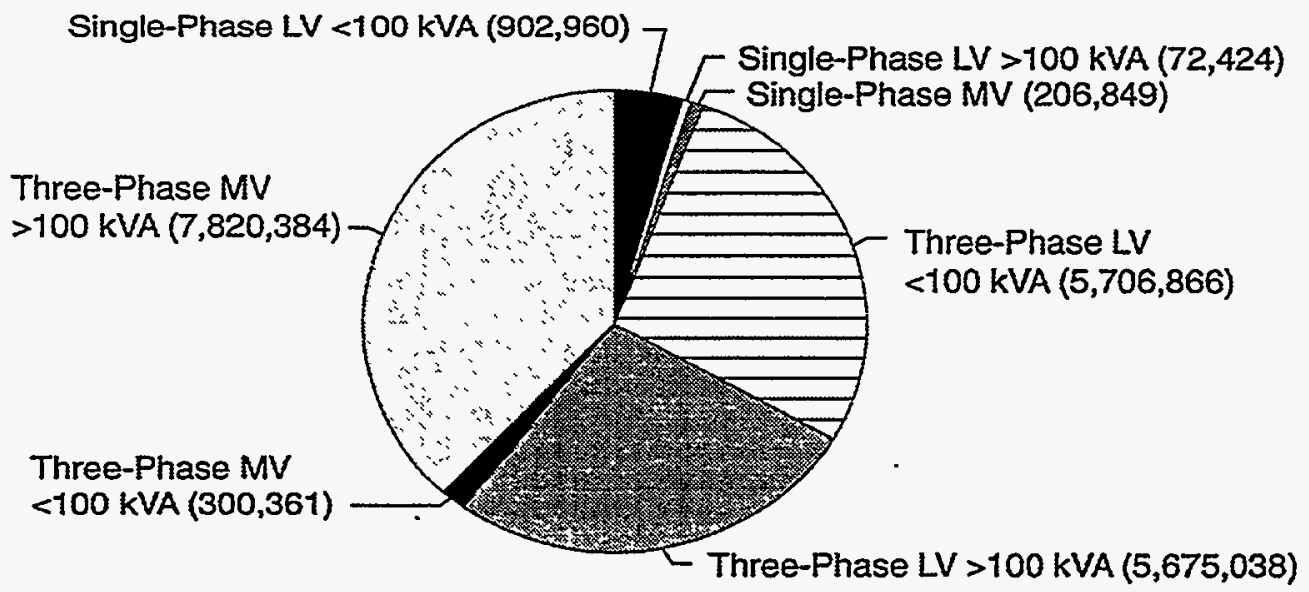

Total annual market size $=$ 20,685 MVA or 248,000 units

Fig. 4.2. Estimated 1995 market for dry-type distribution transformers (kVA).

million single-phase dry-type transformers of less than $10 \mathrm{kVA}$ are currently sold in the market (with an average size of $1 \mathrm{kVA}$ ); these are used by original equipment manufacturers in machine tool applications. Distribution transformer applications in this size category usually average 3- to 5-kVA in capacity and currently have a share of $\sim 400,000$ units (equivalent to $1200 \mathrm{MVA}$ ) of the total market of 1.4 million units (Barnes et al. 1996). Therefore, the fact that single-phase dry-type transformers smaller than $15 \mathrm{kVA}$ are not considered in the present study underestimates the total market for dry-type distribution transformers by $5.5 \%$ (in terms of megavolt-amperage).

The estimate of the liquid-immersed market in this report is about $3 \%$ higher, and for the dry-type market 27\% lower, than the corresponding estimates made in the 1996 determination study (Barnes et al. 1996). The higher estimate shown in the determination study in the case of dry-type market is due to overestimation of the cast resin market ( 8000 vs $4000 \mathrm{MVA}$ ) and the use of a higher value for the non-NEMA market share ( $34 \%$ vs $20 \%$ ). Limited information on estimates of the current size of the distribution market are available in the literature. The market data collected by the U.S. Department of Commerce (DOC 1994a) provide only the value of annual product shipments from manufacturers with shipments of $\$ 100,000$ or more, and the data are limited to only a few major size categories for liquid-immersed and dry-type transformers, which makes it difficult to estimate the total market size. Most of the DOC data is limited to liquid-immersed transformers, and the 1992 estimates were found to be in the range of 65 to $80 \%$ higher (depending on the size category) than the values reported by NEMA (which do not include non-NEMA manufacturers). For example, the DOC estimate of the value of the overhead-type single-phase liquid-immersed 500-kVA and smaller transformers is $\$ 466$ million, compared to a value of $\$ 356$ million reported by NEMA. The Freedonia Group estimates the current size of liquid-immersed and dry-type markets as $\$ 1550$ million and $\$ 445$ million, respectively, an estimate that corresponds well to our estimates, 
Table 4.5. Estimated 1995 annual dry-type distribution transformer market by capacity

\begin{tabular}{|c|c|c|c|c|c|c|c|c|c|}
\hline \multicolumn{5}{|c|}{$\because \because \cdots$} & \multicolumn{5}{|c|}{ Three-phase } \\
\hline \multirow[b]{2}{*}{$\begin{array}{c}\text { Size } \\
(\mathrm{kVA})^{a}\end{array}$} & \multicolumn{2}{|c|}{ Low-voltage } & \multicolumn{2}{|c|}{ Medium-voltage } & \multirow[b]{2}{*}{$\begin{array}{c}\text { Size } \\
(\mathrm{kVA})\end{array}$} & \multicolumn{2}{|c|}{ Low-voltage } & \multicolumn{2}{|c|}{ Medium-voltage } \\
\hline & $\begin{array}{l}\text { Sales in } \\
\text { MVA }^{b}\end{array}$ & $\begin{array}{l}\text { No. of } \\
\text { units }\end{array}$ & $\begin{array}{l}\text { Sales in } \\
\text { MVA }\end{array}$ & $\begin{array}{l}\text { No. of } \\
\text { units }\end{array}$ & & $\begin{array}{c}\text { Sales in } \\
\text { MVA }\end{array}$ & $\begin{array}{l}\text { No. of } \\
\text { units }\end{array}$ & $\begin{array}{c}\text { Sales in } \\
\text { MVA }\end{array}$ & $\begin{array}{l}\text { No. of } \\
\text { units }\end{array}$ \\
\hline 15 & 56 & 3,762 & 3 & 213 & 15 & 1,008 & 67,227 & 12 & 903 \\
\hline 25 & 311 & 12,454 & 5 & 196 & 30 & 1,421 & 47,367 & 26 & 881 \\
\hline 37.5 & 203 & 5,423 & 17 & 453 & 45 & 1,575 & 34,989 & 119 & 2,644 \\
\hline 50 & 215 & 4,298 & 15 & 292 & 75 & 1,703 & 22,706 & 141 & 1,885 \\
\hline 75 & 77 & 1,025 & 9 & 115 & 112.5 & 1,546 & 13,744 & 82 & 718 \\
\hline 100 & 40 & 401 & 14 & 138 & 150 & 1,622 & 10,810 & 116 & 774 \\
\hline 167 & 17 & 101 & 38 & 229 & 225 & 636 & 2,825 & 126 & 562 \\
\hline 250 & 22 & 88 & 31 & 122 & 300 & 446 & 1,486 & 184 & 613 \\
\hline 333 & 9 & 27 & 14 & 41 & 500 & 858 & 1,717 & 274 & 548 \\
\hline 500 & - & - & 52 & 104 & 750 & 491 & 655 & 1,050 & 1,400 \\
\hline 667 & - & - & 6 & 9 & 1,000 & 77 & 77 & 1,240 & 1,240 \\
\hline \multirow[t]{3}{*}{833} & - & - & 4 & 5 & 1,500 & - & - & 2,431 & 1,621 \\
\hline & & & & & 2,000 & - & - & 969 & 485 \\
\hline & & & & & 2,500 & - & - & 1,348 & 539 \\
\hline $\begin{array}{l}\text { All } \\
\text { sizes }\end{array}$ & 950 & 27,578 & 207 & 1,917 & & 11,382 & 203,602 & 8,121 & 14,822 \\
\hline
\end{tabular}

${ }^{a}$ The 10-kVA size is not included in this table because it is not covered by NEMA TP-1. It is estimated that sales are about 55 MVA, or 5,500 units.

${ }^{b}$ The market for sizes less than $10 \mathrm{kVA}$ used for power distribution applications is estimated at $1,200 \mathrm{MVA}$. The number of units in this size category is estimated at 400,000 .

assuming that the dollar per kilovolt-ampere value in both cases is in the low 20s (Freedonia Group 1996).

The total distribution transformer line capacity of investor-owned electric utilities was estimated to be 1036 GVA in 1994, based on the latest FERC Form 1 data (RDI 1996). Total capacity increase and retirements during the same year were estimated to be 28 GVA and 16 GVA, respectively (RDI 1996). Annual sales of liquid-immersed distribution transformers to investor-owned electric utilities can be calculated by adding annual capacity increase and retirements. Total sales of liquid-immersed transformers in 1994 were estimated to be $64 \mathrm{GVA}$, assuming that $76 \%$ of total liquid-immersed 
transformers are investor-owned (EIA 1996c) and that $90 \%$ of the total liquid-immersed market is used for utility applications. Our estimate of the total liquid-immersed transformer market, based on 1995 NEMA sales data, is $68 \mathrm{GVA}$; this is $4 \%$ higher than the estimated 1994 consumption of 64 MVA. Note that this comparison of transformer sales is complicated by the fact that FERC Form 1 distribution transformer line capacity data found in the literature are not necessarily consistent from year to year - i.e., the total line capacity at the beginning of a given year does not always equal the total capacity at the end of the previous year. This is due to the variation in the number of utilities reported in the FERC Form 1 each year. Also, there is not a one-to-one correspondence between transformer sales and capacity additions, owing to the time lag between purchase of transformers and actual addition of transformer capacity. However, our estimate of the liquid-immersed transformer market, $68 \mathrm{MVA}$, compares reasonably well with that derived from FERC Form 1 consumption data.

The outlook for the distribution transformer industry is expected to be the same as that of the past decade. Demand for distribution transformers is based primarily on the rate of replacement for the installed base, new housing starts, and energy consumption demand growth. Since installed distribution transformers are relatively well-developed, efficient devices, the rate of replacement is generally low [estimated to be $20 \%$ of annual installations (Freedonia Group 1996)]. Replacements are mainly due to equipment failures and changes in voltage requirements. The annual growth of liquid-immersed transformers assumed here is $0.8 \%$ (the same as that assumed for dry-type transformers, as discussed later on). This growth rate is based primarily on the Energy Information Administration's (EIA's) forecast of growth in residential energy consumption, which takes into account new housing starts and several other factors (EIA 1996a). Affordability and demographic factors will cause new housing starts to grow more slowly than the overall economy (DOC 1994b), and the number of households is forecast to grow at $1.1 \%$ per year during the next 20 years (EIA 1996a). It is anticipated that growth in this sector will also be affected by increasingly energyconscious consumers and more efficient electrical appliances, which will reduce the rate of energy consumption per household by $0.3 \%$ annually during the same period (EIA 1996a).

Dry-type transformers are used primarily in commercial and industrial applications; thus, estimates for the market growth of this type of transformer are based on the growth in industrial and commercial energy consumption. The dry-type transformer market is assumed to grow annually at $0.8 \%$, the average of growth rates in commercial and industrial energy consumption forecast for the period 1994-2015 (EIA 1996a). Alternatively, the forecast of gross private domestic investment may also be used to forecast the dry-type transformer market, but it does not account for future energy efficiency and conservation potentials.

The growth rate of $0.8 \%$ for both liquid-immersed and dry-type transformers, assumed on the basis of the growth in total energy consumption, represents a pessimistic (or low-growth) scenario for the distribution transformer market. The rate of growth in electricity consumption (a better indicator for the transformer market than total energy consumption) is forecast to be twice the growth in total energy consumption due to a reduction in distillate fuel consumption. For example, in the residential sector, electricity consumption is forecast to grow at $1.6 \%$ per year, compared to $0.8 \%$ for total energy consumption during the 1995-2015 period (EIA 1996a). Similarly, for the commercial sector, the corresponding values are $0.7 \%$ and $1.5 \%$, respectively.

Another scenario, an optimistic (or high-growth) scenario, has been considered here for the transformer market on the basis of growth in electricity consumption. The optimistic scenario 
assumes a growth rate of $1.6 \%$ per year for both liquid-immersed and dry-type transformers, twice the growth rate assumed under the low-growth scenario.

Although a substantial change in the product mix of transformers is forecast in the future, with padmounted transformers gaining at the expense of overhead types and three-phase transformers being substituted for single-phase designs, the growth rates are assumed not to vary with the size and phase of transformers considered here. Overhead vs pad-mounted types of transformers are not explicitly considered here, and the overall impact for a particular transformer size market may not be that significant. Since three-phase transformers often replace three or more single-phase units, this replacement demand will cause only moderate growth in three-phase distribution shipments.

Table 4.6 shows the estimated annual shipments of liquid-immersed and dry-type distribution transformers by different size categories for 1995-2033; for the estimated years, the low and high values of the range correspond to the low- and high-growth scenarios, respectively. Estimated total

Table 4.6. Annual shipments (in MVA) of distribution transformers in sizes of $10 \mathrm{kVA}$ to 2.5 MVA, 1995-2033

\begin{tabular}{|c|c|c|c|c|c|c|c|c|}
\hline $\begin{array}{c}\text { Transformer } \\
\text { type }\end{array}$ & 1995 & 2000 & 2005 & 2010 & 2015 & 2020 & 2025 & 2033 \\
\hline . & $\therefore$ & \multicolumn{4}{|c|}{ Liquid-imunersed } & $\because$ & 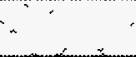 & $\vdots$ \\
\hline $\begin{array}{l}\text { Single-phase } \\
<100 \mathrm{kVA}\end{array}$ & 39,095 & $\begin{array}{l}40,684- \\
42,324\end{array}$ & $\begin{array}{l}42,338- \\
45,820\end{array}$ & $\begin{array}{l}44,058- \\
49,605\end{array}$ & $\begin{array}{l}45,849- \\
53,703\end{array}$ & $\begin{array}{l}47,713- \\
58,139\end{array}$ & $\begin{array}{l}49,652- \\
62,941\end{array}$ & $\begin{array}{l}52,920- \\
71,463\end{array}$ \\
\hline $\begin{array}{l}\text { Single-phase } \\
101-500 \mathrm{kVA}\end{array}$ & 6,471 & $\begin{array}{l}6,734- \\
7,006\end{array}$ & $\begin{array}{l}7,008- \\
7,584\end{array}$ & $\begin{array}{l}7,293- \\
8,211\end{array}$ & $\begin{array}{l}7,589- \\
8,889\end{array}$ & $\begin{array}{l}7,897- \\
9,623\end{array}$ & $\begin{array}{l}8,218- \\
10,418\end{array}$ & $\begin{array}{l}8,759- \\
11,829\end{array}$ \\
\hline $\begin{array}{l}\text { Single-phase } \\
>500 \mathrm{kVA}\end{array}$ & 21 & $22-23$ & $23-25$ & $24-27$ & $25-29$ & $26-31$ & $27-34$ & $28-38$ \\
\hline $\begin{array}{l}\text { Three-phase } \\
<500 \mathrm{kVA}\end{array}$ & 9,095 & $\begin{array}{l}9,465- \\
9,846\end{array}$ & $\begin{array}{l}9,849- \\
10,660\end{array}$ & $\begin{array}{l}10,250 \\
11,540\end{array}$ & $\begin{array}{l}10,666- \\
12,493^{\circ}\end{array}$ & $\begin{array}{l}11,100- \\
13,525\end{array}$ & $\begin{array}{l}11,551- \\
14,642\end{array}$ & $\begin{array}{l}12,311- \\
16,625\end{array}$ \\
\hline $\begin{array}{l}\text { Three-phase } \\
>500 \mathrm{kVA}\end{array}$ & 13,469 & $\begin{array}{l}14,016- \\
14,582\end{array}$ & $\begin{array}{l}14,586- \\
15,786\end{array}$ & $\begin{array}{l}15,179- \\
17,090\end{array}$ & $\begin{array}{l}15,796- \\
18,502\end{array}$ & $\begin{array}{l}16,438- \\
20,030\end{array}$ & $\begin{array}{l}17,106- \\
21,684\end{array}$ & $\begin{array}{l}18,232- \\
24,620\end{array}$ \\
\hline$\therefore$ & & $\therefore$. & & Dry-type & $\therefore \cdots$ & $\cdots$ & & $\therefore$ \\
\hline $\begin{array}{l}\text { Single-phase } \\
\text { LV }<100 \mathrm{kVA}\end{array}$ & 903 & $\begin{array}{l}940- \\
978\end{array}$ & $\begin{array}{l}978- \\
1,058\end{array}$ & $\begin{array}{l}1,018- \\
1,146\end{array}$ & $\begin{array}{l}1,059- \\
1,240\end{array}$ & $\begin{array}{l}1,102- \\
1,343\end{array}$ & $\begin{array}{l}1,147- \\
1,454\end{array}$ & $\begin{array}{l}1,222- \\
1,651\end{array}$ \\
\hline $\begin{array}{l}\text { Single-phase } \\
\mathrm{LV}>100 \mathrm{kVA}\end{array}$ & 72 & $75-78$ & $78-85$ & $82-92$ & $85-99$ & $88-108$ & $92-117$ & $98-132$ \\
\hline $\begin{array}{l}\text { Three-phase LV } \\
<100 \text { kVA }\end{array}$ & 5,707 & $\begin{array}{l}5,939- \\
6,178\end{array}$ & $\begin{array}{l}6,180- \\
6,689\end{array}$ & $\begin{array}{l}6,431- \\
7,241\end{array}$ & $\begin{array}{l}6,693- \\
7,839\end{array}$ & $\begin{array}{l}6,965- \\
8,487\end{array}$ & $\begin{array}{l}7,248- \\
9,188\end{array}$ & $\begin{array}{l}7,725- \\
10,432\end{array}$ \\
\hline $\begin{array}{l}\text { Three-phase LV } \\
>100 \mathrm{kVA}\end{array}$ & 5,675 & $\begin{array}{l}5,906- \\
6,144\end{array}$ & $\begin{array}{l}6,146- \\
6,651\end{array}$ & $\begin{array}{l}6,396- \\
7,201\end{array}$ & $\begin{array}{l}6,655- \\
7,795\end{array}$ & $\begin{array}{l}6,926- \\
8,439\end{array}$ & $\begin{array}{l}7,208- \\
9,137\end{array}$ & $\begin{array}{l}7,682- \\
10,374\end{array}$ \\
\hline $\begin{array}{l}\text { Single-phase } \\
\text { MV }\end{array}$ & 207 & $215-224$ & $224-242$ & $\begin{array}{l}233- \\
262\end{array}$ & $\begin{array}{l}243- \\
284\end{array}$ & $\begin{array}{l}252- \\
308\end{array}$ & $\begin{array}{l}263- \\
333\end{array}$ & $\begin{array}{l}280- \\
378\end{array}$ \\
\hline $\begin{array}{l}\text { Three-phase } \\
\text { MV <100 kVA }\end{array}$ & 300 & $313-325$ & $\begin{array}{l}325- \\
352\end{array}$ & $338-381$ & $\begin{array}{l}352- \\
413\end{array}$ & $\begin{array}{l}367- \\
447\end{array}$ & $\begin{array}{l}381- \\
484\end{array}$ & $\begin{array}{l}407- \\
549\end{array}$ \\
\hline $\begin{array}{l}\text { Three-phase } \\
\text { MV }>100 \mathrm{kVA}\end{array}$ & 7,820 & $\begin{array}{l}8,138- \\
8,466\end{array}$ & $\begin{array}{l}8,469- \\
9,166\end{array}$ & $\begin{array}{l}8,813- \\
9,923\end{array}$ & $\begin{array}{l}9,171- \\
10,742\end{array}$ & $\begin{array}{l}9,544- \\
11,630\end{array}$ & $\begin{array}{l}9,932- \\
12,590\end{array}$ & $\begin{array}{l}10,586- \\
14,295\end{array}$ \\
\hline
\end{tabular}

Note: $\mathrm{LV}=$ low-voltage; $\mathrm{MV}=$ medium-voltage. 
annual shipments of liquid-immersed and dry-type transformers for the same period are shown in Figs. 4.3 and 4.4, respectively. As discussed earlier, annual growth rates are assumed to be constant and the same (i.e., $0.8 \%$ or $1.6 \%$ ) for both types of transformers. Total annual shipments are estimated to increase to $92,251-124,576$ MVA for liquid-immersed transformers and to 28,000-37,811 MVA for dry-type transformers, respectively, by the year 2033. It is estimated that the largest share of the liquid-immersed market (single-phase transformers $<100 \mathrm{kVA}$ ) will grow from 39,095 MVA in 1995 to between 52,920 and 71,463 MVA in 2033. In the largest three-phase liquid-immersed market (transformers $>500 \mathrm{kVA}$ ), annual shipments will grow to between 18,232 and 24,620 MVA by the year 2033. Similarly, the three-phase medium-voltage transformer ( $>100 \mathrm{KVA}$ ) will dominate the dry-type market, which is expected to grow from 7,820 MVA in 1995 to between 10,586 and 14,295 MVA in 2033. Annual shipments of 1,222 to 1,651 MVA are forecast for the single-phase low-voltage (<100 kVA) dry-type market by the year 2033 .

The assumed growth rates of $0.8 \%$ and $1.6 \%$ (under the two scenarios) for both liquid-immersed and dry-type transformers are conservative compared with the historical growth rates and the projections available in the literature, as shown in Table 4.7.

\subsection{BASE CASE ENERGY ANALYSIS}

The energy analysis for the base case involves the determination of the energy delivered by new transformers and the losses attributed to the sales of these transformers at existing levels of energy efficiency. The energy analysis model described in Chapter 3 was used along with the assumptions

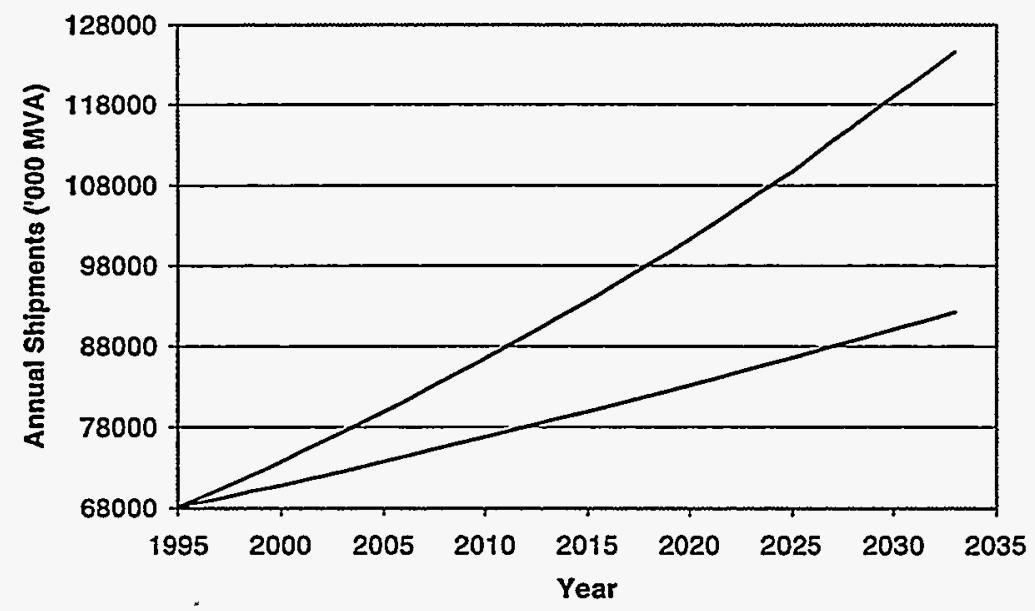

Fig. 4.3. Estimated annual shipments of liquid-immersed transformers, 1995-2033. 


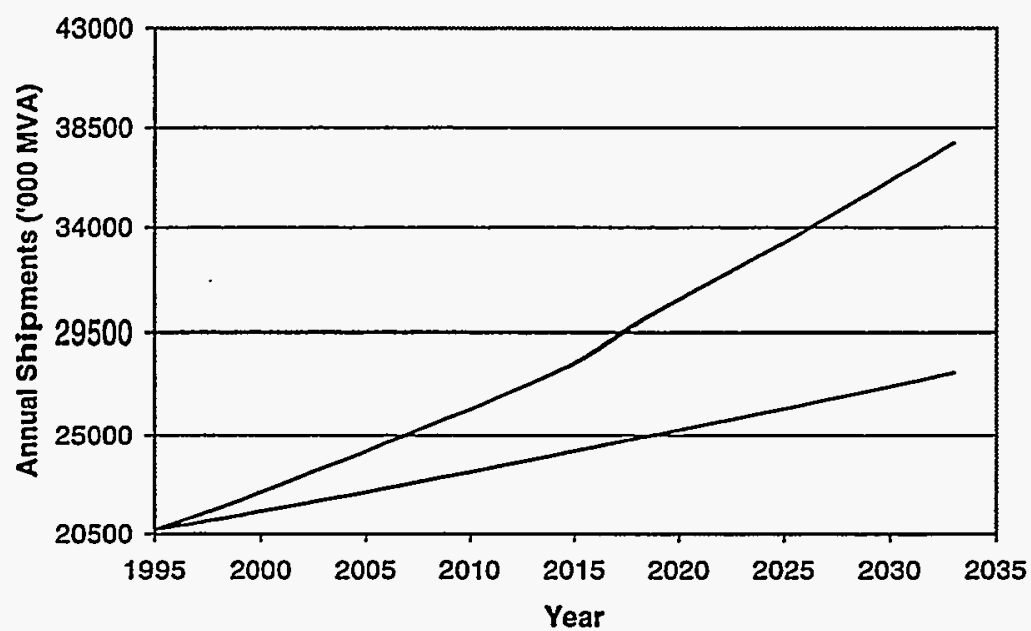

Fig. 4.4. Estimated annual shipments of dry-type transformers, 1995-2033.

Table 4.7. Historical and projected annual growth rates of distribution transformer shipments

\begin{tabular}{|c|c|c|c|c|}
\hline Transformer type & Period & $\begin{array}{l}\text { Basis for calculating/ } \\
\text { projecting growth rate }\end{array}$ & $\begin{array}{l}\text { Compound } \\
\text { annual growth } \\
\text { rate (\%) }\end{array}$ & Source \\
\hline $\begin{array}{l}\text { All transformers, except } \\
\text { electronic (SIC 3612) }\end{array}$ & 1987-1994 & Constant $\$$ value & 1.9 & DOC 1996 \\
\hline $\begin{array}{l}\text { Power and distribution } \\
\text { (SIC 36122) }\end{array}$ & 1987-1992 & Constant $\$$ value & 2.3 & DOC 1994a, 1990 \\
\hline Distribution $^{a}$ & $1995-2000$ & Units & $2.1-3.1$ & $\begin{array}{l}\text { Business Trend } \\
\text { Analysts } 1995\end{array}$ \\
\hline Utility & 1985-1995 & Constant $\$$ value & 2.8 & Freedonia Group 1996 \\
\hline Utility & 1995-2005 & Constant $\$$ value & 1.8 & Freedonia Group 1996 \\
\hline Non-utility & 1985-1995 & Constant $\$$ value & 2.4 & Freedonia Group 1996 \\
\hline Non-utility & 1995-2005 & Constant $\$$ value & 4.5 & Freedonia Group 1996 \\
\hline
\end{tabular}

${ }^{a}$ Including indoor and general-purpose commercial, institutional, and industrial transformers. 
and parameters listed in Tables 4.1 through 4.5 to calculate the annual losses and energy delivered. The calculation of losses was done for sales in 1995 , then escalated by a $1.2 \%$ annual growth rate to 2004 , which is assumed to be the first year that efficiency standards would be in effect. Besides the annual volume of new sales, the base case can be characterized by the annual energy losses associated with the new sales and the average energy efficiency of new sales. The determination of the case losses is related to both the transformer efficiency characteristics and the characteristic load. The energy losses for each size of transformer defined in Tables 4.1 through 4.3 have been calculated and tabulated only by major category of transformer, as shown in Table 4.8 .

The total losses for the base case are calculated to be 3619 million $\mathrm{kWh}$ of electrical energy and 0.0401 quads of primary energy in the year 2004. The total electric energy supplied by the transformers is 222,629 million $\mathrm{kWh}$, and the base case efficiency is $98.4 \%$. A breakdown of the annual losses by major transformer type and application is presented in Table 4.8. Figure 4.5 shows the cumulative base case losses over the 30-year period starting with year 2004 for two annual growth rates, $0.8 \%$ and $1.6 \%$. The rate of sales growth makes relatively little difference in the cumulative energy losses.

Table 4.8. Estimated losses by type of transformer for annual sales starting in 2004 (millions of $\mathbf{k W h}$ )

\begin{tabular}{|c|c|c|c|c|c|}
\hline & \multicolumn{2}{|c|}{ Non-utility } & \multicolumn{2}{|c|}{ Utility } & \multirow{2}{*}{$\begin{array}{l}\text { Totals by } \\
\text { type }\end{array}$} \\
\hline & Nonevaluated & Evaluated & Nonevaluated & Evaluated & \\
\hline \multicolumn{6}{|c|}{ a Transformertype } \\
\hline $\begin{array}{l}\text { Liquid-immersed, } \\
\text { medium-voltage, } \\
\text { single-phase }\end{array}$ & 44 & 3 & 258 & 1040 & 1345 \\
\hline $\begin{array}{l}\text { Liquid-immersed, } \\
\text { medium-voltage, } \\
\text { three-phase }\end{array}$ & 177 & 38 & 61 & 326 & 601 \\
\hline $\begin{array}{l}\text { Dry-type, low-voltage, } \\
\text { single-phase }\end{array}$ & 88 & 0 & 0 & 0 & 88 \\
\hline $\begin{array}{l}\text { Dry-type, low-voltage, } \\
\text { three-phase }\end{array}$ & 1041 & 0 & 0 & 0 & 1041 \\
\hline $\begin{array}{l}\text { Dry-type, medium-voltage, } \\
\text { single-phase }\end{array}$ & 25 & 0 & 0 & 0 & 25 \\
\hline $\begin{array}{l}\text { Dry-type, medium-voltage, } \\
\text { three-phase }\end{array}$ & 519 & 0 & 0 & 0 & 519 \\
\hline Totals & 1893 & 41 & 319 & 1366 & 3619 \\
\hline 4 & & mary ener & 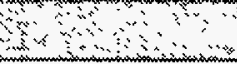 & 3 & \\
\hline First-year losses (quads) & 0.0210 & 0.0005 & 0.0035 & 0.0151 & 0.0401 \\
\hline $\begin{array}{l}\text { Cumulative losses, } \\
30 \text { years (quads) }\end{array}$ & 11.0 & 0.2 & 1.8 & 7.9 & 21.0 \\
\hline
\end{tabular}

${ }^{a}$ Assuming a $1.2 \%$ growth rate for the transformer market. 


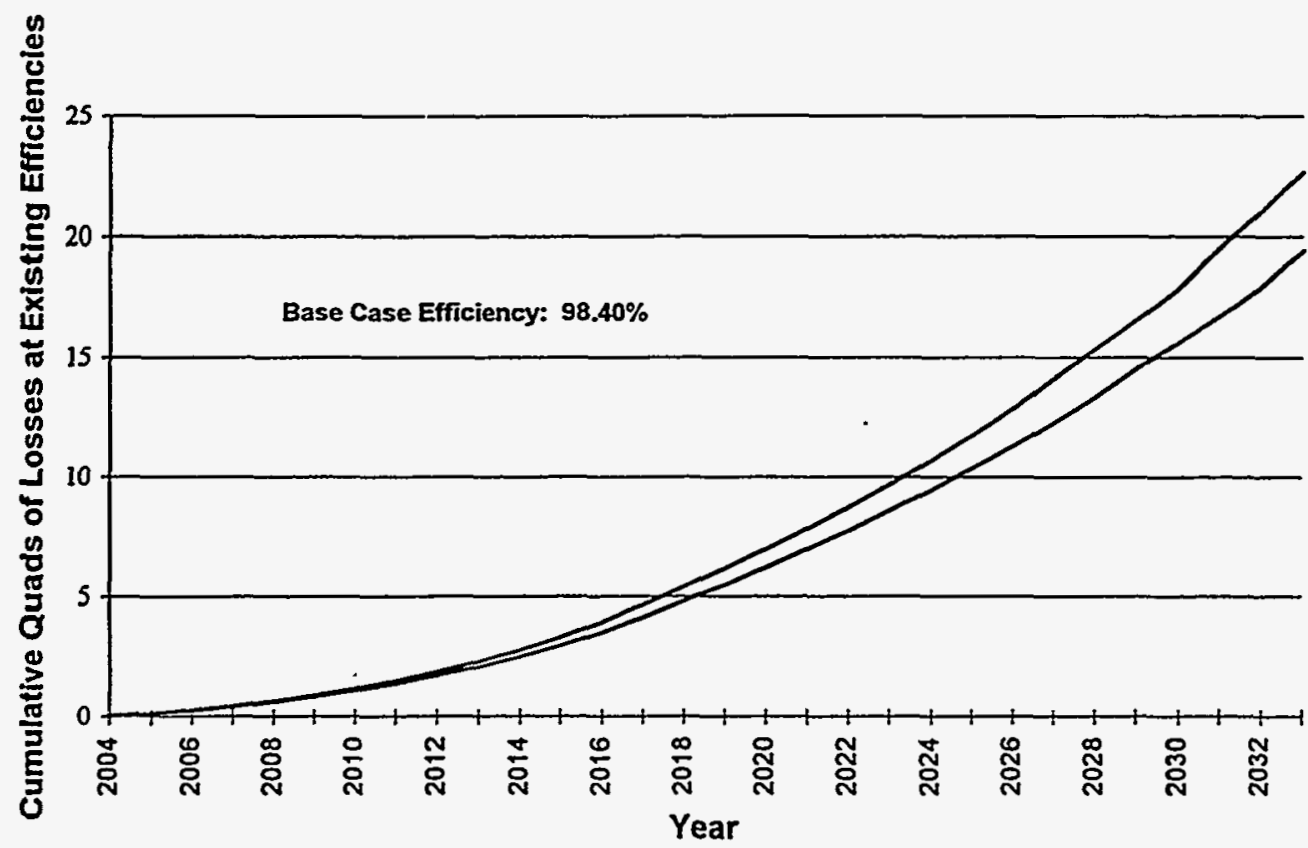

Fig. 4.5. Cumulative base case losses for new distribution transformer sales over 30 years, assuming 0.8 to $1.6 \%$ annual growth. 


\section{THE NEMA ENERGY CONSERVATION STANDARD}

\subsection{BACKGROUND}

The 1996 NEMA standard, NEMA TP 1-1996 (NEMA 1996), is based on a short payback period to recover the additional cost of more efficient transformers from the money saved by the reduced energy consumption. This standard provides a description of the total owning cost (TOC) methodology for distribution transformers and tables of minimum transformer efficiencies for liquidimmersed and dry-type transformers for a range of transformer sizes. The minimum transformer efficiencies are shown in Tables 5.1-5.3. Medium-voltage liquid-immersed and dry-type transformers must meet or exceed the specified efficiencies at a per unit load of 0.5 . Low-voltage dry-type transformers must meet or exceed the specified efficiencies at a per unit load of 0.35 . The sensitivity of the NEMA load specifications to energy savings is presented in this section.

Table 5.1. TP-1 minimum efficiencies and transformer design losses assumed for liquid-immersed transformers

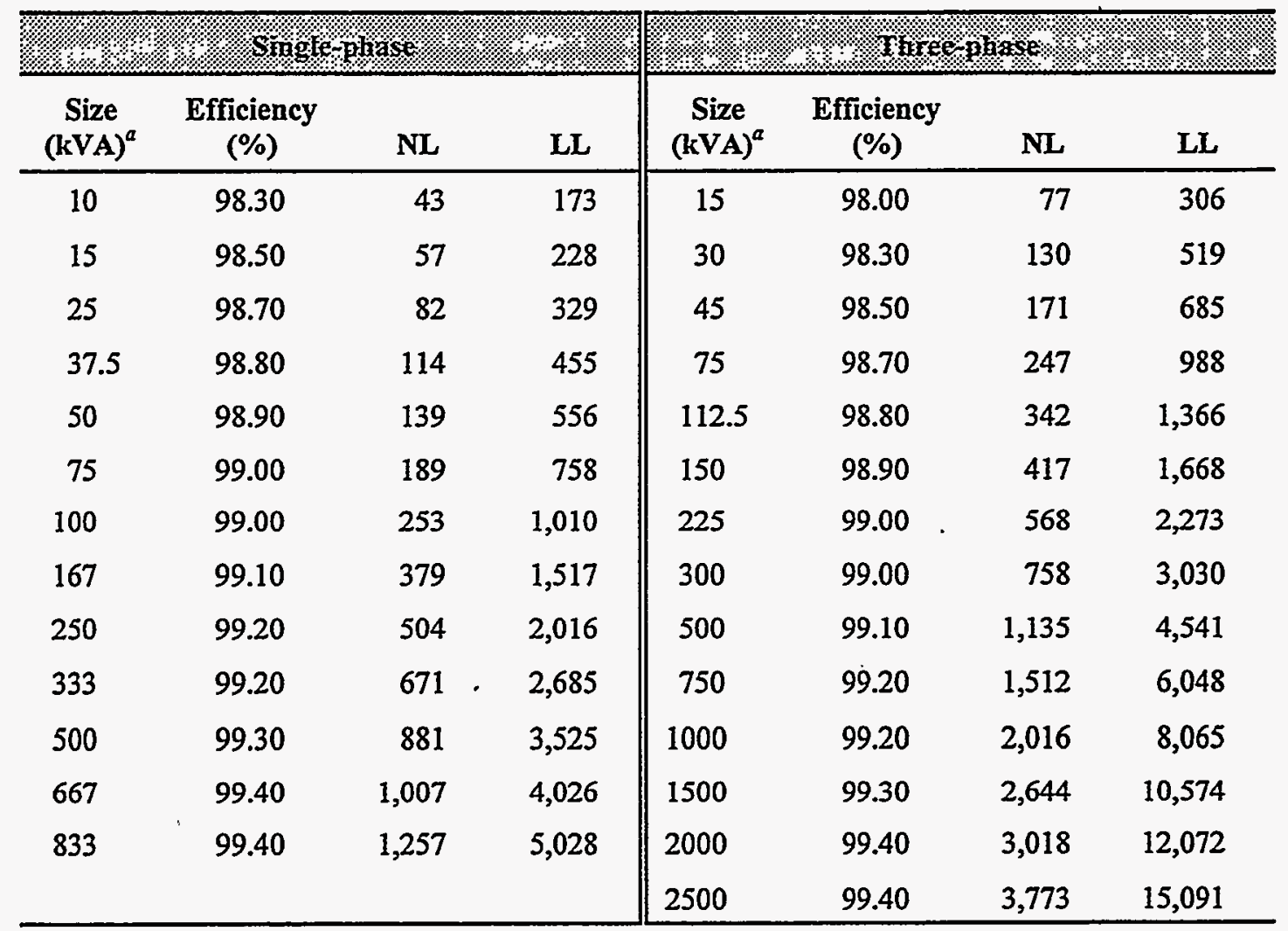

Note: The minimum efficiencies are for an effective per unit load of 0.5 for medium-voltage units. Medium-voltage units include 5-, 15-, 25-, and 35-kV classes. Average winding temperature is $85^{\circ} \mathrm{C}$.

$\mathrm{NL}=$ no-load losses in watts; $\mathrm{LL}=$ full-load losses in watts. Values for NL and LL have been calculated using Eqs. (3.4) and (3.5), respectively.

${ }^{a}$ Nameplate capacity of the transformer in kilovolt-amperes. 
Table 5.2. TP-1 minimum efficiencies and transformer design losses assumed for dry-type low-voltage transformers

\begin{tabular}{|c|c|c|c|c|c|c|c|}
\hline \multicolumn{4}{|c|}{ single-phase } & \multicolumn{4}{|c|}{10 Theetphase } \\
\hline $\begin{array}{c}\text { Size } \\
(\mathrm{kVA})^{a}\end{array}$ & $\begin{array}{c}\text { Efficiency } \\
(\%)\end{array}$ & NL & $\mathbf{L L}$ & $\begin{array}{c}\text { Size } \\
(\mathbf{k V A})^{a}\end{array}$ & $\begin{array}{c}\text { Efficiency } \\
(\%)\end{array}$ & NL & LL \\
\hline 15 & 97.70 & 62 & 619 & 15 & 97.00 & 81 & 813 \\
\hline 25 & 98.00 & 89 & 894 & 30 & 97.50 & 135 & 1,348 \\
\hline 37.5 & 98.20 & 120 & 1,205 & 45 & 97.70 & 185 & 1,856 \\
\hline 50 & 98.30 & 151 & 1,515 & 75 & 98.00 & 268 & 2,682 \\
\hline 75 & 98.50 & 200 & 2,001 & 112.5 & 98.20 & 361 & 3,614 \\
\hline 100 & 98.60 & 248 & 2,488 & 150 & 98.30 & 454 & 4,546 \\
\hline 167 & 98.70 & 385 & 3,855 & 225 & 98.50 & 600 & 6,004 \\
\hline 250 & 98.80 & 531 & 5,321 & 300 & 98.60 & 745 & 7,465 \\
\hline \multirow[t]{3}{*}{333} & 98.90 & 648 & 6,491 & 500 & 98.70 & 1,152 & 11,541 \\
\hline & & & & 750 & 98.80 & 1,594 & 15,963 \\
\hline & & & & 1000 & 98.90 & 1,946 & 19,491 \\
\hline
\end{tabular}

Note: The minimum efficiencies are for an effective per unit load of 0.35 for low-voltage units and 0.5 for medium-voltage units. Medium-voltage units include 5-, 15-, 25-, and 35-kV classes. Average winding temperature is $85^{\circ} \mathrm{C}$. For dry-type units, average winding temperature is $75^{\circ} \mathrm{C}$.

$\mathrm{NL}=$ no-load losses in watts; $\mathrm{LL}=$ full-load losses in watts.

${ }^{a}$ Nameplate capacity of the transformer in kilovolt-amperes.

\subsection{THE POTENTIAL ENERGY SAVINGS}

Data on transformer designs that manufacturers would use to meet the TP-1 standard was obtained through a NEMA survey of NEMA transformer manufacturers and an ORNL survey of non-NEMA transformer manufacturers. The design information collected by the surveys included core losses and full-load losses for both nonevaluated and TP-1 transformers, as well as the added price for TP-1 units. One problem with the surveys was that relatively few firms participated. A review of the reported designs of existing transformers and the projected designs to meet the TP- 1 efficiency standard suggested that averaging the design losses that were reported in the surveys would not yield a good representation of designs if a standard were imposed. On average, there were fewer than three responses per transformer category, and there were significant differences within many of the response categories. Even for the common 25-kVA liquid-immersed transformer category there were only six responses to the survey. Thus, if we were to utilize the six data points for the nonevaluated $25-\mathrm{kVA}$ transformers, the true mean with a $95 \%$ confidence interval would be $\pm 0.13 \%$ from the (sample) mean efficiency, which represents $15 \%$ of the losses. The uncertainty band for most other transformer categories would tend to be even wider because of fewer data points. For this analysis, losses for the TP-1 standard have been calculated as described in Chapter 3. The losses assumed for the base case are described in Chapter 4. 
Table 5.3. TP-1 minimum efficiencies and transformer design losses assumed for dry-type medium-voltage transformers

\begin{tabular}{|c|c|c|c|c|c|c|c|}
\hline \multicolumn{4}{|c|}{ ofingle phase } & \multicolumn{4}{|c|}{ SThéphose } \\
\hline $\begin{array}{c}\text { Size } \\
(\mathrm{kVA})^{a}\end{array}$ & $\begin{array}{c}\text { Efficiency } \\
(\%)\end{array}$ & NL & LL & $\begin{array}{c}\text { Size } \\
(\mathrm{kVA})^{a}\end{array}$ & $\begin{array}{c}\text { Efficiency } \\
(\%)\end{array}$ & NL & $\mathbf{L L}$ \\
\hline 15 & 97.60 & 92 & 452 & 15 & 96.80 & 124 & 608 \\
\hline 25 & 97.90 & 134 & 658 & 30 & 97.30 & 208 & 1,021 \\
\hline 37.5 & 98.10 & 182 & 891 & 45 & 97.60 & 277 & 1,357 \\
\hline 50 & 98.20 & 229 & 1,124 & 75 & 97.90 & 402 & 1,973 \\
\hline 75 & 98.40 & 305 & 1,496 & 112.5 & 98.10 & 545 & 2,673 \\
\hline 100 & 98.50 & 381 & 1,868 & 150 & 98.20 & 687 & 3,373 \\
\hline 167 & 98.70 & $\dot{5} 50$ & 2,698 & 225 & 98.40 & 915 & 4,488 \\
\hline 250 & 98.80 & 759 & 3,725 & 300 & 98.50 & 1,142 & 5,604 \\
\hline 333 & 98.90 & 926 & 4,543 & 500 & 98.70 & 1,646 & 8,079 \\
\hline 500 & 99.00 & 1,263 & 6,195 & 750 & 98.80 & 2,277 & 11,174 \\
\hline 667 & 99.00 & 1,684 & 8,265 & 1000 & 98.90 & 2,781 & 13,644 \\
\hline \multirow[t]{3}{*}{833} & 99.10 & 1,891 & 9,280 & 1500 & 99.00 & 3,788 & 18,586 \\
\hline & & & & 2000 & 99.00 & 5,051 & 24,782 \\
\hline & & & & 2500 & 99.10 & 5,676 & 27,851 \\
\hline
\end{tabular}

Note: The minimum efficiencies are for an effective per unit load of 0.35 for low-voltage units and 0.5 for medium-voltage units. Medium-voltage units include 5-, 15-, 25-, and 35-kV classes. Average winding temperature is $85^{\circ} \mathrm{C}$. For dry-type units, average winding temperature is $75^{\circ} \mathrm{C}$.

$\mathrm{NL}=$ no-load losses in watts; $\mathrm{LL}=$ full-load losses in watts.

${ }^{a}$ Nameplate capacity of the transformer in kilovolt-amperes.

Tables 5.1 through 5.3 present the minimum efficiency levels for the TP-1 standard and the core and full-load design losses assumed to meet the standard as determined by Eqs. (3.4) and (3.5). The potential energy savings can be calculated as the difference between the base case energy losses (see Chapter 4) and the losses resulting from transformers sold under the TP-1 standard. The model used for making these calculations is described in Chapter 3.

The estimated savings are presented in Table 5.4 in terms of the annual kilowatt-hours per kilovoltampere and the total savings in kilowatt-hours for 1995 and 2004. The 1995 savings are presented because this is the year upon which transformer sales data were based; 2004 is currently projected to be the first year of the transformer efficiency standards. Although the same TP-1 standard would apply to utilities and non-utilities, the losses per kilovolt-ampere are different because different loads have been assumed for utility versus non-utility applications. The total annual savings in 2004 would be 434 million $\mathrm{kWh}$. The total annual savings is calculated as the annual savings per kilovolt-ampere times the annual sales for the given year. The annual savings in 2004 reflects the growth in sales, assumed to be at an annual rate of $1.2 \%$. 
Table 5.4. Estimated annual rate of savings of electric energy per kilovoltampere and annual savings by transformer type in 1995 and 2004

\begin{tabular}{|c|c|c|c|c|}
\hline \multirow{2}{*}{$\begin{array}{c}\text { Size } \\
(\mathbf{k V A})^{a}\end{array}$} & \multirow{2}{*}{$\begin{array}{c}\text { Annual } \\
\text { savings } \\
(\mathbf{k W h} / \mathbf{k V A})\end{array}$} & \multirow{2}{*}{$\begin{array}{l}1995 \text { sales } \\
\text { (MVA) }\end{array}$} & \multicolumn{2}{|c|}{ Annual savings (GWh) } \\
\hline & & & 1995 & 2004 \\
\hline \multicolumn{5}{|c|}{ S } \\
\hline 10 & 0.69 & 2,341 & 1.63 & 1.81 \\
\hline $15^{b}$ & $(0.14)$ & 4,962 & $(0.69)$ & $(0.76)$ \\
\hline 25 & 0.54 & 11,474 & 6.24 & 6.95 \\
\hline 37.5 & 0.14 & 3,104 & 0.45 & 0.50 \\
\hline 50 & 0.30 & 10,556 & 3.19 & 3.55 \\
\hline 75 & 0.55 & 3,531 & 1.94 & 2.16 \\
\hline 100 & 0.03 & 3,126 & 0.11 & 0.12 \\
\hline 167 & 0.41 & 3,355 & 1.37 & 1.53 \\
\hline 250 & 0.75 & 809 & 0.61 & 0.68 \\
\hline 333 & 2.69 & 955 & 2.57 & 2.86 \\
\hline 500 & 3.43 & 1,352 & 4.64 & 5.17 \\
\hline 667 & 3.86 & 6 & 0.02 & 0.03 \\
\hline 833 & 3.25 & 15 & 0.05 & 0.05 \\
\hline Total & & 45,586 & 22.1 & 24.6 \\
\hline 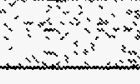 & Trquid & d mediumen & three- & 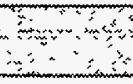 \\
\hline 15 & 1.78 & 45 & 0.08 & 0.09 \\
\hline 30 & 1.41 & 91 & 0.13 & 0.14 \\
\hline 45 & 1.88 & 182 & 0.34 & 0.38 \\
\hline 75 & 1.79 & 455 & 0.81 & 0.91 \\
\hline 112.5 & 1.64 & 273 & 0.45 & 0.50 \\
\hline 150 & 0.62 & 1,182 & 0.73 & 0.81 \\
\hline 225 & 1.15 & 910 & 1.04 & 1.16 \\
\hline 300 & 0.85 & 2,638 & 2.25 & 2.50 \\
\hline 500 & 0.48 & 3,320 & 1.58 & 1.76 \\
\hline 750 & 1.36 & 2,694 & 3.67 & 4.08 \\
\hline
\end{tabular}


Table 5.4 (continued)

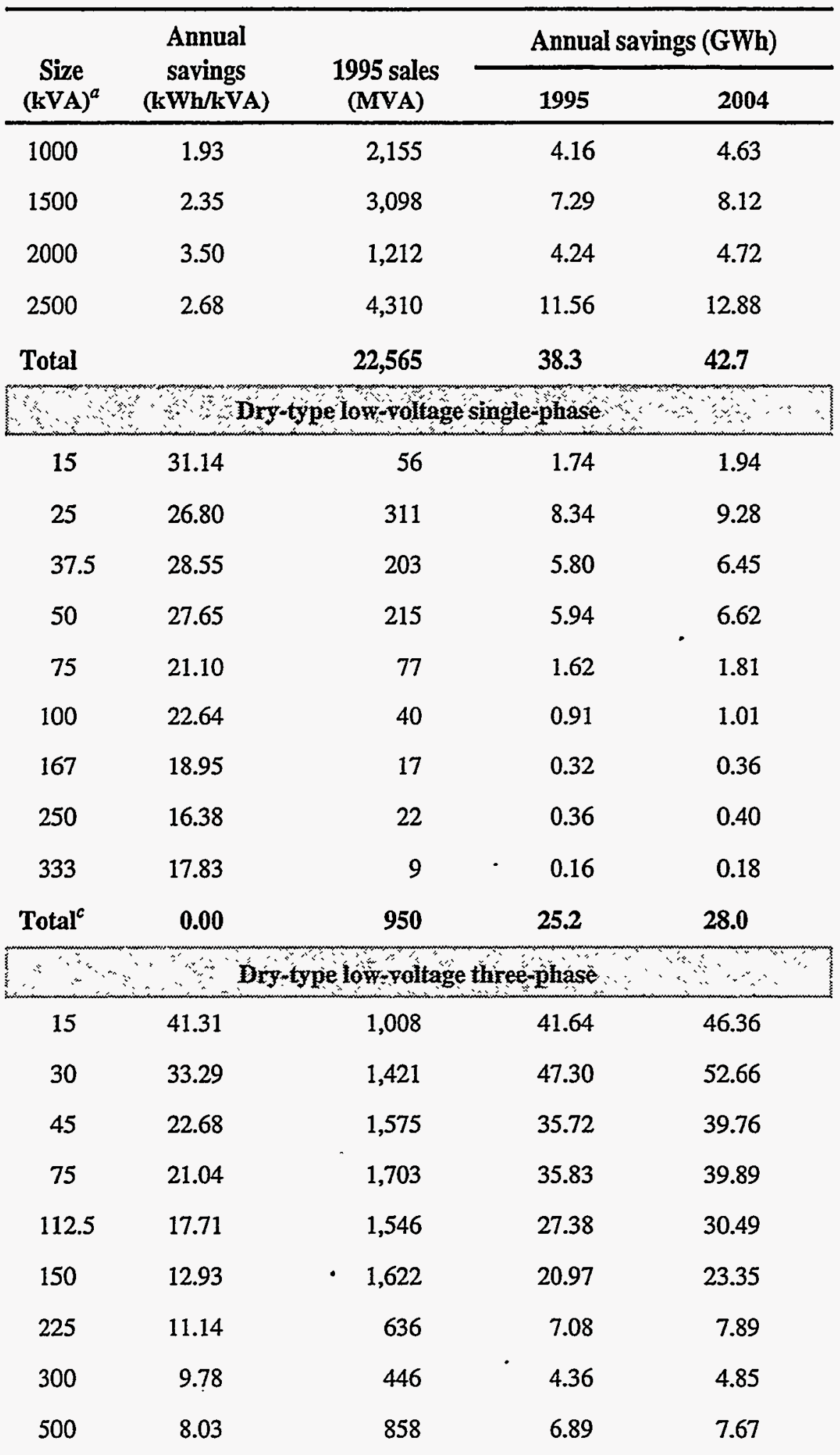


Table 5.4 (continued)

\begin{tabular}{|c|c|c|c|c|}
\hline \multirow{2}{*}{$\begin{array}{c}\text { Size } \\
(\mathrm{kVA})^{a}\end{array}$} & \multirow{2}{*}{$\begin{array}{c}\text { Annual } \\
\text { savings } \\
(\mathrm{kWh} / \mathrm{kVA})\end{array}$} & \multirow{2}{*}{$\begin{array}{l}1995 \text { sales } \\
\text { (MVA) }\end{array}$} & \multicolumn{2}{|c|}{ Annual savings (GWh) } \\
\hline & & & 1995 & 2004 \\
\hline 750 & 5.63 & 491 & 2.76 & 3.08 \\
\hline 1000 & 5.22 & 77 & 0.40 & 0.45 \\
\hline Total & & 11,383 & 230.3 & 256.4 \\
\hline \multicolumn{5}{|c|}{ W } \\
\hline 15 & 123.12 & 3 & 0.37 & 0.41 \\
\hline 25 & 91.07 & 5 & 0.46 & 0.51 \\
\hline 37.5 & 83.26 & 17 & 1.42 & 1.58 \\
\hline 50 & 72.21 & 15 & 1.08 & 1.21 \\
\hline 75 & 57.48 & .9 & 0.52 & 0.58 \\
\hline 100 & 52.34 & 14 & 0.73 & 0.82 \\
\hline 167 & 45.82 & 38 & 1.74 & 1.94 \\
\hline 250 & 38.56 & 31 & 1.20 & 1.33 \\
\hline 333 & 36.61 & 14 & 0.51 & 0.57 \\
\hline 500 & 30.71 & 52 & 1.60 & 1.78 \\
\hline 667 & 23.27 & 6 & 0.14 & 0.16 \\
\hline 833 & 23.22 & 4 & 0.09 & 0.10 \\
\hline Total & & 208 & 9.9 & 11.0 \\
\hline \multicolumn{5}{|c|}{ Worype medium voltage three phase } \\
\hline 15 & 145.51 & 12 & 2.04 & 2.27 \\
\hline 30 & 101.54 & 26 & 2.64 & 2.94 \\
\hline 45 & 74.28 & 119 & 8.84 & 9.84 \\
\hline 75 & 63.49 & 141 & 8.95 & 9.97 \\
\hline 112.5 & 35.24 & 82 & 2.89 & 3.22 \\
\hline 150 & 34.45 & 116 & 4.00 & 4.45 \\
\hline 225 & 22.47 & 126 & 2.83 & 3.15 \\
\hline 300 & 18.35 & 184 & 3.38 & 3.76 \\
\hline
\end{tabular}


Table 5.4 (continued)

\begin{tabular}{ccrcc}
\hline \multirow{2}{*}{$\begin{array}{c}\text { Size } \\
(\mathrm{kVA})^{a}\end{array}$} & $\begin{array}{c}\text { Annual } \\
\text { savings } \\
(\mathrm{kWh} / \mathrm{kVA})\end{array}$ & $\begin{array}{c}\text { 1995 sales } \\
(\mathbf{M V A})\end{array}$ & \multicolumn{2}{c}{ Annual savings (GWh) } \\
\cline { 5 - 5 } 500 & 14.68 & 274 & 4.02 & 4.48 \\
750 & 8.28 & 1,050 & 8.69 & 9.68 \\
1000 & 7.99 & 1,240 & 9.91 & 11.03 \\
1500 & 1.87 & 2,431 & 4.54 & 5.06 \\
$2000^{d}$ & 0.00 & 969 & 0.00 & 0.00 \\
2500 & 0.62 & 1,348 & 0.84 & 0.94 \\
Total & & $\mathbf{8 , 1 1 8}$ & $\mathbf{6 3 . 6}$ & $\mathbf{7 0 . 0}$ \\
\hline
\end{tabular}

${ }^{a}$ Nameplate capacity of the transformer in kilovolt-amperes.

${ }^{b}$ For some transformers, meeting the TP- 1 efficiency at the $50 \%$ load specified by the standard would tend to reduce their efficiency at the actual operating load of about $25 \%$.

${ }^{c}$ The TP-1 Standard does not apply to dry-type low-voltage single phase transformers above $333 \mathrm{kVA}$ although these transformers are included in Table 4.5.

${ }^{d}$ The TP-1 efficiency is below the base case efficiency for this size - transformer.

The annual savings for 2004 and the cumulative savings for the first 30 years of the standard are presented in Table 5.5 by major transformer classifications. The annual savings are summed for the different major categories from the savings in Table 5.4. The cumulative savings are the annual savings in the first year of the standard, 2004, times a cumulative factor of 524, which accounts for the accumulation of energy from transformers that would be covered by the policy over a 30-year span. The factor 524 is for a $1.2 \%$ annual growth in sales. If annual sales grew at $1.6 \%$, the cumulative factor would be about 546 , or $4 \%$ higher; if sales grew at $0.8 \%$ annually, the factor would be 503 , or $4 \%$ lower. The overall efficiency for the TP- 1 case is $98.59 \%$, compared to the base case efficiency of $98.40 \%$. This is a reduction of $12.0 \%$ of base case losses.

There are no savings associated with the dry-type medium-voltage three-phase 2000-kVA transformers because the efficiency for the TP-1 standard is lower than that derived from the base case losses (see Tables 5.1 and 4.3).

Table 5.4 indicates that, in general, the smaller transformers have a higher rate of potential savings. As a group, dry-type, low-voltage, three-phase transformers, often called "lighting transformers," . have the most potential for energy savings if the TP-1 standard is implemented. The efficiency standards for this type of transformer combine potentially high energy savings per kilovolt-ampere with a significant part of the total annual sales volume. 
Table 5.5. Transformer energy savings for NEMA Standard TP-1 for major types of transformers

\begin{tabular}{lcc}
\hline \multicolumn{1}{c}{ Transformer type } & $\begin{array}{c}\text { Savings in 2004 } \\
\text { (GWh) }\end{array}$ & $\begin{array}{c}\text { Cumulative savings }^{b} \\
\text { (quads) }\end{array}$ \\
\hline Liquid-immersed medium-voltage single-phase & 25 & 0.14 \\
Liquid-immersed medium voltage three-phase & 43 & 0.25 \\
Dry-type low-voltage single-phase & 28 & 0.16 \\
Dry-type low-voltage three-phase & 256 & 1.49 \\
Dry-type medium-voltage single-phase & 11 & 0.06 \\
Dry-type medium-voltage three-phase & 71 & 0.41 \\
All types & 434 & 2.51 \\
\hline
\end{tabular}

${ }^{a}$ Electricity savings for first year of TP-1 standard.

${ }^{b}$ Cumulative primary energy savings for the period 2004 through 2033.

\subsection{LOAD SENSITIVITY ANALYSIS}

The efficiency of a transformer is uniquely determined by its no-load and full-load losses and operating load. Setting a minimum efficiency standard includes specifying the load at which the transformer must meet the efficiency standard. Manufacturers will tend to design transformers that can meet the standard at the lowest cost. The costs related to the transformer's core (the determinant of no-load losses) and coils (the determinant of load losses) will be adjusted according to the specified load at which the standard must be met. The higher the specified load, the higher the design no-load losses and the lower the full-load losses. This tradeoff between the no-load and full-load losses could have a significant effect on the potential energy savings that result from a standard. If too high a load is specified, manufacturers will design transformers that overemphasize the importance of load losses relative to the actual load and underemphasize the importance of no-load losses.

This type of problem may well occur for medium-voltage liquid-immersed transformers under the TP-1 standard because it has specified a 50\% load. As noted in Chapter 2, utilities, which purchase about $90 \%$ of liquid-type transformer capacity, typically use these transformers at loads much lower than 50\%. The energy model described in Chapter 3 indicates that adjustment of the specified load to $36 \%$ would result in $74 \%$ more savings for liquid transformers than would occur at the $50 \%$ load specified in the TP-1 standard. This estimate was made by simultaneously adjusting both the specified load for the standard and the transformer's design losses for maximum efficiency to $36 \%$. The total savings would be only about $11 \%$ higher because liquid transformers contribute only about $16 \%$ of total savings. This exercise demonstrates the importance of specifying the load for a standard as close as possible to the actual load. Given uncertainty about actual loads and the potentially large variation across different transformers, specifying the standard at a $40 \%$ load would be effective across a wide range of actual loads, as shown in Fig. 3.2. 


\subsection{PAYBACK ANALYSIS}

Although the TP-1 survey dáta were not used to calculate energy savings, these data were used to calculate the payback periods. These data are appropriate for a payback analysis since information on each transformer included price information that was reported by the same manufacturer, and the data are therefore internally consistent. Although the survey responses were used for the payback analysis, little confidence should be placed in results for any given transformer category because of low survey response. However, the overall results should be more dependable because all survey results have been combined into a weighted average.

The payback analysis is based on the differences between the nonevaluated and TP-1 transformer designs presented in Tables 5.6 through 5.8. The losses shown are the average losses for the unevaluated transformers reported in the TP-1 survey and the manufacturers' submitted design losses to meet the TP-1 standard. The average annual energy saved was calculated for each category; this figure was multiplied by 6.92 cents/kWh (EIA 1997), the average price of electricity for all sectors in 1996, to give an average annual value of electricity saved. The annual energy saved used the assumed operating loads (see Table 4.2 and the note to Table 4.3). The average incremental cost for the TP-1 transformers was divided by the average annual value of electricity saved, to calculate the simple payback period for each size of transformer.

The individual paybacks for each category (size and voltage) of transformer were then weighted by the percentage that the category represented in total annual energy saved as a result of the TP-1 standard. Liquid-immersed transformers were broken out into two separate categories to account for differences in the assumed loading for utilities and non-utilities. The differences in loading result in different payback periods. The overall weighted payback for all transformers is 2.76 years.

Table 5.9 adjusts the overall weighted payback by the ratio of the national average price of electricity (6.76 cents) to the average price of electricity reported for each individual state (see Table 5.9).

Fig. 5.1 graphically presents regional results of the payback analysis. The shortest payback times occur in areas where electricity prices are high; this includes California, Alaska, Hawaii, and most of the,Northeast. The longest payback times are in regions where electricity prices are low, such as the Pacific Northwest and several midwestern and southeastern states. Regional paybacks are inversely related to the regional cost of electricity. 
Table 5.6. Manufacturer survey data for liquid-immersed medium-voltage distribution transformers

\begin{tabular}{|c|c|c|c|c|c|c|}
\hline \multirow{2}{*}{$\begin{array}{c}\text { Size } \\
(\mathrm{kVA})^{a}\end{array}$} & \multicolumn{2}{|c|}{$\begin{array}{l}\text { Noneval. transformers } \\
\text { reported in survey }\end{array}$} & \multicolumn{2}{|c|}{$\begin{array}{l}\text { Submitted design losses } \\
\text { to meet TP-1 }\end{array}$} & \multirow{2}{*}{$\begin{array}{l}\text { Incremental } \\
\operatorname{cost}^{b}\end{array}$} & \multirow{2}{*}{$\begin{array}{c}\text { Payback } \\
\text { period } \\
\text { (years) }\end{array}$} \\
\hline & NL & $\mathbf{L L}$ & NL & $\mathbf{L L}$ & & \\
\hline \multicolumn{6}{|c|}{ 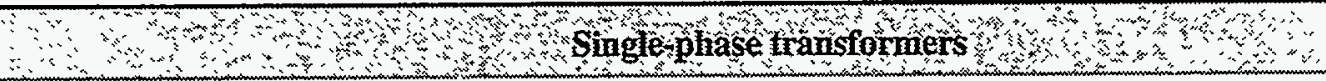 } & $\therefore$ \\
\hline 10 & 45.5 & 258.5 & 36.0 & 195.5 & $\$ 26$ & 3.2 \\
\hline 15 & 60.2 & 335.2 & 44.3 & 277.7 & 34 & 2.9 \\
\hline 25 & 81.2 & 515.5 & 67.2 & 378.8 & 50 & 3.7 \\
\hline 37.5 & 103.7 & 695.5 & 83.3 & 565.7 & 48 & 2.8 \\
\hline 50 & 146.2 & 735.8 & 111.3 & 639.8 & 75 & 3.0 \\
\hline 75 & 181.7 & $1,090.3$ & 160.3 & 853.3 & 81 & 3.7 \\
\hline 100 & 229.0 & $1,381.2$ & 198.5 & $1,162.0$ & 79 & 3.0 \\
\hline 167 & 319.7 & $2,175.5$ & 302.3 & $1,760.5$ & 108 & 5.0 \\
\hline 250 & 486.8 & $2,992.0$ & 334.3 & $2,615.5$ & 212 & 2.0 \\
\hline 333 & 587.5 & $4,042.5$ & 445.3 & $3,598.5$ & 195 & 1.7 \\
\hline 500 & 749.8 & $5,123.5$ & 567.5 & $4,762.8$ & 205 & 1.5 \\
\hline 667 & 945.0 & $6,378.0$ & 639.5 & $5,574.0$ & 802 & 3.1 \\
\hline 833 & $1,081.0$ & $8,024.5$ & 839.5 & $6,585.5$ & 909 & 3.3 \\
\hline \multicolumn{7}{|c|}{ 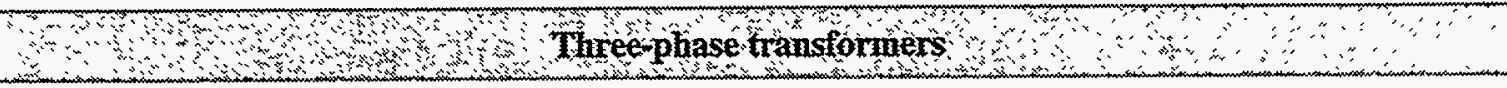 } \\
\hline 15 & 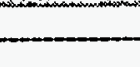 & 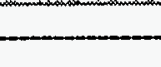 & ondisclosu & - & ב-ב & 2.7 \\
\hline 30 & & - & ondisclosu & & & 3.4 \\
\hline 45 & 204.0 & 921.5 & 183.5 & 612.0 & $\$ 154$ & 6.4 \\
\hline 75 & 325.0 & $1,431.0$ & 211.0 & $1,072.3$ & 295 & 3.6 \\
\hline 112.5 & 412.0 & $1,875.7$ & 329.0 & $1,373.3$ & 327 & 4.7 \\
\hline 150 & 555.0 & $2,455.5$ & 419.8 & $1,626.8$ & 495 & 4.3 \\
\hline 225 & 721.8 & $\cdot 3,597.8$ & 563.8 & $2,356.5$ & 706 & 4.8 \\
\hline 300 & 939.3 & $4,438.3$ & 742.8 & $2,770.3$ & 907 & 4.8 \\
\hline 500 & $1,323.3$ & $6,439.3$ & 970.5 & $4,623.8$ & 1,030 & 3.6 \\
\hline 750 & $1,602.5$ & $9,489.8$ & $1,363.5$ & $6,300.3$ & 1,338 & 3.4 \\
\hline 1000 & $1,986.0$ & $12,055.0$ & $1,506.3$ & $8,528.8$ & 1,585 & 2.3 \\
\hline 1500 & $2,711.0$ & $16,600.5$ & $2,389.8$ & $11,335.3$ & 2,261 & 2.7 \\
\hline
\end{tabular}

Note: Data was provided for the $95-\mathrm{kVA}$ basic insulation level (BIL) $15-\mathrm{kV}$ voltage transformer class.

$\mathrm{NL}=$ no-load losses in watts; $\mathrm{LL}=$ full-load losses in watts.

${ }^{a}$ Nameplate capacity of the transformer in kilovolt-amperes.

${ }^{b}$ The average price difference between the unit designed to meet TP-1 and a nonevaluated unit, with both $\mathrm{A}$ and $\mathrm{B}=\$ 0.00$.

"Nondisclosure" indicates that the only response received was proprietary. Although the response cannot be disclosed here, it is included in the overall calculation of payback. 
Table 5.7. Manufacturer survey data for dry-type low-voltage distribution transformers

\begin{tabular}{|c|c|c|c|c|c|c|}
\hline \multirow{2}{*}{$\begin{array}{c}\text { Size } \\
(\mathbf{k V A})^{a}\end{array}$} & \multicolumn{2}{|c|}{$\begin{array}{l}\text { Noneval. transformers } \\
\text { reported in survey }\end{array}$} & \multicolumn{2}{|c|}{$\begin{array}{c}\text { Submitted design losses } \\
\text { to meet TP-1 }\end{array}$} & \multirow{2}{*}{$\begin{array}{c}\text { Incremental } \\
\text { cost }^{b}\end{array}$} & \multirow{2}{*}{$\begin{array}{c}\text { Payback } \\
\text { period } \\
\text { (years) }\end{array}$} \\
\hline & NL & $\mathbf{L L}$ & NL & LL & & \\
\hline \multicolumn{7}{|c|}{ Singe phase transformers } \\
\hline 15 & 153.3 & 599.0 & 83.0 & 400.0 & $\$ 256$ & 4.7 \\
\hline 25 & 199.0 & 963.3 & 103.0 & 731.7 & 270 & 3.7 \\
\hline 37.5 & 258.3 & $1,368.3$ & 144.0 & 934.7 & 291 & 3.1 \\
\hline 50 & 335.0 & $1,828.7$ & 186.3 & $1,165.3$ & 302 & 2.3 \\
\hline 75 & 436.3 & $2,405.0$ & 235.7 & $1,593.3$ & 373 & 2.2 \\
\hline 100 & 516.0 & $2,993.3$ & 300.3 & $1,953.3$ & 417 & 2.2 \\
\hline 167 & 729.0 & $3,758.0$ & 483.3 & $2,834.0$ & 564 & 2.8 \\
\hline 250 & & & ondisclosu & & & 3.2 \\
\hline 333 & - & (2) & ondisclosu & & & 3.1 \\
\hline \multicolumn{7}{|c|}{ Theephase transformers } \\
\hline 15 & 211.0 & 653.0 & 99.3 & 600.3 & $\$ 314$ & 4.4 \\
\hline 30 & 277.3 & $1,347.0$ & 150.7 & $1,158.7$ & 296 & 3.4 \\
\hline 45 & 363.8 & $1,699.8$ & 202.0 & $1,432.8$ & 313 & 2.7 \\
\hline 75 & 485.0 & $2,512.5$ & 296.5 & $2,097.8$ & 476 & 3.4 \\
\hline 112.5 & 667.5 & $3,531.3$ & 397.0 & $2,873.0$ & 629 & 3.1 \\
\hline 150 & 783.0 & $5,091.3$ & 475.5 & $3,853.0$ & 789 & 3.0 \\
\hline 225 & $1,032.5$ & $6,565.8$ & 614.5 & $5,275.8$ & 879 & 2.7 \\
\hline 300 & $1,190.0$ & $7,998.8$ & 754.3 & $6,662.0$ & 909 & 2.6 \\
\hline 500 & $1,900.0$ & $9,612.5$ & $1,308.0$ & $8,629.5$ & 1,274 & 3.0 \\
\hline 750 & $2,625.0$ & $12,550.0$ & $1,844.0$ & $11,453.3$ & 1,587 & 2.9 \\
\hline 1000 & $3,351.0$ & $14,655.0$ & $2,348.8$ & $13,454.5$ & 1,986 & 2.9 \\
\hline
\end{tabular}

Note: Data was provided for the $95-\mathrm{kVA}$ basic insulation level (BIL) $15-\mathrm{kV}$ voltage transformer class. $\mathrm{NL}=$ no-load losses in watts; $\mathrm{LL}=$ full-load losses in watts.

${ }^{a}$ Nameplate capacity of the transformer in kilovolt-amperes.

${ }^{b}$ The average price difference between the unit designed to meet TP- 1 and a nonevaluated unit, with both $\mathrm{A}$ and $\mathrm{B}=\$ 0.00$.

"Nondisclosure" indicates that the only response received was proprietary. Although the response cannot be disclosed here, it is included in the overall calculation of payback. 
Table 5.8. Manufacturer survey data for dry-type medium-voltage three-phase distribution transformers

\begin{tabular}{|c|c|c|c|c|c|c|}
\hline \multirow{2}{*}{$\begin{array}{c}\text { Size } \\
(\mathrm{kVA})^{a}\end{array}$} & \multicolumn{2}{|c|}{$\begin{array}{l}\text { Noneval. transformers } \\
\text { reported in survey }\end{array}$} & \multicolumn{2}{|c|}{$\begin{array}{l}\text { Submitted design losses } \\
\text { to meet TP-1 }\end{array}$} & \multirow{2}{*}{$\begin{array}{c}\text { Incremental } \\
\cos ^{b}\end{array}$} & \multirow{2}{*}{$\begin{array}{c}\text { Payback } \\
\text { period } \\
\text { (years) }\end{array}$} \\
\hline & NL & LL & NL & $\mathbf{L L}$ & & \\
\hline 150 & & 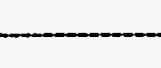 & ondisclost & & 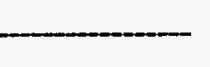 & 3.1 \\
\hline 225 & $1,488.3$ & $5,738.3$ & 952.3 & $4,055.0$ & 2,632 & 4.9 \\
\hline 300 & $1,796.7$ & $6,803.3$ & $1,284.0$ & $4,387.3$ & 2,529 & 4.2 \\
\hline 500 & $2,640.0$ & $9,319.3$ & $1,646.7$ & $7,265.0$ & 2,795 & 3.3 \\
\hline 750 & $3,450.0$ & $13,045.0$ & $2,299.0$ & $9,810.3$ & 3,176 & 2.9 \\
\hline 1,000 & $4,306.7$ & $16,416.7$ & $2,731.3$ & $12,353.7$ & 3,554 & 2.4 \\
\hline 1,500 & $5,823.3$ & $20,576.7$ & $3,631.7$ & $17,614.3$ & 3,865 & 2.3 \\
\hline 2,000 & $6,943.3$ & $25,031.7$ & $4,553.3$ & $22,863.7$ & 3,974 & 2.3 \\
\hline 2,500 & $8,376.7$ & $27,933.3$ & $5,620.0$ & $25,062.0$ & 4,467 & 2.2 \\
\hline
\end{tabular}

Note: No survey responses were received for single-phase transformers. Data was provided for the 95$\mathrm{kVA}$ basic insulation level (BIL) $15-\mathrm{kV}$ voltage class. $\mathrm{NL}=$ no-load losses in watts; $L L=$ full-load losses in watts.

${ }^{a}$ Nameplate capacity of the transformer in kilovolt-amperes.

${ }^{b}$ The average price difference between the unit designed to meet TP- 1 and a nonevaluated unit, with both $\mathrm{A}$ and $\mathrm{B}=\$ 0.00$.

"Nondisclosure" indicates that only one response was received. Although the response cannot be disclosed here, it is included in the overall calculation of payback. 
Table 5.9. Simple payback by state for TP-1 standard

\begin{tabular}{|c|c|c|c|c|c|}
\hline State & $\begin{array}{l}\text { Electricity for all } \\
\text { sectors in } 1996 \\
\text { (cents per kWh) }\end{array}$ & $\begin{array}{l}\text { Simple } \\
\text { payback } \\
\text { (years) }\end{array}$ & State & $\begin{array}{l}\text { Electricity for all } \\
\text { sectors in } 1996 \\
\text { (cents per kWh) }\end{array}$ & $\begin{array}{l}\text { Simple } \\
\text { payback } \\
\text { (years) }\end{array}$ \\
\hline Alabama & 5.3 & 3.4 & Montana & 5.4 & 3.4 \\
\hline Alaska & 10.1 & 1.8 & Nebraska & 4.7 & 3.9 \\
\hline Arizona & 6.9 & $\cdot 2.6$ & Nevada & 5.7 & 3.2 \\
\hline Arkansas & 5.9 & 3.1 & New Hampshire & 11.7 & 1.6 \\
\hline California & 9.1 & 2.0 & New Jersey & 10.2 & 1.8 \\
\hline Colorado & 6.1 & 3.0 & New Mexico & 6.6 & 2.8 \\
\hline Connecticut & 10.7 & 1.7 & New York & 10.6 & 1.7 \\
\hline Delaware & 6.7 & 2.7 & North Carolina & 6.5 & 2.8 \\
\hline District of Columbia & 5.8 & 3.1 & North Dakota & 5.1 & 3.6 \\
\hline Florida & 7.3 & 2.5 & Ohio & 6.0 & 3.0 \\
\hline Georgia & 6.0 & 3.0 & Oklahoma & 4.6 & 4.0 \\
\hline Hawaii & 11.5 & 1.6 & Oregon & 5.0 & 3.6 \\
\hline Idaho & 4.1 & 4.5 & Pennsylvania & 7.7 & 2.4 \\
\hline Illinois & 7.2 & 2.5 & Rhode Island & 10.0 & 1.8 \\
\hline Indiana & 5.2 & 3.5 & South Carolina & 5.7 & 3.2 \\
\hline Iowa & 5.4 & 3.4 & South Dakota & 6.0 & 3.0 \\
\hline Kansas & 6.2 & 2.9 & Tennessee & 5.2 & 3.5 \\
\hline Kentucky & 4.1 & 4.5 & Texas & 5.8 & 3.1 \\
\hline Louisiana & 5.8 & 3.1 & Utah & 5.3 & 3.4 \\
\hline Maine & 11.0 & 1.7 & Vermont & 11.2 & 1.6 \\
\hline Maryland & 6.2 & 2.9 & Virginia & 6.0 & 3.0 \\
\hline Massachusetts & 9.4 & 1.9 & Washington & 4.4 & 4.1 \\
\hline Michigan & 7.2 & 2.5 & West Virginia & 5.2 & 3.5 \\
\hline Minnesota & 5.4 & 3.4 & Wisconsin & 5.4 & 3.4 \\
\hline Mississippi & 5.7 & 3.2 & Wyoming & 4.3 & 4.2 \\
\hline Missouri & 5.3 & 3.4 & U.S. Average & 6.6 & 2.8 \\
\hline
\end{tabular}




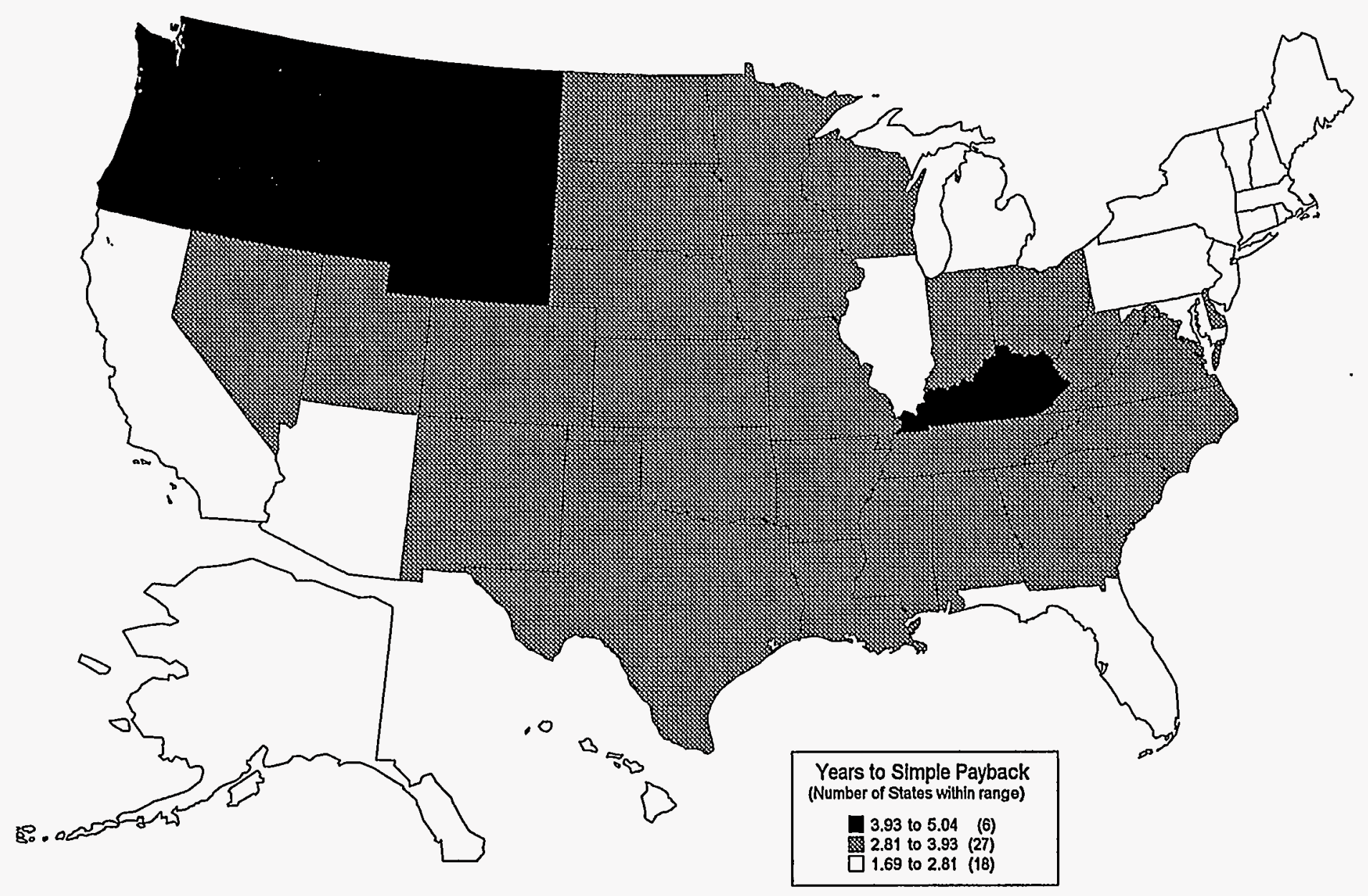

Fig. 5.1. Regional results of payback analysis. 


\section{THE DETERMINATION CASES}

In the report Determination Analysis of Energy Conservation Standards for Distribution Transformers, ORNL-6847 (Barnes et al. 1996), five alternative conservation cases for distribution transformers were analyzed. Four of these cases are summarized in Table 6.1. One other case, the two-year payback case, was considered in ORNL-6847. However, it has been omitted in this analysis, since it was originally.included in the previous study as a surrogate for the NEMA TP-1 standard.

The four cases in Table 6.1 have been reestimated with the disaggregated model to compute the savings. There is a difference from the earlier estimates of energy savings in the determination study because the assumptions in this report have been refined. The annual sales of dry-type transformers and the operating loads for liquid-immersed transformers have been revised and are significantly less than those utilized in the previous report (ORNL-6847). In addition to changes in these key parameters, the model used in this analysis is disaggregated into 73 different types of transformers, while the earlier report used only 12 types of transformers. The earlier report was based on a survey requesting proprietary information about manufacturer designs and prices for transformers that met total owning cost (TOC) criteria, which consisted of a lowest TOC for transformers of less than 50 $\mathrm{kVA}$ at a rate of $\$ 3.50$ per watt of no-load loss and $\$ 0.75$ per watt of load loss, and for transformers of $50 \mathrm{kVA}$ and more at $\$ 3.50$ per watt of no-load loss and $\$ 2.25$ per watt of load loss.

The determination study developed conservation cases based on the survey responses. For instance, the lowest TOC case utilized the reported design losses for the transformer from each of the 12 categories that had the lowest TOC. The losses from each of these 12 lowest TOC transformers were subtracted from the typical losses for the base case, and the results were used to estimate a rate of. savings per kilovolt-ampere for each of the 12 types of transformers. The 12 rates of savings were assigned to a fraction of total sales such that the fractions summed to $1.0(100 \%)$. Then the sum of the savings per kilovolt-ampere times the corresponding assigned fraction of sales times the projected total annual sales across the 12 types of transformers gave an estimate of total savings for the case.

The no-load and full-load losses and price information that was used to define the cases is proprietary and cannot be disclosed. However, the transformer efficiency at a specified load for the cases can be

Table 6.1. Summary of conservation cases analyzed in ORNL-6847

\begin{tabular}{llccc} 
& \multicolumn{1}{c}{$\begin{array}{c}\text { Transformers selected from survey } \\
\text { Case }\end{array}$} & \multicolumn{1}{c}{$\begin{array}{c}\text { Cumulative savings (quads) } \\
\text { as basis for losses }\end{array}$} & \multicolumn{3}{c}{ 30ears } \\
\cline { 3 - 5 } Lowest TOC & Lowest total owning cost (TOC) & Liquid & Dry & Total \\
Median TOC & Median TOC & 1.1 & 8.3 & 10.4 \\
Average losses & Average losses of three lowest TOC transformers & 2.4 & 6.5 & 6.1 \\
High-efficiency & $\begin{array}{l}\text { Highest-efficiency transformer of those } \\
\text { submitted }\end{array}$ & 5.4 & 8.3 & 13.7 \\
\hline
\end{tabular}


disclosed, since proprietary data cannot be derived from this information. Table 6.2 shows the efficiencies for 12 transformer types in the determination study cases.

The losses for each of the 12 transformers that defined a case in ORNL-6847 were mapped either directly or through extrapolation to the 73 types of transformers in the disaggregated model utilized in Chapter 5 to estimate TP-1 savings. Where there was no corresponding transformer size from the ORNL-6847 survey, the transformer losses for the closest size of the same type defining the determination study cases were extrapolated using a rule of thumb. The extrapolation algorithm was the ratio of the extrapolated transformer size to the base transformer size taken to the 0.75 power times the design losses of the base transformer.

No dry-type medium-voltage single-phase transformers were included in the earlier survey described in ORNL-6847. For this category, dry-type medium-voltage three-phase transformers from the survey were extrapolated to single-phase transformers that were exactly one-third the rated kilovoltamperage by taking one-third of their design no-load and load losses. The remaining transformers for this category were extrapolated using the 0.75 power rule of thumb described above.

The estimated savings for the determination study cases using the disaggregated model and the new market and load assumptions are presented in Table 6.3. These estimates are less than the estimates from the previous study (see Table 6.1). The cumulative liquid transformer sales assumed in the current study were about $10 \%$ less than in the ORNL-6847 report. However, the cumulative sales for dry-type transformers, which represent over $80 \%$ of estimated savings were only about one-half of those used in the previous study. This lower market level for dry-type transformers has resulted in lower energy savings. 
Table 6.2. Transformer efficiencies corresponding to losses for determination study cases

\begin{tabular}{|c|c|c|c|c|}
\hline \multirow{2}{*}{$\begin{array}{c}\text { Transformer size } \\
\text { (kVA), type, and } \\
\text { load }\end{array}$} & \multicolumn{4}{|c|}{ Efficiency (\%) by case } \\
\hline & Lowest TOC & Median TOC & $\begin{array}{c}\text { Average } \\
\text { losses }\end{array}$ & $\begin{array}{c}\text { High- } \\
\text { Efficiency }\end{array}$ \\
\hline 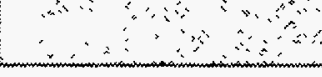 & 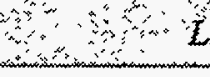 & dimmersed & 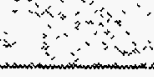 & $\because \cdots$ \\
\hline 25 , pole, 0.5 & 98.93 & 98.87 & 99.06 & 99.22 \\
\hline 50 , pole, 0.5 & 99.14 & 99.15 & 99.17 & 99.53 \\
\hline 50, pad, 0.5 & 99.23 & 99.15 & 99.22 & 99.53 \\
\hline 150, pad, 0.5 & 99.13 & 99.00 & 99.28 & 99.51 \\
\hline 750, pad, 0.5 & 99.45 & 99.35 & 99.39 & 99.60 \\
\hline $2000, \mathrm{pad}, 0.5$ & 99.49 & 99.50 . & 99.47 & 99.50 \\
\hline 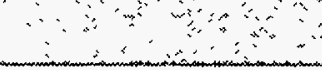 & 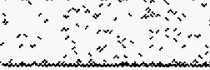 & brisype & 3 & $\because$ \\
\hline 1, small, 0.35 & 95.47 & 95.50 & 94.88 & 95.50 \\
\hline 10, small, 0.35 & 98.04 & 98.72 & 98.19 & 98.72 \\
\hline 45, lighting, 0.35 & 98.70 & 97.58 & 97.99 & 98.70 \\
\hline 1500 , epoxy-cast, 0.5 & 99.29 & 99.28 & 99.30 & 99.32 \\
\hline 2000 , load center, 0.5 & 99.51 & 99.30 & 99.42 & 99.51 \\
\hline 2500 , epoxy-cast, 0.5 & 99.37 & $99.31^{\circ}$ & 99.35 & 99.37 \\
\hline
\end{tabular}


Table 6.3. Alternative conservation case savings: first year of policy and over a 30-year period beginning in 2004

\begin{tabular}{|c|c|c|c|c|c|}
\hline \multirow[b]{2}{*}{$\begin{array}{l}\text { Transformer } \\
\text { type }\end{array}$} & \multicolumn{5}{|c|}{ Conservation case } \\
\hline & TP-1 & $\begin{array}{l}\text { Lowest } \\
\text { TOC }\end{array}$ & $\begin{array}{l}\text { Median } \\
\text { TOC }\end{array}$ & $\begin{array}{l}\text { Average } \\
\text { losses }\end{array}$ & $\begin{array}{l}\text { High- } \\
\text { efficiency }\end{array}$ \\
\hline 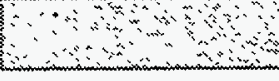 & \multicolumn{5}{|c|}{ 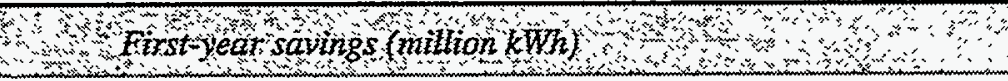 } \\
\hline $\begin{array}{l}\text { Liq. med.-voltage } \\
\text { single-phase }\end{array}$ & 25 & 123 & 87 & 229 & 727 \\
\hline $\begin{array}{l}\text { Liq. med.-voltage } \\
\text { three-phase }\end{array}$ & 43 & 94 & 76 & 89 & 225 \\
\hline $\begin{array}{l}\text { Dry low-voltage } \\
\text { single-phase }\end{array}$ & 28 & 41 & 57 & 45 & 57 \\
\hline $\begin{array}{l}\text { Dry low-voltage } \\
\text { three-phase }\end{array}$ & 256 & 599 & 209 & 350 & 599 \\
\hline $\begin{array}{l}\text { Dry med.-voltage } \\
\text { single-phase }\end{array}$ & 11 & 15 & 15 & 15 & 15 \\
\hline $\begin{array}{l}\text { Dry med.-voltage } \\
\text { three-phase }\end{array}$ & 70 & 213 & 193 & 208 & 221 \\
\hline Total & 433 & 1086 & 650 & 936 & 1846 \\
\hline \multicolumn{6}{|c|}{ 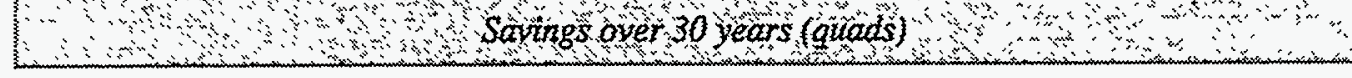 } \\
\hline $\begin{array}{l}\text { Liq. med.-voltage } \\
\text { single-phase }\end{array}$ & 0.14 & 0.71 & 0.50 & 1.33 & 4.22 \\
\hline $\begin{array}{l}\text { Liq. med.-voltage } \\
\text { three-phase }\end{array}$ & 0.25 & 0.54 & 0.44 & 0.51 & 1.31 \\
\hline $\begin{array}{l}\text { Dry low-voltage } \\
\text { single-phase }\end{array}$ & 0.16 & 0.24 & 0.33 & 0.26 & 0.33 \\
\hline $\begin{array}{l}\text { Dry low-voltage } \\
\text { three-phase }\end{array}$ & 1.49 & 3.48 & 1.21 & 2.03 & 3.48 \\
\hline $\begin{array}{l}\text { Dry med.-voltage } \\
\text { single-phase }\end{array}$ & 0.06 & 0.09 & 0.09 & 0.09 & 0.09 \\
\hline $\begin{array}{l}\text { Dry med.-voltage } \\
\text { three-phase }\end{array}$ & 0.41 & 1.24 & 1.12 & 1.21 & 1.28 \\
\hline Total & 2.51 & 6.30 & 3.70 & 5.42 & 10.70 \\
\hline Case efficientey & 9859 & 9 & 98.689 & $9881 \%$ & $9921 \%$ \\
\hline
\end{tabular}




\section{SUMMARY AND CONCLUSIONS}

\subsection{EFFECTIVE LOADS}

The NEMA standard TP-1 reference load for liquid-immersed distribution transformers - 50\% of nameplate capacity (NEMA 1996) - appears to be higher than the typical loads for utility applications. Analysis of the FERC Form 1 data indicates that the per unit annual average load for utility-owned liquid-immersed distribution transformers is 0.24 . The effective load (i.e., RMS load) appears to be about $10 \%$ higher, or 0.27 . Limited data from several utilities surveyed by ORNL support a relatively low per unit effective load of 0.25 to 0.35 . The lower-than-expected transformer loading may be due to high air conditioning loads or the application of high motor loads with frequent starts. The desire to prevent voltage sag and lighting flicker also contributes to the relatively low loading, even for the larger sizes. The data obtained from ORNL's survey of utilities indicate both a relatively low peak load and a low average load. Although the surveyed utilities are located primarily in the central and southern United States, the FERC Form 1 data indicate that the relatively low loading is being applied nationally. Limited data are available for nonutility applications; however, the reference loads in the NEMA TP- 1 standard $(0.35$ for low voltage or 0.5 for medium voltage) appear to be only slightly high and not inconsistent with the available data.

\subsection{DISTRIBUTION TRANSFORMER MARKET}

There is no single source of information for the total distribution transformer market, and many of the data sources are not always consistent with other sources. We have considered various private and government sources along with checks on the reasonableness of the sales or transformer capacity (MVA) to arrive at the present and future market data presented in this report. The current distribution transformer market is shown in Table 7.1. Small dry-type single-phase transformers used for power distribution (less than $15 \mathrm{kVA}$ ) are listed separately. This market is significantly small, accounting for about $5.5 \%$ of the total dry-type distribution transformer market.

Table 7.1. Current distribution transformer market

\begin{tabular}{lccc}
\hline \multicolumn{1}{c}{ Type of transformer } & $\begin{array}{c}\text { Av. size of unit } \\
\text { (kVA) }\end{array}$ & No. of units & $\begin{array}{c}\text { Total capacity } \\
\text { (MVA) }\end{array}$ \\
\hline Liquid-immersed $^{a}$ & 46 & $1,480,000$ & 68,150 \\
Dry-type $^{a}$ & 83 & 248,000 & 20,660 \\
Small dry-type (10 kVA) & 10 & $\sim 6,000$ & 60 \\
Small dry-type (<10 kVA) & 3 & $\sim 400,000$ & 1,200 \\
\hline
\end{tabular}

${ }^{a}$ Sizes that are described in NEMA TP-1 standard. 
The future outlook of the distribution transformer industry is not expected to be significantly . different from that of the past decade. The assumed growth rates ranged from 0.8 to $1.6 \%$ for both liquid-immersed and dry-type transformer markets. This range is consistent with low-to moderategrowth energy scenarios.

\subsection{ENERGY SAVINGS}

The energy savings from more efficient distribution transformers in the United States have been determined for the NEMA TP-1 minimum efficiency standard and the conservation cases considered earlier in the determination study (Barnes et al. 1996). The energy savings for the determination study cases have been revised downward because of a number of factors. The transformer market, both present and future, was overestimated in the previous study, particularly for dry-type transformers, which have the greatest energy-saving potential. In addition, a downward revision in the effective annual loads for utility-owned transformers has also resulted in less energy savings.

We have developed a more accurate disaggregated model to compute the base case losses and the energy savings due to an efficiency standard. This model was used to determine the savings resulting from the NEMA TP-1 standard as well as from the conservation cases. Data needed for the disaggregated model - i.e., data for all sizes and types of transformers - were not collected for the earlier conservation cases. Therefore, data for the complete range of transformers had to be developed from the limited earlier data by applying the 0.75 power rule, which relates the losses of similar types of transformers with different sizes. Unfortunately, this approach may not be as accurate as the analysis for TP-1, in which a complete set of data was available.

The energy savings for the cases considered in this report are summarized in Table 7.2. The savings ranged from 2.5 to 10.7 quads of primary energy for the period 2004 through 2033 . For the TP-1 case, data were available to calculate the payback period required to recover the extra cost from the value of the energy saved. The average payback is 2.76 years.

\subsection{CONCLUSIONS}

The NEMA TP-1 minimum efficiency standard could save about 2.5 quads of primary energy cumulated during the 30-year period from 2004 through 2033 if there is $100 \%$ participation in compliance with the voluntary standard. TP-1 can be easily justified economically, since the simple payback period is, on average, less than 3 years. The conservation cases considered in the determination study could save more energy, from 3.7 to 10.7 quads. The payback periods for these cases could not be determined because of insufficient data from the earlier surveys. The potential for saving energy with an efficiency standard is increased if the load specified by the standard is near the effective operating load. For example, TP-1 saving could be increased to 2.73 quads if the liquidimmersed transformer loads were specified at $40 \%$ instead of at $50 \%$ in the standard. 
Table 7.2 Results of the energy analysis

\begin{tabular}{lccccc}
\hline \multicolumn{1}{c}{ Conservation case } & $\begin{array}{c}\text { Losses }^{a} \\
\text { (quads) }\end{array}$ & $\begin{array}{c}\text { Savings }^{a} \\
\text { (quads) }^{a}\end{array}$ & $\begin{array}{c}\text { Loss } \\
\text { reduction }^{b} \\
(\%)\end{array}$ & $\begin{array}{c}\text { Efficiency }^{a} \\
(\%)\end{array}$ & $\begin{array}{c}\text { Cumulative }_{\text {savings }^{c}} \\
\text { (quads) }\end{array}$ \\
\hline Base case & 0.0401 & NA $^{d}$ & NA $^{d}$ & 98.40 & NA $^{d}$ \\
NEMA standard TP-1 & 0.0353 & 0.0048 & 12.0 & 98.59 & 2.51 \\
Median TOC & 0.0330 & 0.0071 & 17.6 & 98.68 & 3.70 \\
Average losses & 0.0297 & 0.0104 & 25.8 & 98.81 & 5.42 \\
Lowest TOC & 0.0280 & 0.0120 & 30.0 & 98.88 & 6.30 \\
High efficiency & 0.0196 & 0.0204 & 51.0 & 99.21 & 10.70 \\
\hline
\end{tabular}

${ }^{a}$ Primary energy for year 2004.

${ }^{b}$ Case loss reduction as defined by Eq. (3.10) for year 2004.

${ }^{c}$ Primary energy savings for $1.2 \%$ annual growth in sales over the period 2004 through 2033.

${ }^{d} \mathrm{NA}=$ Not applicable. 


\section{REFERENCES}

Austin, M. 1994. Cooper Power Systems, letter to P. R. Bames, December 21.

Barnes, P. R., J. W. Van Dyke, B. W. McConnell, S. M. Cohn, and S. L. Purucker 1994. The

Feasibility of Replacing or Upgrading Utility Distribution Transformers During Routine

Maintenance, ORNL-6804, Oak Ridge National Laboratory, Oak Ridge, Tenn., October 1994.

Barnes, P. R., J. W. Van Dyke, B. W. McConnell, and S. Das 1996. Determination Analysis of

Energy Conservation Standards for Distribution Transformers, ORNL-6847, Oak Ridge

National Laboratory, Oak Ridge, Tenn., July.

Business Trend Analysts, Inc., 1995. The U.S. Transformer Industry, Study LE609, Commack, N.Y., January.

DOC (U.S. Department of Commerce) 1990. 1987 Census of Manufactures - Industry Series: Electrical Transmission and Distribution Equipment and Electrical Industrial Apparatus, MC871-36A, Bureau of the Census, Washington, D.C.

- 1994a. 1992 Census of Manufactures - Industry Series: Electrical Transmission and Distribution Equipment and Electrical Industrial Apparatus, MC92-1-36A, Bureau of the Census, Washington, D.C.

1994b. U.S. Industrial Outlook 1994 - Construction, U.S. International Trade Administration, Washington, D.C.

1996. The Statistical Abstract of the United States, 1995, Bureau of Census, Washington, D.C., sect. 31 (found at $h t t p: / / w w w . i t a . d o c . g o v / i n d u s t r y / o t e a / ~ u s i o / 95 s 1483 . t x t$ ).

EIA (Energy Information Administration) 1997. Electric Power Monthly April 1997: With Data for January 1997, DOE/EIA-0226 (97/04), U.S. Department of Energy, Washington, D.C., April.

EIA (Energy Information Administration) 1996a. Annual Energy Outlook 1997: With Projections to 2015, DOE/EIA-0383(97), U.S. Department of Energy, Washington, D.C., December.

1996b. Annual Energy Review 1995, DOE/EIA-0384(95), U.S. Department of Energy, Washington, D.C., July.

1996c. Electric Sales and Revenue 1995, DOE/EIA-0540(95), U.S. Department of Energy, Washington, D.C., December.

EPRI (Electric Power Research Institute) 1983. Improved Methods for Distribution Loss Evaluation, vol. 1, Analytic and Evaluative Techniques, EL-3261, prepared by Westinghouse Electric Corp., Pittsburgh, for the Electric Power Research Institute, Palo Alto, Calif., November.

Fink, D. G., and J. M. Carroll, eds. 1969. Standard Handbook for Electrical Engineers, 10th ed., McGraw-Hill, New York.

The Freedonia Group, Inc., 1996. U.S. Electric Power Equipment to 2000, Cleveland, Ohio, September.

Gangel, M. W., and R. F. Propst 1965. "Distribution Transformer Load Characteristics," IEEE Transactions on Power Apparatus and Systems PAS-84, August, pp. 671-85.

Hall, K. 1996. Edison Electric Institute, personal communication to P. R. Barnes, May 15.

Hopkinson, P. 1996. Square D Co., Monroe, N.C., personal communication to S. Das, Lockheed Martin Energy Research Corp., Oak Ridge National Laboratory, September 12. 
Hurst, J. 1996. Dynapower, South Burlington, Vt., personal communication to S. Das, Lockheed Martin Energy Research Corp., Oak Ridge National Laboratory, May 1.

IEEE (Institute of Electrical and Electronic Engineers) 1989. Guide for Loading Dry-Type Distribution and Power Transformers, ANSI/IEEE C57.96-1989.

IEEE (Institute of Electrical and Electronic Engineers) 1994. "Distribution, Power, and Regulating Transformers," IEEE Standards Collection - C57, IEEE, New York.

IEEE (Institute of Electrical and Electronic Engineers) 1995. Guide for Loading Mineral OilImmersed Transformers, ANSI/IEEE C57.91-1995.

Mulkey, Dan 1996. "Transformer-Loss Study Cuts Out Unneeded Ratings," Electrical World, February.

NEMA (National Electrical Manufacturers Association) 1996. Guide for Determining Energy Efficiency for Distribution Transformers, NEMA Standards Publication TP 1-1996, National Electrical Manufacturers Association, Rosslyn, Va.

Nickel, D. L., and H. R. Braunstein 1981. "Distribution Transformer Loss Evaluation: II — Load Characteristics and System Cost Parameters," IEEE Transactions on Power Apparatus and Systems PAS-100(2), February.

Nizinski, S. 1996. Square D Co., Oshkosh, Wis., personal communication to S. Das, Lockheed Martin Energy Research Corp., Oak Ridge National Laboratory, March 4.

RDI (Resource Data International) 1996. "FERC Form No. 1: Annual Report of Major Electric Utilities, Licensees, and Others" (compiled data), Boulder, Colo., March.

Smith, E. 1996. Central Moloney Co., Pine Bluff, Ark., personal communication to S. Das, Lockheed Martin Energy Research 'Corp., Oak Ridge National Laboratory, March 11.

Westinghouse Electric 1959. "Load Characteristics," ch. 2 in Electric Utility Engineering Reference Book, Vol. 3, Distribution Systems, Westinghouse Electric Corp., East Pittsburgh, Pa. 


\title{
Appendix A: FERC Form 1 Summary
}

\author{
Table A.1. Analysis of 1992 FERC Form 1 Data
}

\begin{tabular}{|c|c|c|c|c|c|c|c|c|}
\hline UTILITIES & Number of & Capacity & Residential & Commercial & Residential & Commerical & Average & Average \\
\hline & Transformers & MVA & Sales (MWh) & Sales (MWh) & Customers & Customers & Unit (kVA) & p.u. Load" \\
\hline ALABAMA POWER CO. & 542,541 & 17,466 & $12,069,268$ & $8,629,869$ & $1,004,343$ & 150,526 & 32.19 & 0.150 \\
\hline APPALACHIAN POWER CO. & 336,782 & 10,784 & $8,944,292$ & $4,955,878$ & 717,154 & 94,572 & 32.02 & 0.163 \\
\hline ARIZONA PUBLIC SERVICE CO. & 189,600 & 11,722 & $6,066,830$ & $6,904,072$ & 549,778 & 68,650 & 61.82 & 0.140 \\
\hline ARKANSAS POWER \& LIGHT CO. & 284,945 & 10,089 & $5,102,300$ & $3,840,370$ & 503,741 & 63,068 & 35.41 & 0.112 \\
\hline ATLANTIC CITY ELECTRIC CO & 127,706 & 4,781 & $3,289,492$ & $3,100,133$ & 402,950 & 51,996 & 37.44 & 0.170 \\
\hline BALTIMORE GAS \& ELECTRIC CO. & 180,505 & 11,590 & $9,677,272$ & $2,500,060$ & 949,258 & 94,862 & 64.21 & 0.133 \\
\hline BANGOR HYDRO-ELECTRICCO. & 37,321 & 861 & 515,381 & 143,800 & 85,613 & 12,421 & 23.07 & 0.097 \\
\hline BLACK HILLS CORP. & 18,147 & 975 & 339,341 & 446,036 & 43,824 & 8,308 & 53.73 & 0.102 \\
\hline BLACKSTONE VALLEY ELECTRIC CO & 12,591 & 745 & 363,917 & 396,066 & 74,764 & 8,575 & 59.17 & 0.129 \\
\hline BOSTON EDISON CO. & 60,752 & 4,905 & $3,424,275$ & $7,202,580$ & 561,838 & 90,605 & 80.74 & 0.275 \\
\hline CAROLINA POWER \& LIGHT CO. & 378,169 & 14,933 & $10,490,030$ & $8,060,282$ & 846,232 & 145,858 & 39.49 & 0.158 \\
\hline CENTRAL HUDSON GAS \& ELEC CORP. & 83,636 & 2,340 & $1,527,459$ & $1,156,954$ & 221,077 & 31,423 & 27.98 & 0.146 \\
\hline CENTRAL ILLINOIS LIGHT CO. & 61,856 & 2,815 & $1,507,911$ & $1,310,638$ & 167,447 & 20,026 & 45.51 & 0.127 \\
\hline CENTRAL LOUISIANA ELEC CO., INC. & 112,357 & 3,289 & $2,353,449$ & $1,061,478$ & 178,981 & 23,648 & 29.27 & 0.132 \\
\hline CENTRAL MAINE POWER CO. & 199,511 & 4,635 & $2,989,402$ & $2,365,898$ & 446,696 & 49,529 & 23.23 & 0.147 \\
\hline CENTRAL POWER \& LIGHT CO. & 207,474 & 8,055 & $5,407,570$ & $4,181,265$ & 485,713 & 72,649 & 38.82 & 0.151 \\
\hline CENTRAL VERMONT PUB SERV CORP. & 65,690 & 1,212 & 813,279 & 775,031 & 118,239 & 16,205 & 18.45 & 0.166 \\
\hline CHEYENNE LIGHT FUEL \& POWER CO & 6,815 & 270 & 185,535 & 218,560 & 27,594 & 3,981 & 39.62 & 0.190 \\
\hline CINCINNATI GAS \& ELECTRIC CO & 153,192 & 9,565 & $5,552,285$ & $4,456,160$ & 520,026 & 58,384 & 62.44 & 0.133 \\
\hline CITIZENS ELECTRIC CO. & 2,110 & 70 & 62,736 & 18,970 & 4,860 & 984 & 33.18 & 0.148 \\
\hline CITIZENS UTILITIES CO. (CT) & 39,593 & 1,190 & 618,637 & 389,794 & 81,600 & 11,506 & 30.06 & 0.107 \\
\hline CLEVELANDELECTRICILLUM CO & 138,754 & 7,622 & $4,724,996$ & $5,466,615$ & 668,136 & 70,655 & 54.93 & 0.170 \\
\hline COLUMBUS SOUTHERN POWER CO & 144,261 & 6,425 & $4,859,226$ & $5,151,327$ & 509,495 & 51,591 & 44.54 & 0.198 \\
\hline COMMONWEALTHEDISON CO. & 529,363 & 35,028 & $19,269,209$ & $22,661,665$ & $2,965,652$ & 280,451 & 66.17 & 0.152 \\
\hline COMMONWEALTHELECTRIC CO. & 58,575 & 2,254 & $1,584,219$ & $1,021,038$ & 266,513 & 34,348 & 38.48 & 0.147 \\
\hline CONCORD ELECTRIC CO & 6,885 & 181 & 142,326 & 143,910 & 21,255 & 3,033 & 26.29 & 0.201 \\
\hline CONNECTICUT LIGHT \& POWER CO. & 221,433 & 10,007 & $8,253,207$ & $7,820,932$ & 980,146 & 88,333 & 45.19 & 0.204 \\
\hline CONNECTICUT VALLEYELEC CO, INC. & 3,643 & 61 & 56.809 & 62,022 & 8,871 & 1,354 & 16.74 & 0.247 \\
\hline CONOWNGO POWER CO. & 9,911 & 392 & 371,709 & 145,627 & 31,402 & 3,172 & 39.55 & 0.167 \\
\hline CONSOLIDATED EDISON CO.-NY, INC. & 78,702 & 23,305 & $9,845,397$ & $23,527,194$ & $2,544,846$ & 403,475 & 296.12 & 0.182 \\
\hline DAYTON POWER \& LIGHT CO & 136,831 & 6,443 & $4,259,572$ & $2,896,081$ & 411,254 & 39,401 & 47.09 & 0.141 \\
\hline DELMARVA POWER \& LIGHT CO. & 103,387 & 4,564 & $3,232,067$ & $3,140,515$ & 333,485 & 41,905 & 44.14 & 0.177 \\
\hline DETROIT EDISON CO. & 357,823 & 20,341 & $11,378,490$ & $8,668,326$ & $1,774,085$ & 166,798 & 56.85 & 0.125 \\
\hline DUKE POWER CO. & 590,409 & 33,394 & $17,827,792$ & $15,812,145$ & $1,431,403$ & 225,245 & 56.56 & 0.128 \\
\hline DUQUESNE LIGHT CO. & 99,243 & 5,089 & $3,069,087$ & $5,358,492$ & 520,077 & 52,695 & 51.28 & 0.210 \\
\hline EASTERN EDISON CO. & 31,325 & 1,356 & $1,023,542$ & $1,114,702$ & 154,871 & 20,096 & 43.29 & 0.200 \\
\hline EDISON SAULT ELECTRIC CO. & 7,994 & 252 & 144,203 & 173,141 & 16,919 & 2,964 & 31.52 & 0.160 \\
\hline EMPIRE DISTRICT ELECTRIC CO. & 63,555 & 2,011 & $1,068,596$ & 850,829 & 101,943 & 17,796 & 31.64 & 0.121 \\
\hline EXETER \& HAMPTON ELECTRIC CO & 6,885 & 258 & 215,442 & 109,596 & 28,946 & 4,724 & 37.47 & 0.160 \\
\hline FITCHBURG GAS \& ELEC LIGHT CO. & 5,692 & 162 & 127,371 & 98,860 & 22,766 & 2,768 & 28.46 & 0.177 \\
\hline FLORIDA POWER \& LIGHT CO. & 672,156 & 36,340 & $34,198,302$ & $26,990,914$ & $2,911,812$ & 350,271 & 54.06 & 0.214 \\
\hline FLORIDA POWER CORP. & 312,667 & 13,937 & $12,825,815$ & $7,544,084$ & $1,050,077$ & 116,727 & 44.57 & 0.185 \\
\hline GEORGIA POWER CO. & 538,137 & 25,493 & $14,939,172$ & $17,260,614$ & $1,408,953$ & 181,996 & 47.37 & 0.160 \\
\hline GRANITE STATE ELECTRIC CO & 8,172 & 332 & 233,379 & 320,104 & 29,360 & 4,854 & 40.63 & 0.211 \\
\hline GREEN MOUNTAIN POWER CORP. & 29,294 & 893 & 563,608 & 584,053 & 67,201 & 11,245 & 30.48 & 0.163 \\
\hline GULFPOWER CO. & 113,008 & 4,054 & $3,596,515$ & $2,369,236$ & 265,374 & 36,009 & 35.87 & 0.187 \\
\hline GULF STATES UTILITIES CO. & 283,632 & 12,651 & $6,824,670$ & $5,474,432$ & 510,003 & 64,000 & 44.60 & 0.123 \\
\hline HAWAIIANELECTRIC CO, INC. & 29,764 & 2,689 & $1,730,537$ & $1,698,076$ & 224,417 & 30,320 & 90.34 & 0.162 \\
\hline HOUSTON LIGHTING \& POWER CO. & 393,266 & 27,073 & $16,375,400$ & $12,541,636$ & $1,250,888$ & 164,051 & 68.84 & 0.135 \\
\hline IDAHO POWER CO. & 161,267 & 7,220 & $3,474,325$ & $4,147,843$ & 250,750 & 51,784 & 44.77 & 0.134 \\
\hline ILLINOIS POWER CO. & 191,323 & 7,947 & $4,137,858$ & $3,055,345$ & 495,948 & 56,800 & 41.54 & 0.115 \\
\hline INDIANA MICHIGAN POWER CO. & 161,208 & 6,143 & $4,633,779$ & $3,747,194$ & 458,470 & 51,845 & 38.11 & 0.173 \\
\hline INDIANAPOLIS POWER \& LIGHT CO. & 81,228 & 5,471 & $3,675,431$ & $2,158,752$ & 349,539 & 38,066 & 67.35 & 0.135 \\
\hline INTERSTATE POWER CO. & 47,734 & 1,775 & 931,849 & 776,521 & 126,935 & 30,808 & 37.19 & 0.122 \\
\hline IOWA ELECTRIC LIGHT \& POWER CO & 69,618 & 2,451 & $1,434,269$ & $1,342,627$ & 180,771 & 30,608 & 35.21 & 0.144 \\
\hline IOWA SOUTHERN UTILITIES & 34,072 & 1,433 & 734,242 & 433,999 & 81,656 & 12,695 & 42.06 & 0.103 \\
\hline IOWA-ILLINOIS GAS \& ELEC. CO. & 57,612 & 2,783 & $1,142,078$ & $1,268,117$ & 175,591 & 20,257 & 48.31 & 0.110 \\
\hline JERSEY CENTRAL POWER \& LIGHT CO & 198,438 & 10,257 & $6,567,957$ & $6,207,321$ & 794,776 & 93,615 & 51.69 & 0.158 \\
\hline KANSAS CITY POWER \& LIGHT CO. & 97,901 & 5,602 & $3,172,611$ & $4,984,285$ & 365,069 & 48,522 & 57.22 & 0.185 \\
\hline
\end{tabular}


Table A.1 (Continued)

\begin{tabular}{|c|c|c|c|c|c|c|c|c|}
\hline UTILITIES & Number of & Capacity & Residential & Commercial & Residential & Commerical & Average & Average \\
\hline & Transformers & MVA & Sales $(M W h)$ & Sales $(M W h)$ & Customers & Customers & Unit (kVA) & p.u. Load \\
\hline KANSAS GAS \& ELECTRIC CO. (WR) & 97,092 & 4,447 & $2,101,531$ & $1,892,382$ & 238,286 & 22,840 & $\quad 45.80$ & 0.114 \\
\hline KENTUCKY POWER CO. & 79,023 & 2,432 & $1,886,021$ & 991,361 & 133,840 & 21,136 & 30.78 & 0.150 \\
\hline KENTUCKY UTILITIES CO. & 176,731 & 6,111 & $4,278,098$ & $3,080,045$ & 356,287 & 59,685 & 34.58 & 0.153 \\
\hline KINGSPORT POWER CO. & 12,652 & 558 & 591,502 & 302,692 & 35,413 & 3,986 & 44.10 & 0.203 \\
\hline LOCKHART POWER CO & 2,827 & 82 & 53,138 & 14,395 & 4,594 & 741 & 29.01 & 0.104 \\
\hline LONG ISLAND LIGHTING CO. & 179,888 & 9,835 & $6,787,601$ & $3,473,585$ & 902,885 & 98,396 & $54.67 !$ & 0.132 \\
\hline LOUISIANA POWER \& LIGHT CO. & 182,366 & 9,127 & $6,996,327$ & $4,307,235$ & 522,641 & 60,145 & 50.05 & 0.157 \\
\hline LOUISVILLE GAS \& ELECTRIC CO. & 78,104 & 4,265 & $2,923,517$ & $2,635,271$ & 292,084 & 33,474 & $54.61 i$ & 0.165 \\
\hline MAINE PUBLIC SERVICE CO. & 11,568 & 222 & 176,814 & 155,267 & 28,102 & $5,261:$ & 19.19 & $\overline{0.190}$ \\
\hline MASSACHUSETTS ELECTRIC CO. & 147,507 & 7,473 & $5,645,350$ & $5,645,867$ & 819,782 & 83,231 & 50.66 & 0.192 \\
\hline MAUIELECTRIC CO LTD & 9,124 & 465 & 295,148 & 286,284 & 42,238 & 6,933 & 50.96 & 0.159 \\
\hline METROPOLITAN EDISON CO. & 148,504 & 5,904 & $3,567,292$ & $2,637,650$ & 390,339 & 46,615: & 39.76 & 0.133 \\
\hline MIDWEST POWER SYSTEMS, INC. & 131,377 & 5,845 & $2,956,489$ & $2,617,781$ & 358,018 & 51,231 & 44.49 & 0.121 \\
\hline MINNESOTA POWER \& LGHT & 37,897 & 1,247 & 816,240 & 821,376 & 100,784 & 15,358 & 32.90 & 0.167 \\
\hline MISSISSIPPI POWER \& LIGHT CO & 151,999 & 5,489 & $3,644,164$ & $2,803,672$ & 302,768 & 45,533 & 36.111 & 0.149 \\
\hline MISSISSIPPI POWER COMPANY & 73,339 & 2,794 & $1,804,858$ & $1,811,042$ & 149,585 & 27,889 & 38.10 & 0.164 \\
\hline MONONGAHELA POWER CO. & 172,499 & 2,963 & $2,527,247$ & $1,742,469$ & 292,646 & 33,749 & 17.18 & 0.183 \\
\hline MONTANA DAKOTA UTILITIES CO & 32,835 & 1,144 & 695,717 & 771,692 & 92,717 & 16,378 & 34.84 & 0.163 \\
\hline MONTANA POWER CO. & 107,387 & 3,518 & $1,738,899$ & $2,018,319$ & 210,483 & 38,077 & 32.76 & 0.135 \\
\hline MT CARMEL PUBLIC UTILITY CO. & 2,449 & 65 & 43,980 & 12,474 & 4,557 & $957:$ & 26.54 & 0.110 \\
\hline NANTAHALA POWER \& LIGHT CO & 34,286 & 731 & 415,117 & 248,293 & 44,699 & 5,624 & 21.32 & 0.115 \\
\hline NARRAGANSETT ELECTRIC CO & 53,352 & 2,207 & $1,783,754$ & $1,877,738$ & 284,711 & 31,417 & 41.37 & 0.210 \\
\hline NEVADA POWER CO. & 57,527 & 5,323 & $4,372,948$ & $1,963,539$ & 328,387 & 45,245 & 92.53 & 0.151 \\
\hline NEW ORLEANS PUBLIC SERVICE, INC. & 34,847 & 3,180 & $1,805,611$ & $1,976,586$ & 170,621 & 16,662 & 91.26 & 0.151 \\
\hline NEW YORK STATE ELEC \& GAS CORP. & 282,864 & 9,116 & $5,386,969$ & $3,282,756$ & 697,707 & 72,535 & $32.23 !$ & 0.121 \\
\hline NEWPORT ELECTRIC CORP & 5,256 & 276 & 192,552 & 199,363 & 27,243 & 4,230 & $52.51 !$ & 0.180 \\
\hline NIAGARA MOHAWK POWER CORP. & 410,343 & 16,462 & $10,298,064$ & $11,555,795$ & $1,378,467$ & 141,129 & 40.12 & 0.168 \\
\hline NORTHERN INDIANA PUBLIC SERVICE C & 107,418 & 4,554 & $2,343,303$ & $2,608,614$ & 344,861 & 40,034 & 42.40 & 0.138 \\
\hline NORTHERN STATES POWER CO (MN) & 206,019 & 11,975 & $7,106,001$ & $4,410,209$ & $1,027,013$ & 129,932 & $58.13 !$ & 0.122 \\
\hline NORTHERN STATES POWER CO (WI) & 67,111 & 2,347 & $1,574,622$ & 811,965 & 172,802 & 26,405 & 34.97 & 0.129 \\
\hline NORTHWESTERN PUBLIC SERVICE CO. & 17,928 & 921 & 352,801 & 198,204 & 44,241 & 8,607 & $51.37^{1}$ & 0.076 \\
\hline NORTHWESTERN WISCONSIN ELEC CO & 5,695 & 102 & 57,957 & 38,413 & 10,207 & 1,454 & 17.91 & 0.120 \\
\hline OHIO EDISON CO. & 261,441 & 8,863 & $6,634,111$ & $5,697,850$ & 818,038 & 90,210 & 33.901 & 0.176 \\
\hline OHIO POWER CO. & 230,000 & 7,468 & $5,728,601$ & $4,176,841$ & 565,020 & 72,860 & 32.47 & 0.168 \\
\hline OKLAHOMA GAS \& ELECTRIC CO. & 170,510 & 12,620 & $5,980,308$ & $4,327,325$ & 561,114 & 68,467 & $74.01 i$ & 0.104 \\
\hline ORANGE \& ROCKLAND UTILITIES, INC. & 61,922 & 3,214 & $1,034,849$ & 834 & 162,641 & 23,116 & 51.90 & 0.068 \\
\hline OTIER TAIL POWER CO. & 40,192 & 1,698 & 941,844 & 522,527 & 95,870 & 23,625 & 42.25 & 0.109 \\
\hline PACIFIC GAS \& ELECTRIC CO. & 917,933 & 35,915 & $23,663,905$ & $30,709,655$ & $3,708,374$ & 550,032 & 39.13 & 0.192 \\
\hline PECO ENERGYCO. & 164,556 & 11,222 & $9,522,301$ & $5,222,052$ & $1,297,917$ & 137,933 & 68.201 & 0.167 \\
\hline PENNSYLVANIA ELECTRIC CO. & 175,727 & 6,946 & 0,161 & $3,488,165$ & 485,599 & 66,631 & 39.53 & 0.129 \\
\hline PENNSYLVANIA POWER \& LIGHT CO. & 393,282 & 11,943 & $10,614,208$ & $9,031,604$ & $1,038,880$ & 133,622 & 30.37 & 0.209 \\
\hline PENNSYLVANIA POWER CO. & 53,004 & 1,407 & $1,050,601$ & 781,830 & 121,147 & 15,287 & 26.55 & 0.165 \\
\hline PORTLAND GENERAL ELECTRIC CO & 162,186 & 7,123 & $6,225,936$ & $5,717,035$ & 532,194 & 74,002 & $43.92 !$ & 0.213 \\
\hline POTOMAC EDISON CO. & 155,864 & 4,738 & $3,822,387$ & $1,954,025$ & 299,415 & 38,939 & 30.40 & 0.155 \\
\hline POTOMAC ELECTRIC POWER CO. & 104,762 & 12,118 & $6,155,793$ & $10,473,702$ & 587,677 & 68,660 & $115.67 !$ & 0.174 \\
\hline PSCOF COLORADO & 168,942 & 9,355 & $5,561,513$ & $10,131,595$ & 859,561 & 115,753 & 55.37 & 0.213 \\
\hline PSC OF NEW HAMPSHIRE & 124,387 & 4,332 & $2,342,789$ & $1,224,080$ & 344,409 & 52,056 & 34.83 & 0.104 \\
\hline PSCOF NEW MEXICO & 66,757 & 2,688 & $1,671,563$ & $2,375,799$ & 267,546 & 32,045 & $40.27^{\prime}$ & 0.191 \\
\hline PSCOF OKLAHOMA & 143,015 & 6,377 & $4,139,572$ & $4,091,944$ & 402,010 & 51,937 & $44.59 !$ & 0.164 \\
\hline PSI ENERGY, INC. & $184,857:$ & 7,925 & $5,942,542$ & $5,121,099$ & 530,920 & 72,274 & $42.87 !$ & 0.177 \\
\hline PUBLIC SERVICE ELECTRIC\& GAS & 302,064 & $19, \overline{704}$ & $9,816,046$ & $17,454,352$ & $1,623,396$ & 213,344 & 65.23 & 0.176 \\
\hline PUGET SOUND POWER \& LIGHT CO. & 247,956 & 10,492 & $8,441,893$ & $5,996,355$ & 692,100 & 80,963 & 42.31 & 0.175 \\
\hline ROCHESTER GAS \& ELECTRIC CORP. & 73,733 & 2,888 & $2,084,934$ & $1,949,750$ & 299,327 & 29,256 & $39.17^{i}$ & 0.177 \\
\hline ROCKLAND ELECTRIC CO & 21,091 & 1,062 & 474,587 & 360,260 & 55,483 & 7,049 & $50.35 i$ & 0.100 \\
\hline SANDIEGO GAS \& ELECTRIC CO. & 161,567 & 9,829 & $5,611,070^{-}$ & $6,066,556$ & 998,432 & 116,982 & $60.84 !$ & 0.151 \\
\hline SIERRA PACIFIC POWER CO & 60,728 & 3.462 & $1,647,766$ & $2,082,615$ & 219,202 & 33,718 & 57.01 & 0.137 \\
\hline SIERRA PACIFIC POWER CO & $59,669:$ & 3,427 & $1,571,350$ & $2,077,857$ & 214,530 & 33,159 & 57.43 & 0.135 \\
\hline SOUTH BELOIT WATER GAS \& ELECTRI & 2,0621 & 103 & 43,198 & 27,279 & 5,482 & 711 & 49.951 & 0.087 \\
\hline SOUTH CAROLINA ELECTRIC \& GAS & $193,066_{1}$ & 7,991 & $5,155,886$ & $4,538,862$ & 395,471 & 59,413 & 41.39 & 0.154 \\
\hline
\end{tabular}


Table A.1 (Continued)

\begin{tabular}{|c|c|c|c|c|c|c|c|c|}
\hline UTILITIES & INumber of & Capacity & Residential & iCommercial & IResidential & Commerical & Average & Average \\
\hline & Transformers : & $M V A$ & Sales (MWh) & ISales $(M W h)$ & Customers & ICustomers & Unit (kVA) & L.u. Load" \\
\hline SOUTHERN INDIANA GAS \& ELECTRIC C! & 46,436 & $1,87.0^{-1}$ & $1,119,517$ & $1,044,824$ & 101,547 & 14,316 & $40.27 \mathrm{I}$ & 0.147 \\
\hline SOUTHWESTERN ELECTRIC SERV CO. & 24,685 & 611 & 364,906 & 244,298 & 33,344 & 5,743 & 24.75 & 0.126 \\
\hline ST JOSEPH LIGHT \& POWER CO. & 20,995 & $89 \ddot{4}$ & 505,047 & 387,013 & 53,037 & 6,434 & 42.58 & 0.127 \\
\hline SUPERIOR WATER LIGHT \& POWER CO & 1,983 & 83 & $\overline{71,544}$ & 80,793 & 11,747 & 1,562 & $41.86 i$ & 0.233 \\
\hline TAMPA ELECTRIC CO. & 121,448 & 6,496 & $5,559,833$ & $4, \overline{3} 32,572$ & 412,970 & 51,727 & 53.49 & 0.193 \\
\hline TEXAS UTILITIES ELECTRIC CO. & 676,443 & 35,561 & $27,266,411$ & $22,959,464$ & $1,936,787$ & 208,361 & $52.57 !$ & 0.179 \\
\hline TEXAS-NEW MEXICO POWERCO. & 97,787 & 3,131 & $1,947,593$ & $1,964,097$ & 176,998 & 30,644 & 32.02 & 0.158 \\
\hline TOLEDO EDISON CO. & 73,263 & 3,631 & $1,940,661$ & $1,619,478$ & 254,268 & 26,006 & 49.56 & 0.124 \\
\hline TUCSON ELECTRIC POWER CO. & 61,004 & 3,692 & $2,146,268$ & $1,215,179$ & 248,633 & 26,272 & 60.52 & 0.115 \\
\hline UNION ELECTRIC CO. & 274,837 & 15,055 & $9,690,260$ & $10,553,257$ & 982,368 & 125,147 & 54.78 & 0.171 \\
\hline UNION LIGHT, HEAT \& POWER CO. & 26,713 & 1,441 & $1,028,082$ & 730,486 & 96,723 & 10,110 & 53.941 & 0.155 \\
\hline UNITED ILLUMINATING CO. & 56,574 & 3,493 & $1,799,455$ & $2,303,216$ & 273,936 & 28,848 & 61.741 & 0.149 \\
\hline UPPER PENINSULA POWER CO. & 18,876 & 440 & 253,690 & 186,094 & 54,896 & 6,259 & 23.31 & 0.127 \\
\hline VIRGINIA ELECTRIC \& POWER CO & 523,135 & 27,552 & $19,984,489$ & $17,692,997$ & $1,617,743$ & 175,653 & $52.67 !$ & 0.173 \\
\hline WASHINGTON WATER POWER CO. & 90,422 & 3,444 & $3,023,854$ & $2,298,515$ & 227,576 & 27,781 & $38.09 !$ & 0.196 \\
\hline WEST PENN POWER CO. & 294,400 & $6,449^{\circ}$ & $5,396,533$ & $3,374,355$ & 5061,659 & 63,368 & 21.91 & 0.173 \\
\hline WEST TEXAS UTILITIES CO. & 80,471 & 2,469 & $1,343,774$ & $1,057,568$ & 141,681 & 25,438 & 30.681 & 0.123 \\
\hline WESTERN MASSACHUSETTS ELEC CO. & 38,345 & 1,743 & $1,359,845$ & $1,238,578$ & 175,673 & 14,865 & $45.46 !$ & 0.189 \\
\hline WHEELING POWER CO. & 11,441 & 440 & 354,950 & 335,448 & 35,889 & 4,574 & $38.46:$ & 0.199 \\
\hline WISCONSIN ELECTRIC POWER CO & 209,136 & 10,407 & $6,230,136$ & $6,154,530$ & 824,544 & 85,990 & 49.76 & 0.151 \\
\hline WISCONSIN POWER \& LIGHTCO & 137,494 & 4,534 & $2,571,242$ & $1,524, \overline{543}$ & 302,395 & 40,901 & $32.98 !$ & 0.115 \\
\hline WISCONSIN PUBLIC SERVICE CORP. & 141,344 & 4,555 & $2,268,685$ & $2,384,098$ & 300,973 & 34,356 & 32.231 & 0.130 \\
\hline Totals & $20,022,780 !$ & 1940,062 & $614,861,839$ & $566,412,649$ & $67,597,533$ & $8,454,341$ & 46.95 & 0.159 \\
\hline
\end{tabular}


Table A.2. 1992 FERC Form 1 Data

\begin{tabular}{|c|c|c|c|c|c|c|c|c|}
\hline UTILITIES & Transformers & Capacity & Transformers & In-Service & Number of & Total Annual & Annual Sa/es & Average $^{\circ}$ \\
\hline & in Inventory & $M V A$ & In-Service & Capacity & Customers & Sales (MWh) & Via Dist Ximrs. & p.u. Load \\
\hline ALABAMA POWER CO. & 542,541 & 17,466 & 529,315 & 16,550 & $1,160,981$ & $39,136,209$ & $33,265,778$ & 0.255 \\
\hline APPALACHIAN POWER CO. & 336,782 & 10,784 & 326,562 & 9,948 & 820,773 & $23,761,020$ & $20,196,867$ & 0.258 \\
\hline ARIZONA PUBLIC SERVICE CO. & 189,600 & 11,721 & 174,416 & 10,557 & 623.100 & $16,034,731$ & $13,629,521$ & 0.164 \\
\hline ARKANSAS POWER \& LGHTCO. & 284,945 & 10,089 & 274,263 & 9,253 & 588,191 & $14,699,692$ & $12,494,738$ & 0.171 \\
\hline ATLLANTIC CITY ELECTRRIC CO & 127,706 & 4,781 & 123,520 & 4,606 & 456,460 & $7,668,300$ & $6,518,055$ & 0.179 \\
\hline BALTIMORE GAS \& ELECTRIC CO. & 180,505 & 11.591 & 175,656 & 11,015 & $1,052,088$ & $25,307,432$ & $21.511,317$ & 0.248 \\
\hline BANGOR HYDRO-ELECTRIC CO. & 37,321 & 861 & 37,321 & 861 & 115.434 & $1,574,528$ & $1,338,349$ & 0.197 \\
\hline BLACK HILLS CORP. & 18,147 & 975 & 16,685 & 943 & 52,288 & $1,379,420$ & $1,172,507$ & 0.158 \\
\hline BLACKSTONE VALLEY ELECTRIC CO & 12,591 & 745 & 11,236 & 570 & 83,904 & $1,226,938$ & $1,042,897$ & 0.232 \\
\hline BOSTON EDISON CO. & 60,752 & 4,905 & 53,442 & 4,249 & 657,080 & $12,597,607$ & $10,707,966$ & 0.320 \\
\hline CAMBRIDGE ELECTRICLIGHTCO. & 2,334 & 165 & 1,881 & 131 & 44,714 & $1,298,313$ & $1,103,566$ & 1.069 \\
\hline CAROUINA POWER \& LIGHT CO. & 378,169 & 14,933 & 366,912 & 14,056 & 999,063 & $32,896,617$ & $27,962,124$ & 0.252 \\
\hline CENTRAL HUDSON GAS \& ELEC CORP. & 83,636 & 2,340 & 80,175 & 2,189 & 256,503 & 0,244 & 14,207 & 0.238 \\
\hline CENTRAL ILLINOIS LIGHT CO. & 61,856 & 2,815 & 59,964 & 2,648 & 187,933 & $4,972,366$ & 26,511 & 0.202 \\
\hline CENTRAL ILLINOIS PUB SERV CO. & 106,801 & 4,234 & 100,929 & 3,739 & 308,752 & $7,327,890$ & 28,707 & 0.211 \\
\hline LOUISIANA ELEC CO., INC. & 112,357 & 3,289 & 112,222 & 3,024 & 208,335 & $5,863,212$ & 3,730 & 0.209 \\
\hline CENTRAL MAINE POWER CO. & 199,511 & 4,635 & 194,208 & 4,182 & & 9,978 & 3,531 & 0.234 \\
\hline CENTRAL POWER \& LIGHT CO. & 207,474 & 8,055 & 199,582 & 7,467 & 568,265 & $15,803,038$ & $13,432,582$ & 0.228 \\
\hline CENTRAL VERMONT PUB SERV CORP. & 65,690 & 1,211 & 63,898 & 1.148 & 134,661 & $1,978,337$ & $1,681,586$ & 0.186 \\
\hline NE LJGHT FUEL \& POWER CO & 6,815 & 270 & 6,581 & 252 & 351 & 547 & 1,015 & 0.292 \\
\hline CINCINNATI GAS \& ELECTRIC CO & 153,192 & 9,565 & 135,240 & 7,9231 & 584,691 & $16,436,040$ & $13,970,634$ & 0.224 \\
\hline SELECTRIC CO. & 2,110 & 70 & 2,070 & $-\overline{67 i}$ & 5,900 & 945 & 123,203 & 0.233 \\
\hline CITIZENS UT̃LITIES CO. (CT) & 39,583 & 1.190 & 36,090 & $\overline{993}$ & 94,622 & $1,400,504$ & 30,428 & 0.152 \\
\hline CLEVELAND ELECTRICILLUM CO & 138.754 & 7,622 & $130, \overline{711}$ & $\overline{6}, \overline{557}$ & 747,168 & 2,814 & 5,892 & 0.308 \\
\hline S SOUTTHERN POWER CO & 144,261 & 6,425 & 138,779 & 5,998 & 564,425 & $\overline{13,2}$ & 8.691 & 0.238 \\
\hline NEALTHEDISON CO. & 529,363 & 35,028 & 517,457 & 33,703 & $3,259,577$ & 816 & 05,944 & 0.227 \\
\hline WEALTH ELECTRIC CO. & 58,575 & 2,254 & 52,340 & 1,911 , & 304,380 & 036 & 5,131 & 0.181 \\
\hline DELECTRIC CO & 6,885 & 181 & 6,603 & 167 & 25,501 & 24,392 & $\overline{.733}$ & 0.274 \\
\hline TCUT LIGHT \& POWER CO. & 221,433 & 10,007 & 215,359 & 9,734 & $1,075,409$ & 5,822 & $17.310,949$ & 0.226 \\
\hline SUT VALLEY ELEC CO, INC. & 3.643 & 61 & 3,600 & 61 & 10,246 & $817 !$ & 3,294 & 0.277 \\
\hline CONSOLIDATED EDISON CO.-NY, INC. & 78,702 & 23,305 & $7 \overline{4,518}$ & 22,020 & $2,950,612$ & $35,119,289$ & $29,851,396$ & 0.172 \\
\hline CONSOLIDATED WATER POWER CO & 505 & 8,686 & 365 & 5,435 & $\overline{1,012}$ & $1,140,252$ & 969,214 & 0.023 \\
\hline VPOWER \& LGHT CO & 136,831 & 6,443 & 125,107 & 5,768 & 458,188 & $12,408,522$ & 10.547 .244 & 0.232 \\
\hline DELMARVA POWER \& LIGHT CO. & 103,387 & 4,564 & 98,274 & $4,251 !$ & 376,704 & 3,418 & 03,405 & 0.242 \\
\hline DETROIT EDISON CO. & 357,823 & 20,341 & 351,438 & $19,771 !$ & $1,945,624$ & 813 & 0,291 & 0.215 \\
\hline WERCO. & 590,409 & 33,394 & 575,601 & $32,029 \vdots$ & $1,672,970$ & 188 & 4,910 & 0.205 \\
\hline DUQUESNE LIGHT CO. & 99,243 & 5,089 & 97,621 & 5,014 & 576,616 & $11,557,196$ & 23,617 & 0.249 \\
\hline NEDISON CO. & 30,960 & 1,352 & 28,998 & $1,156 !$ & 175,618 & $2,458,593$ & $2,089,804$ & 0.229 \\
\hline EDISON SAULT ELECTRIC CO. & 7,994 & 252 & $7,26 \overline{9}$ & $214 !$ & 19,928 & 557,375 & 473,769 & 0.281 \\
\hline EMPIRE DISTRICT ELECTRIC CO. & 63,555 & 2,011 & 60,333 & 1,908 & 121,482 & $2,694,130$ & $2,290,011$ & 0.152 \\
\hline EXETER \& HAMPTON ELECTRIC CO & 6,885 & $259^{-1}$ & 6,412 & 235 & 35,119 & 457.116 & 388,549 & 0.210 \\
\hline FITCHBURG GAS \& ELEC LIGHT CO. & 5,692 & 162 & 5,198 & 142 & 25,573 & 9,304 & 322,408 & 0.288 \\
\hline FLORIDA POWER \& LIGHT CO. & 672,156 & 36,340 & $65 \overline{65,078}$ & 34,990 & $3,281,239$ & & 541 & 0.20 \\
\hline ER CORP. & 312,667 & 13,937 & 149 & $13,600 !$ & 1,182 & & 01,912 & 0.201 \\
\hline POWER CO. & 538,137 & 25,493 & 512,961 & 22,997 & $1,604,811$ & $55,614,242$ & $47,272,106$ & 0.261 \\
\hline GRANITE STATE ELECTRIC CO & 8,172 & 332 & 6,815 & 302 & 34,500 & 644,590 & 547,902 & 0.230 \\
\hline GREEN MOUNTAIN POWER CORP. & 29,294 & 894 & 27,973 & 825 & 78,526 & $1,692,179$ & $1,438,352$ & 0.221 \\
\hline GULF POWER CO. & 113,008 & 4,054 & 108,676 & $3,8 \overline{0}$ & 301,713 & & $6,937,560$ & 0.230 \\
\hline GULF STATTES UTILITIES CO. & 283,632 & 12,651 & 281,121 & 12,309 & 583,766 & $\overline{27,4}$ & $23,321,295$ & 0.24 \\
\hline EWATER POWER CO. & 201 & 102 & 169 & 85 & 53 & 112,823 & 95,900 & 0.143 \\
\hline ILIGHTING \& POWER CO. & $393,266 !$ & 27,073 & 383,171 & $\overline{14,737}$ & $\overline{1,416,786}$ & $59,376,419$ & $50, \overline{469,956}$ & 0.434 \\
\hline IDAHO POWER CO. & 161,267 & 7,220 & 156,449 & 6.664 & 302,834 & $11,606,255$ & $9,865,317$ & 0.188 \\
\hline IILLINOIS POWER CO. & 191,323 & 7,947 & 184,695 & 7,390 & 553,881 & $15,581.797$ & $13,244,527$ & 0.227 \\
\hline INDIANA MICHIGAN POWER CO. & 161,208 & $\overline{6.143}$ & 158,348 & $5,863 !$ & 517,391 & $14,259,949$ & $12,120,957$ & 0.26 \\
\hline INDIANAPOLIS POWER \& LIGHT CO. & 81,228 & 5,471 & 76,351 & 4,961 & 390,919 & $11,752,441$ & $9,989,575$ & 0.255 \\
\hline INTERSTATE POWER CO. & 47,734 & 1,775 & 45,787 & 1,665 & 159,282 & $4,534,889$ & $3,854,656$ & 0.294 \\
\hline IOWA ELECTRIC LIGHT \& POWER CO & 69,618 & 2,451 & 66,757 & 2,268 & 212,070 & $4,274,932$ & $3,633,692$ & 0.203 \\
\hline
\end{tabular}


Table A.2 (Continued)

\begin{tabular}{|c|c|c|c|c|c|c|c|c|}
\hline UTILITIES & Transformers & Capacity & Transformers & In-Service & Number of & Total Annual & Annual Salos & Average ${ }^{\circ}$ \\
\hline IOWA SOUTHERN UTILITIES & 34,072 & 1,432 & 32,701 & 1,329 & 94,863 & $2,361,162$ & $2,006,988$ & 0.192 \\
\hline IOWA-ILLINOIS GAS \& ELEC. CO. & 57,612 & 2,784 & 53,643 & 2,466 & 196,624 & $4,589,440$ & $3,901,024$ & 0.201 \\
\hline JERSEY CENTRAL POWER \& LIGHT CO & 198,438 & 10,257 & 190,511 & 9,535 & 893,125 & $16,574,401$ & $14,088,241$ & 0.187 \\
\hline KANSAS CITY POWER \& LIGHT CO. & 97,901 & 5,601 & 96,372 & 5,333 & 416,052 & $10,658,908$ & $9,060,072$ & 0.215 \\
\hline KANSAS GAS \&ELECTRIC CO. (WR) & 97,092 & 4,447 & 93,842 & 4,160 & 265.275 & $7,287.278$ & $6,194,186$ & 0.189 \\
\hline KENTUCKY POWER CO. & 79,023 & $\overline{2,432}$ & 77,231 & 2,276 & 157,116 & $5,705,743$ & $4,849,882$ & 0.270 \\
\hline KENTUCKY UTILITIES CO. & 176,731 & 6,111 & 170,500 & 5,389 & 425,377 & $12,551,782$ & $10,669,015$ & 0.251 \\
\hline KINGSPORT POWER CO. & 12,652 & 558 & 12,180 & 520 & 39,715 & $1,804,267$ & $1,533,627$ & 0.374 \\
\hline LOCKHART POWER CO & 2,827 & 81 & 2,679 & 76 & 5,352 & 191,359 & 162,655 & 0.271 \\
\hline LONG ISLAND LIGHTING CO. & 179,888 & 9,834 & 154,191 & 7,742 & $1,009,313$ & $15,443,788$ & $13,127,220$ & 0.215 \\
\hline LOUISIANA POWER \& LIGHT CO. & 182,366 & 9,127 & 172,586 & 8,195 & 593,297 & $26,701,341$ & $22,696,140$ & $\mathbf{0 . 3 5 1}$ \\
\hline LOUISVILLE GAS \& ELECTRIC CO. & 78,104 & 4,265 & 75,717 & 4,135 & 331,156 & $9,234,911$ & $7,849,674$ & 0.241 \\
\hline MADISON GAS \& ELECTRIC CO. & 18,870 & 1,173 & 17,497 & 1,053 & 114,216 & $2,310,018$ & $1,963,515$ & 0.237 \\
\hline MAINE PUBLIC SERVICE CO. & 11,568 & 222 & 11,004 & 195 & 34,499 & 523,852 & 445,274 & 0.290 \\
\hline MASSACHUSETTS ELECTRIC CO. & 147,507 & 7,473 & 137,517 & 6,556 & 908,606 & $15,304,099$ & $13,008,484$ & 0.252 \\
\hline METROPOLITANEDISON CO. & 148,504 & 5,904 & 145,241 & 5,509 & 440,295 & $9,934,412$ & $8,444,250$ & 0.194 \\
\hline MIDWEST POWER SYSTEMS, INC. & 131,377 & $\mathbf{5 , 8 4 5}$ & 130,405 & 5,772 & 414,513 & $8,858,682$ & $7,529,880$ & 0.165 \\
\hline MINNESOTA POWER \& LIGHT & 37,897 & 1,247 & 35,284 & 1,075 & 117.168 & $8,039,939$ & $6,833,948$ & 0.806 \\
\hline MISSISSIPPIPOWER \& LIGHT CO & 151,999 & 5,489 & 148,490 & 5,251 & 354,215 & $9,397,402$ & $7,987,792$ & 0.193 \\
\hline MONONGAHELA POWER CO. & 172,499 & 2,963 & 169,383 & 2,837 & 334,543 & $9,167,541$ & $7,792.410$ & 0.348 \\
\hline MONTANA DAKOTA UTILITIES CO & 32,835 & 1,144 & 29,396 & 1,008 & 109,834 & $1,829,933$ & $1,555,443$ & 0.196 \\
\hline MONTANA POWER CO. & 107,387 & 3,518 & 100,911 & 3,066 & 255,233 & $6,973,801$ & $5,927,731$ & 0.245 \\
\hline NARRAGANSETT ELECTRIC CO & 53,352 & 2,207 & 50,158 & 1,933 & 319,004 & $4,586,030$ & $3,898,126$ & 0.256 \\
\hline NEVADA POWER CO. & 57,527 & 5,323 & 54,077 & 4,857 & 374,317 & $10,067,905$ & $8,557,719$ & 0.223 \\
\hline NEWORLEANS PUBLIC SERVICE, INC. & 34,847 & 3,180 & 32,251 & 2,509 & 189,682 & $5,129,622$ & $4,360,179$ & 0.220 \\
\hline NEW YORK STATE ELEC \& GAS CORP. & 282,864 & 9,116 & 273,090 & 8,233 & 782,772 & $13,209,253$ & $11,227,865$ & 0.173 \\
\hline NEWPORT ELECTRIC CORP & 5.256 & 275 & 4,829 & 230 & 31,490 & 540,385 & 459,327 & 0.253 \\
\hline NIAGARA MOHAWK POWER CORP. & 410,343 & 16,462 & 358,440 & 13,524 & $1,525,625$ & $33,351,333$ & $28,348,633$ & 0.266 \\
\hline NORTHERN INDIANA PUBLLC SERVICE CO & 107,418 & 4,554 & 103,403 & 4,111 & 388,223 & $13,271,106$ & $11,280,440$ & 0.348 \\
\hline NORTHERN STATES POWER CO (MN) & 206,019 & 11,975 & 197.191 & 11.125 & $1,168,211$ & $26,111,894$ & $22,195,110$ & 0.253 \\
\hline NORTHERN STATES POWER CO (WI) & 67.111 & 2,346 & 64,128 & 2,150 & 201,347 & $4,529,793$ & $3,850,324$ & 0.227 \\
\hline NORTHWESTERN PUBLIC SERVICE CO. & 17,928 & 921 & 16,461 & 772 & 53,615 & 894,077 & 759,965 & 0.125 \\
\hline NORTHWESTERN WISCONSIN ELEC CO & 5,695 & 103 & 5,215 & 89 & 11,734 & 114,408 & 97,247 & 0.139 \\
\hline OHIO EDISON CO. & 261,441 & 8,863 & 251,829 & 8,166 & 912,543 & $20,545,476$ & $17,463,655$ & 0.271 \\
\hline OHIO POWER CO. & 230,000 & 7,468 & 224,364 & 7,052 & 648,358 & $28,948,620$ & $24,606,327$ & 0.443 \\
\hline OKLAHOMA GAS \& ELECTRIC CO. & 170,510 & 12,620 & 157,283 & 4,702 & 649,773 & $18,316,230$ & $15,568,796$ & 0.420 \\
\hline ORANGE \& ROCKLAND UTILITIES, INC. & 61,922 & 3,213 & 48,104 & 2,251 & 186,560 & $2,973,008$ & $2,527,057$ & 0.142 \\
\hline OTTER TAIL POWER CO. & 40,192 & 1,698 & 38,434 & 1,560 & 121,947 & $2,926,878$ & $2,487,846$ & 0.202 \\
\hline PACIFIC GAS \& ELECTRIC CO. & 917,933 & 35,915 & 873,364 & 34,072 & $4,275,304$ & $71,799,944$ & $61,029,952$ & 0.227 \\
\hline PECOENERGYCO. & 164,556 & 11,222 & 159,218 & 10,537 & $1,440,637$ & $31,264,491$ & $26,574,817$ & 0.320 \\
\hline PENNSYLVANIA ELECTRIC CO. & 175,727 & 6.946 & 163,291 & 5,959 & 556.541 & $11,710,902$ & $9,954,267$ & 0.212 \\
\hline PENNSYLVANIA POWER \& LIGHT CO. & 393,282 & 11,943 & 388.479 & 11,630 & $1,179,137$ & $28,477,129$ & $24,205,560$ & 0.264 \\
\hline PENNSYLVANIA POWER CO. & 53,004 & 1,407 & 51.064 & 1,297 & 136,760 & $3,513,321$ & $2,986,323$ & 0.292 \\
\hline PORTLAND GENERALELECTRIC CO & 162,186 & 7,123 & 153,656 & 6,655 & 607,051 & $15,643,858$ & $13,297,279$ & 0.253 \\
\hline POTOMACEDISONCO. & 155,864 & 4,738 & 149,915 & 4,385 & 343.189 & $10,777,749$ & $9,161,087$ & 0.265 \\
\hline POTOMAC ELECTRIC POWER CO. & 104,762 & 12,119 & 95,661 & 10,846 & 656,875 & $22,354,746$ & $19,001,534$ & 0.222 \\
\hline PSCOF COLORADO & 168,942 & 9,355 & 162,011 & 8.659 & 976,095 & $19,003,387$ & $16,152,879$ & 0.237 \\
\hline PSCOFNEW HAMPSHIRE & 124,387 & 4,332 & 120,870 & 4,031 & 398,153 & $6,206,786$ & $5,275,768$ & 0.166 \\
\hline PSCOFNEW MEXICO & 66,757 & 2,688 & 65,841 & 2,602 & 300,492 & $5,358,246$ & $4,554,509$ & 0.222 \\
\hline PSIENERGY,INC. & 184,857 & 7,925 & 179,099 & 7,418 & 607,473 & $19,460,853$ & $16,541,725$ & 0.283 \\
\hline PUBUC SERVICE ELECTRIC \& GAS & 302,064 & 19,704 & 297,668 & 19,154 & $1,853,398$ & $36,786,395$ & $31,268,436$ & 0.207 \\
\hline PUGET SOUND POWER \& LIGHT CO. & 247,956 & 10,493 & 241,936 & 10,087 & $\pi 77,967$ & $18,224,495$ & $15,490,821$ & 0.195 \\
\hline ROCHESTER GAS \& ELECTRIC CORP. & 73,733 & 2,888 & 65.183 & 2,175 & 332,565 & $6,455,986$ & $5,487,588$ & 0.320 \\
\hline ROCKLAND ELECTRIC CO & 21,091 & 1.062 & 17,717 & 859 & 62,761 & $1,196,191$ & $1,016,762$ & 0.150 \\
\hline SAN DIEGO GAS \& ELECTRIC CO. & 161,567 & 9,829 & 157,453 & 9,409 & $1,117,352$ & $15,093,221$ & $12,829,238$ & 0.173 \\
\hline SIERRA PACIFIC POWER CO & 59,669 & 3,427 & 54,241 & 2,938 & 247,927 & $6,055,518$ & $5,147,190$ & 0.222 \\
\hline SOUTH BELOIT WATER GAS \& ELECTRIC CO & 2,062 & 103 & 2,062 & 103 & 6,234 & 165,606 & 140,765 & 0.173 \\
\hline SOUTH CAROLINA ELECTRIC \& GAS & 193,066 & 7,990 & 188,568 & 7.469 & 458,205 & $14,854,884$ & $12,626,651$ & 0.214 \\
\hline
\end{tabular}


Table A. 2 (Continued)

\begin{tabular}{|c|c|c|c|c|c|c|c|c|}
\hline UTILITIES & Transformers: & Capacity & Transformers. & In-Service : & Number of & Total Annual & Annual Sales & Average $^{\circ}$ \\
\hline SOUTHERN CALIFORNIA EDISON CO. & 652,198 & 35,362 & 641,250 & 34,758 & $4,094,689$ & $70,933,334$ & $60,293,334 !$ & 0.220 \\
\hline SOUTHERN INDIANA GAS \& ELECTRIC CO. & 46,436 & 1,870 & 44,414 & 1,732 & 116,065 & $3,953,177$ & $3,360,200$ & $\overline{0.246}$ \\
\hline SOUTHWESTERN ELECTRIC SERV CO. & 24,685 & 611 & 23,361 & $553:$ & 39,794 & $877,530 !$ & 745,901 & 0.171 \\
\hline ST JOSEPH LIGHT \& POWER CO. & 20,995 & $89 \overline{4}$ & 19,490 & $761^{\circ}$ & 59,751 & $1,343,297$ & $1,141,802$ & 0.190 \\
\hline SUPERIOR WATER LIGHT \& POWER CO & 1,983 & 83 & 1,829 & 74 & 13,409 & 526,876 & 447,845 & $\overline{0.768}$ \\
\hline TAMPA ELECTRIC CO. & 121,448 & 6,497 & 120,028 & 6,356 & 468,996 & $13,551,758$ & $11,518,994$ & 0.230 \\
\hline TEXAS UTILITIES ELECTRIC CO. & 676,443 & $3 \overline{5,561}$ & 653,610 & 33,267 & $2,195,151$ & $76,367,549$ & $64,912,417$ & 0.247 \\
\hline TEXAS-NEW MEXICO POWER CO. & 97,787 & 3,132 & 91,000 & 2,777 & 207,885 & $6,063,137$ & $5,153,666$ & 0.235 \\
\hline TOLEDO EDISON CO. & 73,263 & 3,631 & $7 \overline{0,776}$ & 3,429 & 284,700 & $7,601,055$ & $6,460,897$ & 0.239 \\
\hline TUCSON ELECTRIC POWER CO. & 61,004 & 3,692 & 57,889 & 3,425 & 275,488 & $6,381,097$ & $5,423,932$ & 0.201 \\
\hline UNIONELECTRIC CO. & 274,837 & 15,055 & 267,577 & 14,324 & $1,116,678$ & $29,418,239$ & $25,005,503$ & $\overline{0.221}$ \\
\hline UNION LIGHT, HEAT \& POWER CO. & 26,713 & 1,441 & 25,240 & 1,327 & 108,127 & $2,807,171$ & $2,386,095$ & 0.228 \\
\hline UNITED ILLUMINATING CO. & 56,574 & 3,493 & $\overline{53,356: 3}$ & 3,052 & 305,159 & $5,152,824$ & $4,379,900$ & 0.182 \\
\hline UPPER PENINSULA POWER CO. & 18,876 & $440^{-}$ & 18,016 & 400 & $61,3 \overline{27}$ & 679,683 & 577,731 & 0.183 \\
\hline VIRGINIA ELECTRIC \& POWER CO & 523,135 & 27,552 & 510,307 & 26,293 & $1,819,054$ & $54, \overline{664,734}$ & $46,465,024$ & 0.224 \\
\hline WASHINGTON WATER POWER CO. & 90,422 & 3,444 & 88,005 & 3,273 & 256,675 & $6,920,831$ & $5,882,706$ & 0.228 \\
\hline WEST PENN POWER CO. & $294,400 !$ & 6,449 & $285.809^{-}$ & $\overline{6.141}$ & 636,629 & $15,882,702$ & $13,500,297$ & 0.279 \\
\hline WEST TEXAS UTILTTIES CO. & 80,471 & 2,469 & 78,095 & 2,292 & $17 \overline{9,573}$ & $4,067,352$ & $3,457,249$ & $0 . \overline{191}$ \\
\hline WESTERN MASSACHUSETTS ELEC CO. & 38,345 & 1,743 & 37,108 & $1,6 \overline{8}$ & 191,912 & $3,600,887$ & $3,060,754$ & 0.233 \\
\hline WHEELING POWER CO. & 11,441 & 440 & 11,123 & 408 & 40,920 & $1,825,970$ & $1,552,075$ & $\overline{0.483}$ \\
\hline WSCONSIN ELECTRIC POWER CO & $209,136 !$ & 10,407 & 188,218 & $8,922 !$ & 913,123 & $22,303,551$ & $18,958,018$ & 0.270 \\
\hline WISCONSIN POWER \& LIGHT CO & 137,494 & 4,534 & 134,656 & 4,260 & $3 \overline{45,124}$ & $7,433,018$ & $6,318,065$ & 0.188 \\
\hline WISCONSIN PUBLIC SERVICE CORP. & 141,344 & 4,556 & 133,279 & 3,916 & 336,268 & $7,702,176$ & $6,546,850$ & $\overline{0.212}$ \\
\hline TOTALS & $20,440,698$ & 937,443 & $19,456,361$ & 879,977 & $\overline{79,974,333}$ & $1,922,172,695$ & $1,633,846,791$ & $\overline{0.236}$ \\
\hline
\end{tabular}

1 


\section{Appendix B: Derivation of Total Owning Cost}

The usual expression for total owning cost (TOC) is of the form

TOC $=$ bid price + cost of core losses + cost of load losses ,

where

cost of core losses $=\mathrm{A}(\$ / \mathrm{W}) \times$ core loss $(\mathrm{W}) \times$ loss multiplier

cost of load losses $=\mathrm{B}(\$ / \mathrm{W}) \times$ load loss $(\mathrm{W}) \times$ loss multiplier ,

and

$A=$ equivalent first cost of no-load losses $(\$ / W)$

$\mathrm{B}=$ equivalent first cost of load losses $(\$ / W)$.

The $\mathrm{A}$ and $\mathrm{B}$ factors are given by the expressions

$\mathrm{A}=(\mathrm{SC}+\mathrm{EC} \times \mathrm{HPY}) /(\mathrm{FCR} \times 1000)$

and

$\mathrm{B}=(\mathrm{SC} \times \mathrm{RF}+\mathrm{EC} \times \mathrm{LsF} \times \mathrm{HPY}) \times \mathrm{PL}^{2} /(\mathrm{FCR} \times 1000)$,

where $\mathrm{SC}=$ avoided cost of system capacity $=\mathrm{GC}+\mathrm{TD}$. The basic financial, cost, and load parameters are defined as follows:

$\mathrm{SC}=$ avoided cost of system capacity $(\$ / \mathrm{kW})$ - The levelized avoided (incremental) cost of generation, transmission, and distribution capacity necessary to supply the next kilowatt of load to the transformer coincident with peak load.

$\mathrm{GC}=$ avoided cost of generating capacity $(\$ / \mathrm{kW})$

$\mathrm{TD}=$ avoided cost of transmission and distribution capacity $(\$ / \mathrm{kW})$

$\mathrm{EC}=$ avoided cost of energy $(\$ / \mathrm{kW})$ - The levelized avoided (incremental) cost for the next kilowatt produced by the utility's generating system.

HPY = energized hours per year - Usually 8760 , but lower in special cases (for example, seasonal loads).

$\mathrm{FCR}=$ fixed charge rate (\%) - The cost of carrying a capital investment, made up of the weighted cost of capital, depreciation, taxes, and insurance. Expressed in decimal form. 
$\mathrm{RF}=$ peak responsibility factor (unit-less) $-\mathrm{A}$ measure of the load diversity on the transformer. It is never greater than 1 and is expressed in decimal form.

$\mathrm{L}_{\mathrm{s}} \mathrm{F}=$ transformer loss factor (unit-less) - The ratio of average load losses to peak load losses. It is never greater than 1 and is expressed in decimal form.

PL = equivalent annual peak load (unit-less) - The transformer's levelized annual peak load. It is generally assumed that the load grows from an initial peak load with an estimated growth rate to some maximum level where the transformer is changed out to a lower load site. By its very nature, there is great uncertainty in this parameter. However, levelizing tends to reduce the impact of this uncertainty.

The loss multiplier (unit-less) is a measure of transmission and distribution system losses between the generating unit and the transformer being evaluated. It is generally about 50 to $75 \%$ of total system losses ( 5 to $7 \%$ ).

The transformer cost and performance parameters are as follows:

$\mathrm{P} \quad=$ bid price $(\$)$ - The price for which a manufacturer will supply the transformer delivered to a specified point.

$\mathrm{NL}=$ no-load or core losses (watts) - The excitation losses at rated voltage when the transformer is not supplying a load. These losses are continuous and are not loaddependent.

$L L=$ load losses (watts) - Losses that are a result of $I^{2} R$ losses and eddy current losses in the transformer windings. They are dependent on the square of the per unit load, and specifications should state the allowed temperature rise. Load at less than full load should be corrected to account for the effects of lower temperature. 


\section{Appendix C: Temperature Corrections}

\section{C.1 INTRODUCTION}

The NEMA proposed standard TP-1 incorporates certain temperature adjustments in calculating the efficiency of both dry and liquid-immersed transformers. Basically, the load losses are measured or adjusted to full load rise plus $20^{\circ} \mathrm{C}-$ i.e., $85^{\circ} \mathrm{C}$ for liquid-immersed transformers and typically $150^{\circ} \mathrm{C}$ for dry transformers. The efficiency is then calculated from the equation

$$
\eta=100 \times(S \times \mathrm{kVA} \times 1000) /\left(S \times S_{B} \times 1000+N L+L L \times S^{2} \times T\right)
$$

where

$S=$ per unit load relative to nameplate rating $=0.35$ for low voltage dry or 0.5 for medium voltage dry and liquid-filled transformers;

$S_{B}=$ nameplate rating in $\mathrm{kVA}$;

$N L=$ no load or core losses in watts at $20^{\circ} \mathrm{C}$;

$L L=$ load loss in watts at full-load rated temperature, consistent with IEEE C57.12.00 and C57.91-1995 (liquid) and C57.12.01 and C57.96-1989 (dry); and

$T=$ load loss temperature correction factor to correct to a specified temperature; i.e., $75^{\circ} \mathrm{C}$ for dry-type transformers and $85^{\circ} \mathrm{C}$ for liquid-immersed transformers.

\section{C.2 LOAD LOSS CORRECTION FACTOR}

Since efficiency is stated at $85^{\circ} \mathrm{C}$ for liquid-filled transformers, $T=1.0$ as discussed below. For drytype transformers, the standard assumes that $10 \%$ of the $L L$ value is attributed to eddy and stray losses. The standard specifies six correction factors corresponding to $80^{\circ} \mathrm{C}, 115^{\circ} \mathrm{C}$, and $150^{\circ} \mathrm{C}$ rise designs and either aluminum or copper windings. The choice of a value to use in the present analysis is discussed in the following paragraphs.

The nominal temperature correction point for liquid-immersed transformers is essentially full load temperature rise plus ambient; hence, no temperature correction is required. Liquid units could have been corrected to the same $75^{\circ} \mathrm{C}$ point as dry-type units, but the correction would have been minor $(T=0.97-0.98)$. Taking into account the change in oil viscosity essentially eliminates even this small correction; C57.91-1995 (par. 6.4.2, Load Loss, and par. 6.4.3, Viscosity of Oil) states that the reduction in viscosity of the insulating (cooling) liquid with increased temperature "tends to offset the increase in winding resistance." This implies that for this small temperature change, the average winding resistance is essentially constant and that no temperature correction is required in the standard specification. Temperature correction can be applied to liquid-immersed transformers loaded at less than full load; however, the effects are not as pronounced as those found in dry-type . transformer evaluations.

On the other hand, the TP-1 efficiency standard for dry transformers does include a temperature correction. For dry transformers, the number of insulation classes (three), the number of conductor types (two), the wide range of loading conditions, the variation of design and ventilation types, the voltage levels (two), and the need to carefully consider the ambient temperature make this correction 
very difficult to include in a standard. Nevertheless, TP-1 includes in an appendix a set of temperature-correction coefficients. They are based upon the following assumptions:

- a $10 \%$ stray and eddy resistance component that varies inversely with temperature,

- both copper and aluminum conductor,

- three full-load temperature rises (insulation types),

- a $20^{\circ} \mathrm{C}$ ambient, and

- a conductor operating temperature of $75^{\circ} \mathrm{C}$.

While this reduces the number of correction coefficients to six (three insulation systems times two conductor types), explicit evaluation of a standard would require a knowledge of the number of transformers produced in each size, voltage class, insulation system, and conductor type. Adding load variation further complicates the evaluation. Fortunately, the $75^{\circ} \mathrm{C}$ conductor temperature corresponds to a transformer with aluminum windings and $150^{\circ} \mathrm{C}$ full-load temperature rise operating at $35 \%$ load in a hot environment $\left(40^{\circ} \mathrm{C}\right.$ ambient) or at $50 \%$ load in a normal environment $\left(20^{\circ} \mathrm{C}\right.$ ambient), which essentially constitute the operating conditions for low- and medium-voltage dry transformers. Since most dry-type transformer designs incorporate a $150^{\circ} \mathrm{C}$ rise insulation system and an aluminum conductor and the correction factor presents a minimal load loss savings, in this analysis those cases requiring an the efficiency calculation from inputs $N L$ and $L L$ will use the correction factor $T=0.8152$ for all dry transformer systems loaded as specified in TP-1. Evaluations of dry transformers loaded at other than the TP-1 levels require the calculation of a more realistic correction factor; unless otherwise indicated, this correction factor will be assumed to be an aluminum conductor with a $150^{\circ} \mathrm{C}$ full-load temperature rise above $20^{\circ} \mathrm{C}$ ambient. For those cases in this study for which only the efficiency is available and values of $N L$ and $L L$ are required, estimates of the losses are obtained by assuming an appropriate point of maximum efficiency (typically a $35 \%$ or $50 \%$ load), an appropriate load, and an appropriate temperature correction, and calculating the maximum $N L$ and $L L$ values just meeting the specified efficiency. Details and examples of these calculations are presented in Appendix D.

\section{C.3 DRY-TYPE TRANSFORMERS}

The correction factor for temperature for dry-type transformers is based upon material presented in IEEE C59.96-1989, Guide for Loading Dry-Type Distribution and Power Transformers.

To calculate the approximate change in the electrical resistance of the winding conductor relative to the full-load resistance, certain parameters must be specified - viz., the coefficient of resistance for the conductor material, the relative transformer load, the type of dry transformer, the ambient temperature, and the full-load temperature rise above ambient. Since eddy and stray losses vary inversely with temperature and dc resistive losses vary directly with temperature, the fraction of eddy and stray losses must be specified (5-15\% is typical) to determine the final correction factor.

The coefficient is calculated as follows:

1. Determine conductor operating temperature at the operating load specified using the equation

$$
T_{\mathrm{op}}=S^{2 m} \times T_{\text {rise }}
$$


where

$S=$ per unit load relative to nameplate;

$m=0.8$ for a ventilated, self-cooled dry-type,

$=1.0$ for a forced-cooled dry-type, or

$=0.7$ for sealed self-cooled dry-type; use $m=0.8$ if uncertain;

$T_{\text {rise }}=80^{\circ} \mathrm{C}, 115^{\circ} \mathrm{C}$, or $150^{\circ} \mathrm{C}$ for $150^{\circ} \mathrm{C}, 180^{\circ} \mathrm{C}$, or $220^{\circ} \mathrm{C}$ insulation system, respectively; use $150^{\circ} \mathrm{C}\left(220^{\circ} \mathrm{C}\right.$ insulation system $)$ if uncertain.

2. Calculate the resistance ratio from the equation

$$
R_{\mathrm{op}} / R_{\mathrm{ref}}=\left(F+T_{\mathrm{op}}+\text { ambient }\right) /\left(F+T_{\text {rise }}+\text { ambient }\right) \text {, }
$$

where $F=$ thermal coefficient of resistance $=225$ for aluminum and 234.5 for copper, and the ambient temperature $=20^{\circ} \mathrm{C}$ unless otherwise specified. Note that TP-1 takes conductor temperature to be $75^{\circ} \mathrm{C}$ and thus does not explicitly specify either ambient or $T_{\mathrm{op}}$.

3. Calculate the temperature correction factor using the equation

$$
\text { - } T=L_{\mathrm{dc}} \times\left(R_{\mathrm{op}} / R_{\mathrm{ref}}\right)+L_{\mathrm{edd} y} \times\left(R_{\mathrm{ref}} / R_{\mathrm{op}}\right) \text {, }
$$

where $L_{\text {eddy }}=$ per unit load loss due to stray and eddy currents ( 0.1 unless specified $)$ and $L_{\mathrm{dc}}=$ per unit load loss due to dc resistance $\left(1-\mathrm{L}_{\text {eddy }}\right)$.

As an example, assume $S=0.5, m=0.8, T_{\text {rise }}=150^{\circ} \mathrm{C}$, aluminum conductor, $10 \%$ eddy and stray loss fraction, and an ambient temperature of $20^{\circ} \mathrm{C}$. Then,

$$
\begin{aligned}
& T_{\mathrm{op}}=0.5^{1.6} \times 150=49.48^{\circ} \mathrm{C} \\
& R_{\mathrm{op}} / R_{\mathrm{ref}}=(225+49.48+20) /(225+150+20)=0.7455 \\
& T=0.9 \times 0.7455+0.1 / 0.7455=0.8051
\end{aligned}
$$

Note that, as would be expected, the average winding temperature $\left(49.48+20=69.48^{\circ} \mathrm{C}\right)$ is less than the $75^{\circ} \mathrm{C}$ average specified by TP- 1 and that the effective load losses are lower. 


\section{Appendix D: Calculation of No Load and Load Losses from a Specified Efficiency}

Given the condition that a transformer design must exceed a specified efficiency level, the following inequality holds:

$$
\% \eta \leq 100 \times S_{B} \times P \times 1000 /\left(S_{B} \times P \times 1000+N L+L L \times P^{2} \times T\right),
$$

where

$$
\begin{aligned}
P \quad= & \text { per unit load relative to nameplate rating at which the efficiency is specified; } \\
S_{B}= & \text { nameplate rating in } \mathrm{kVA} ; \\
\mathrm{NL}= & \text { no-load or core losses in watts at } 20^{\circ} \mathrm{C} ; \\
\mathrm{LL}= & \text { load loss in watts at full-load rated temperature, consistent with IEEE C57.12.00 and } \\
& \mathrm{C} 57.91-1981 \text { (liquid) and } \mathrm{C} 57.12 .01 \text { and } \mathrm{C} 57.96-1989 \text { (dry); and } \\
\mathrm{T}= & \text { load loss temperature correction factor to correct to a specified temperature; i.e., } 75^{\circ} \mathrm{C} \\
& \text { for dry type and } 85^{\circ} \mathrm{C} \text { for liquid-filled transformers. }
\end{aligned}
$$

Thus, for the efficiency to be greater than $\% \eta$, the inequality

$$
\text { Total Losses }=\left(N L+L L \times P^{2} \times T\right) \leq \mathrm{kVA} \times P \times 1000 \times[(100-\% \eta) / \% \eta]
$$

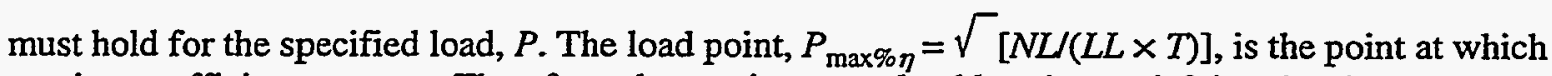
maximum efficiency occurs. Therefore, the maximum no-load loss just satisfying the above inequality is given by

$$
N L=S_{B} \times P \times 1000 \times[(100-\% \eta) / \% \eta] /\left[1+\left(P / P_{\max \% \eta}\right)^{2}\right]
$$

and

$$
L L=N L /\left[T \times\left(P_{\max \% \eta}\right)^{2}\right]
$$

For the TP-1 designs supplied by manufacturers, the value of $P_{\max } \% \eta$ ranges from 45 to $65 \%$, with the majority near $50 \%$ for medium-voltage transformers. For low-voltage units, $P_{\max } \% \eta$ is near $35 \%$. Hence, unless otherwise stated, the nominal load $P$, minimum $\% \eta$, and temperature correction factor used in this analysis assumes $P_{\max \% \eta}=P=50 \%$ for medium voltage or $35 \%$ for low voltage, and $T=$ 0.8152 for dry type or 1.0 for liquid-immersed.

As an example, consider the 150-kVA, low-voltage, aluminum, wound dry-type, three-phase transformer design. The specified minimum efficiency is $98.3 \%$ and

$$
N L \leq 150 \times 0.35 \times 1000 \times(1.7 / 98.3) / 2=454 \text { watts. }
$$


Taking $N L=454 \mathrm{~W}, L L=454 /\left(0.8152 \times 0.35^{2}\right)=4546 \mathrm{~W}$. Variation of \% $\eta$ with load for both nominal and temperature-corrected designs is shown in Fig. D.1. Temperature correction for an ambient of $40^{\circ} \mathrm{C}$ was calculated explicitly for the design; as discussed in the section on temperature correction, the NEMA standard's value (0.8152) is slightly larger than the calculated value of $T=$ 0.8111 at $P=35 \%$ and $T_{\text {rise }}=115^{\circ} \mathrm{C}$. Had the designer chosen to place the point of maximum efficiency at $P_{\max \% \eta}=50 \%$, the minimal core and load loss values become $\dot{N} L=609 \mathrm{~W}$ and $L L=$ $2988 \mathrm{~W}$. Similarly, if $P_{\max \% \eta}=60 \%, N L=677 \mathrm{~W}$, and $L L=2308 \mathrm{~W}$, illustrating the extreme options open to the designer in meeting NEMA TP-1.

\section{0 kVA LV Dry Type}

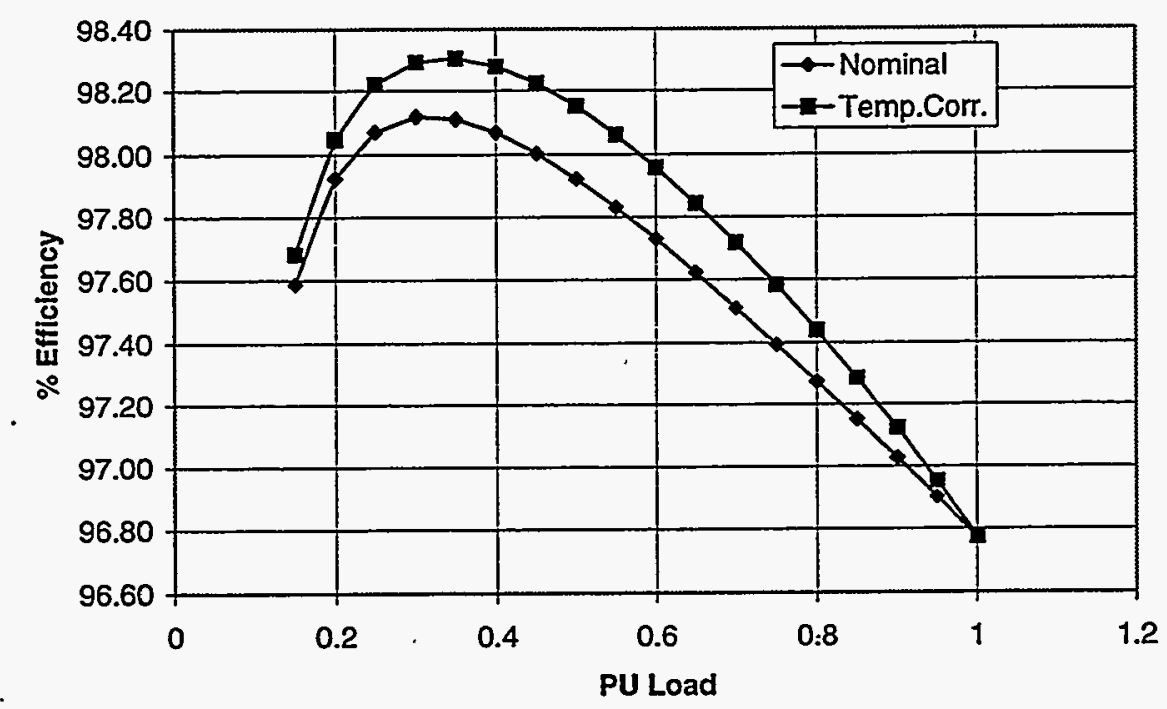

Fig. D.1 


\section{Appendix E: The TP-1 Survey of Transformer Manufacturers}

This survey of NEMA and non-NEMA manufacturers was conducted by NEMA and ORNL during 1996 to determine how transformer manufacturers would design transformers to meet the NEMA TP1 transformer efficiency standard. The survey also requested information on nonevaluated transformers and the additional costs associated with the purchase of a TP-1 transformer instead of a nonevaluated one.

DISTRIBUTION TRANSFORMER SURVEY DATA

July 15,1996

Tables 1-4

Table 1. The NEMA minimum efficiency standard TP 1-1996 for distribution transformers

\begin{tabular}{|c|c|c|c|c|c|c|c|}
\hline$\therefore$ & $\because$ Sing & Phase & $x_{2}$ & 等, & $\mathbf{T h r}$ & Phașe & $\because$ \\
\hline $\begin{array}{c}\text { Size } \\
(\mathrm{kVA})^{a}\end{array}$ & $\begin{array}{c}\text { Liquid } \\
\text { MV }\end{array}$ & $\begin{array}{c}\text { Dry-type } \\
\text { LV }\end{array}$ & $\begin{array}{c}\text { Dry-type } \\
\text { MV }\end{array}$ & $\begin{array}{c}\text { Size } \\
(\mathrm{kVA})^{a}\end{array}$ & $\begin{array}{c}\text { Liquid } \\
\text { MV }\end{array}$ & $\begin{array}{c}\text { Dry-yype } \\
\text { LV }\end{array}$ & $\begin{array}{c}\text { Dry-type } \\
\text { MV }\end{array}$ \\
\hline 10 & 98.3 & - & - & 15 & 98.0 & 97.0 & 96.8 \\
\hline 15 & 98.5 & 97.7 & 97.6 & 30 & 98.3 & 97.5 & 97.3 \\
\hline 25 & 98.7 & 98.0 & 97.9 & 45 & 98.5 & 97.7 & 97.6 \\
\hline 37.5 & 98.8 & 98.2 & 98.1 & 75 & 98.7 & 98.0 & 97.9 \\
\hline 50 & 98.9 & 98.3 & 98.2 & 112.5 & 98.8 & 98.2 & 98.1 \\
\hline 75 & 99.0 & 98.5 & 98.4 & 150 & 98.9 & 98.3 & 98.2 \\
\hline .100 & 99.0 & 98.6 & 98.5 & 225 & 99.0 & 98.5 & 98.4 \\
\hline 167 & 99.1 & 98.7 & 98.7 & 300 & 99.0 & 98.6 & 98.5 \\
\hline 250 & 99.2 & 98.8 & 98.8 & 500 & 99.1 & 98.7 & 98.7 \\
\hline 333 & 99.2 & 98.9 & 98.9 & 750 & 99.2 & 98.8 & 98.8 \\
\hline 500 & 99.3 & - & 99.0 & 1000 & 99.2 & 98.9 & 98.9 \\
\hline 667 & 99.4 & - & 99.0 & 1500 & 99.3 & - & 99.0 \\
\hline 833 & 99.4 & - & 99.1 & 2000 & 99.4 & - & 99.0 \\
\hline & & & & 2500 & 99.4 & - & 99.1 \\
\hline
\end{tabular}

Note: The minimum efficiencies are for an effective per unit load of 0.35 for low-voltage (LV) units and 0.5 for medium-voltage (MV) units. Medium voltage includes 5-, 15-, 25-, and 35-kV classes. Average winding temperature $=85^{\circ} \mathrm{C}$ for liquid-filled units, corresponding to a $65^{\circ} \mathrm{C}$ rise plus $20^{\circ} \mathrm{C}$ ambient. For dry-type units, average winding temperature $=75^{\circ} \mathrm{C}$, corresponding to $55^{\circ} \mathrm{C}$ rise plus $20^{\circ} \mathrm{C}$ ambient.

${ }^{a}$ Nameplate capacity of the transformer in kilovolt-amperes. 
DISTRIBUTION TRANSFORMER SURVEY DATA

Manufacturer Survey Code Number

Table 2. Medium-voltage liquid-immersed distribution transformers

\begin{tabular}{|c|c|c|c|c|c|c|c|c|c|c|c|}
\hline \multirow{2}{*}{$\begin{array}{l}\text { Size } \\
(\mathrm{kVA})\end{array}$} & \multicolumn{2}{|c|}{ Noneval $(0 / 0)$} & \multicolumn{2}{|c|}{ TP 1-1996 } & \multirow{2}{*}{$\begin{array}{l}\Delta \\
\text { price }\end{array}$} & \multirow{2}{*}{$\begin{array}{c}\text { Size } \\
\text { (kVA) }\end{array}$} & \multicolumn{2}{|c|}{ Noneval $(0 / 0)$} & \multicolumn{2}{|c|}{ TP 1-1996 } & \multirow{2}{*}{$\begin{array}{c}\Delta \\
\text { price }\end{array}$} \\
\hline & NL & $\mathbf{L L}$ & NL & LI & & & NL & LL & NL & LL & \\
\hline 10 & & & & & & 15 & & & & & \\
\hline 15 & & & & & & 30 & & & & & \\
\hline 25 & & & & & & 45 & & & & & \\
\hline 37.5 & & & 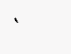 & & & 75 & & & & & \\
\hline 50 & & & & & & 112.5 & & & & & \\
\hline 75 & & & & & & 150 & & & & & \\
\hline 100 & & & & & & 225 & & & & & \\
\hline 167 & & & & & & 300 & & & & & \\
\hline 250 & & & & & & 500 & & .. & & & \\
\hline 333 & & & & & “ & 750 & & & & & \\
\hline 500 & & & & & & 1000 & & & & & \\
\hline 667 & & & & & & 1500 & & & & & \\
\hline 833 & & & & & & 2000 & & & & & \\
\hline & & & & & & 2500 & & & & & \\
\hline
\end{tabular}

Note: Data should be provided for the $95-\mathrm{kVA}$ BIL $15-\mathrm{kV}$ voltage class. No-load (NL) and full-load (LL) losses should be provided in watts. The $\Delta$ price is the price difference between the unit designed to meet NEMA Standard TP 1-1996 and a nonevaluated unit with both $A$ and $B=\$ 0.0$. 


\section{DISTRIBUTION TRANSFORMER SURVEY DATA}

Manufacturer Survey Code Number

Table 3. Medium-voltage dry-type distribution transformers

\begin{tabular}{|c|c|c|c|c|c|c|c|c|c|c|c|}
\hline \multirow{3}{*}{$\begin{array}{c}\text { Size } \\
\text { (kVA) }\end{array}$} & \multicolumn{5}{|c|}{ Singlephase } & \multicolumn{5}{|c|}{ Three-Phase } & \multirow{3}{*}{$\begin{array}{c}\Delta \\
\text { price }\end{array}$} \\
\hline & \multicolumn{2}{|c|}{ Noneval $(0 / 0)$} & \multicolumn{2}{|c|}{ TP $1-1996$} & \multirow{2}{*}{$\underset{\text { price }}{\Delta}$} & \multirow{2}{*}{$\begin{array}{c}\text { Size } \\
\text { (kVA) }\end{array}$} & \multicolumn{2}{|c|}{ Noneval $(0 / 0)$} & \multicolumn{2}{|c|}{ TP 1-1996 } & \\
\hline & NL & $\mathbf{L L}$ & NL & LL & & & NL & LL & $\mathrm{NL}$ & LL & \\
\hline 10 & & & & & & 15 & & & & & \\
\hline 15 & & & & & & 30 & & & & & \\
\hline 25 & & & & & & 45 & & & & & \\
\hline 37.5 & & & & & & 75 & & & & & \\
\hline 50 & & & & & & 112.5 & & & & & \\
\hline 75 & & & & & & 150 & & & & & \\
\hline 100 & & & & & & 225 & & & & & \\
\hline 167 & & & & & & 300 & & & & & \\
\hline 250 & & & & & & 500 & & & & & \\
\hline 333 & & & & & & 750 & & & & & \\
\hline 500 & & & & & & 1000 & & & & & \\
\hline 667 & & & & & & 1500 & & & & & \\
\hline 833 & & & & & & 2000 & & & & & \\
\hline & & & & & & 2500 & & & & & \\
\hline
\end{tabular}

Note: Data should be provided for the $95-\mathrm{kVA}$ BIL $15-\mathrm{kV}$ voltage class. No-load (NL) and full-load (LL) losses should be provided in watts. The $\Delta$ price is the price difference between the unit designed to meet NEMA Standard TP 1-1996 and a nonevaluated unit with both $A$ and $B=\$ 0.0$. 


\section{DISTRIBUTION TRANSFORMER SURVEY DATA}

Manufacturer Survey Code Number

Table 4. Low-voltage dry-type distribution transformers

\begin{tabular}{|c|c|c|c|c|c|c|c|c|c|c|c|}
\hline \multirow{2}{*}{$\begin{array}{c}\text { Size } \\
(\mathrm{kVA})\end{array}$} & \multicolumn{2}{|c|}{ Noneval $(0 / 0)$} & \multicolumn{2}{|c|}{ TP 1-1996 } & \multirow{2}{*}{$\underset{\text { price }}{\Delta}$} & \multirow{2}{*}{$\begin{array}{c}\text { Size } \\
\text { (kVA) }\end{array}$} & \multicolumn{2}{|c|}{ Noneval $(0 / 0)$} & \multicolumn{2}{|c|}{ TP 1-1996 } & \multirow{2}{*}{$\underset{\text { price }}{\Delta}$} \\
\hline & NL & LL & NL & $\mathbf{L L}$ & & & NL & $\mathbf{L L}$ & NL & LL & \\
\hline 10 & & & & & & 15 & & & & & \\
\hline 15 & & & & & & 30 & & & & & \\
\hline 25 & & & & & & 45 & & & & & \\
\hline 37.5 & & & & & & 75 & & & & & \\
\hline 50 & & & & & & 112.5 & & & & & \\
\hline 75 & & & & & & 150 & & & & & \\
\hline 100 & & & & & & 225 & & & & & \\
\hline 167 & & & & & & 300 & & & & & \\
\hline 250 & & & & & & 500 & & & & & \\
\hline 333 & & & & & & 750 & & & & & \\
\hline $500^{\circ}$ & & & & & & 1000 & & & & & \\
\hline 667 & & & & & & 1500 & & & & & \\
\hline 833 & & & & - & & 2000 & & & & & \\
\hline & & & & & & 2500 & & & & & \\
\hline
\end{tabular}

Note: Data should be provided for the 600-V voltage class. No-load (NL) and full-load (LL) losses should be provided in watts. The $\Delta$ price is the price difference between the unit designed to meet NEMA Standard TP 1-1996 and a nonevaluated unit with both $\mathrm{A}$ and $\mathrm{B}=\$ 0.0$. 